\title{
Mechanisms of Measles Virus-Induced Immune Suppression in the Cotton Rat Model
}

\author{
Dissertation
}

Presented in Partial Fulfillment of the Requirements for the Degree Doctor of Philosophy in the Graduate School of The Ohio State University

\author{
By \\ Mary Elizabeth Carsillo, DVM \\ Graduate Program in Veterinary Biosciences \\ $* * * * *$ \\ The Ohio State University \\ 2009 \\ Dissertation Committee: \\ Dr. Stefan Niewiesk, Advisor \\ Dr. Michael Oglesbee \\ Dr. Larry Schlesinger \\ Dr. Joanne Turner
}


Copyright by

Mary Elizabeth Carsillo

2009 


\begin{abstract}
The World Health Organization estimates that approximately 200,000 people, the majority of them children, died in 2007 following acute measles. Bacterial pneumonia following virus-induced immune suppression is one of the leading fatal complications of acute Measles virus (MV) infection. Despite its clinical importance, the underlying mechanisms of MV-induced immunosuppression remain unresolved. To study MVinduced immune suppression we use the cotton rat, because it is the only rodent shown to replicate $\mathrm{MV}$ in the respiratory tract after intranasal infection and to develop T-cell proliferation inhibition, a hallmark of MV-induced immune suppression. Enhanced pulmonary susceptibility to secondary bacterial infection in MV-infected patients is well established. This might indicate a defect in the macrophage response, as these cells play an important role in immune responses against bacterial infections through phagocytosis and microbicidal activity as well as through cytokine production and the stimulation and modulation of $\mathrm{T}$ helper cell responses.
\end{abstract}

To test the effect of MV on macrophages in vitro, we have established a method to culture cotton rat macrophages. Cotton rat bone marrow-derived macrophages are phenotypically and functionally more similar to human than rodent macrophages because they secrete little nitric oxide. After infection with measles virus, macrophages produce less IL12 than uninfected macrophages. Based on studies in humans it has been 
hypothesized that the lack of IL12 might lead to a T helper type 2 (TH2) response which might be mechanistically linked to immune suppression. In cotton rats, IL12 secretion was suppressed after infection with both wildtype and vaccine virus. After stimulation of spleen or lymph node cells with MV antigen, only IFN $\gamma$ was detected, indicative of a TH1 response. Cytokines compatible with a mixed TH0 response, IFN and IL4, were detectable in supernatants after stimulation with PMA/ionomycin. A recombinant vaccine virus which secretes cotton rat IL4 was used to investigate the contribution of a TH2 response to immune suppression. This virus enhanced IL4 secretion but did not increase T-cell proliferation inhibition. These data show that measles virus infection leads to a decrease in IL12 secretion and an increase in IL4 secretion but this does not seem to correlate with development of a $\mathrm{TH} 2$ response and immune suppression.

Inhibition of T-cell proliferation following MV infection results from down regulation of AKT kinase activity. AKT is also a key signalling molecule in a number of pathways for primary macrophage functions. In cotton rats, wildtype and vaccine MV infection lead to a downregulation of AKT activity in macrophages concurrent with decreased phagocytosis and bacterial killing, and increased susceptibility to S. aureus pneumonia in vivo.

Contrary to MV, many viruses activate the PI3K-AKT signaling pathway as a strategy to slow down apoptosis and increase virus replication. Our data indicate that an increased level of active AKT kinase does not significantly effect MV transcription, replication and progeny release. This leads us to conclude that MV growth is independent of AKT kinase activity and that MV-induced pAKT suppression may be purely a strategy to contain immune responses. 
Dedicated to Tom

"The best of what's around" 


\section{Acknowledgements}

I owe my deepest gratitude to my advisor, colleague and friend, Dr. Stefan Niewiesk, for giving me the opportunity to work on this important and interesting project. Your support and encouragement were critical to my success. I am also grateful to my committee members Drs. Oglesbee, Schlesinger and Turner for their guidance throughout this process. I would also like to extend a heartfelt thanks to all the members of the Niewiesk lab from whom I have learned "teamwork doesn’t seem work": Devra Huey, Thomas Carsillo, Dhohyung Kim, and Natasha Petroff. I am also grateful for all of the faculty, staff and students in the Department of Veterinary Biosciences that have contributed to my success. Drs. Weisbrode and Stromberg, your dedication to the pathology residency has made it second to none. Bevin and Gillian, you are two of my very best friends and I look forward to our lifelong friendship.

To my family, thank you for your love and support. Your perpetual student is

finally finished. Last but never least; to my husband Tom, you are my best friend and my greatest love. We have a whole new life ahead of us filled with excitement.

This work was supported by funds from the National Institutes of Health Training Grant (RR007073) and the NIH Pediatric Loan Repayment Program. Permission was granted by Elsevier to reproduce the publication "Nitric Oxide Production and Nitric Oxide Synthase Type 2 Expression by Cotton Rat (Sigmodon hispidus) Macrophages 
reflect the Same Pattern as Human Macrophages" by Mary Carsillo, Karen Puschel, Jorge Blanco, and Stefan Niewiesk. Developmental and Comparative Immunology 33 (2009), pp. 718-724, as chapter 2 of this thesis. Permission granted by the American Society of Microbiology Journals Department reproduce the publication "Cytokine imbalance after measles virus infection but no correlation with immune suppression" by Mary Carsillo, K. Klapproth, S. Niewiesk. Journal of Virology 2009 May 6, in chapter 3 of this thesis. 


\section{Vita}

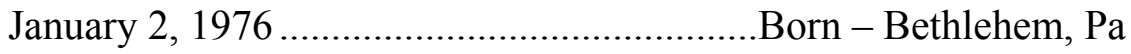

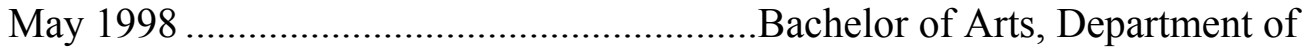
Chemistry, East Stroudsburg University, East Stroudsburg, PA
May 1998 .................................................. Bachelor of Science, Department of Biological Sciences, East Stroudsburg University, East Stroudsburg, PA

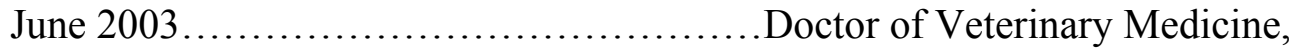 The College of Veterinary Medicine The Ohio State University, Columbus, $\mathrm{OH}$
June 2003 - August 2009 Anatomic Pathology Resident and Graduate Research Associate, Department Of Veterinary Biosciences, The Ohio State University, Columbus, $\mathrm{OH}$

Publications

1. Carsillo M, Kim D and Niewiesk S. Role of AKT kinase in measles virus replication. (2009). Submitted to Journal of Virology.

2. Carroll E.E., Fossey SL, Mangus L.M., Carsillo M, Rush L, McLeod C.G., Johnson T.O. (2009). Canine Metastatic Malignant Pilomatricoma: Characterization of Four Cases and Literature Review. Submitted to Veterinary Pathology. 
3. Runkler N, Dietzel E, Carsillo M, Niewiesk S, and Maisner A. (2009). Sorting Signals in the Measles Virus Wild-type Glycoproteins Differently Influence Virus Spread in Polarized Epithelia and Lymphocytes. Journal of General Virology, July 1. [Epub ahead of print].

4. Carsillo M, Klapproth K, Niewiesk S. (2009). Cytokine imbalance after measles virus infection but no correlation with immune suppression. Journal of Virology, May 6. [Epub ahead of print].

5. Cooper E, Wellman M, and Carsillo M. (2009) Hyperalbuminemia Associated with Hepatocellular Carcinoma in a Dog. Veterinary Clinical Pathology, May 15. [Epub ahead of print].

6. Carsillo T, Carsillo M, Traylor Z, Rajala-Schultz P, Niewiesk S, Oglesbee M. (2009). MHC Haplotype Determines Hsp70-Dependent Protection against Measles Virus Neurovirulence. Journal of Virology, March 25. [Epub 2009].

7. Carsillo M, Puschel K, Blanco J, and Niewiesk S. (2009). Nitric Oxide Production and Nitric Oxide Synthase Type 2 Expression by Cotton Rat (Sigmodon hispidus) Macrophages Reflect the Same Pattern as Human Macrophages. Developmental and Comparative Immunology 33:718-724.

8. Pueschel K, Tietz A, Carsillo M, Steward M, Niewiesk S. (2007) Measles Virus Specific CD4 T Cell Activity Does Not Correlate with Protection Against Lung Infection or Viral Clearance. Journal of Virology, August, 81(16): 8571-8.

9. Carsillo T, Carsillo M, Niewiesk S, Vasconcelos D and Oglesbee M. (2004). Hyperthermic Pre-conditioning Promotes Measles Virus Clearance from Brain in a Mouse Model of Persistent Infection. Brain Research 1004: 73-82.

10. Oglesbee M, Pratt (Carsillo) M and Carsillo T. (2002). Role of Heat Shock Proteins in the Immune Response to Measles Virus Infection. Viral Immunology 15(3): 399-416.

Fields of Study

Major Field: Veterinary Biosciences

Anatomic Veterinary Pathology 
Table of Contents

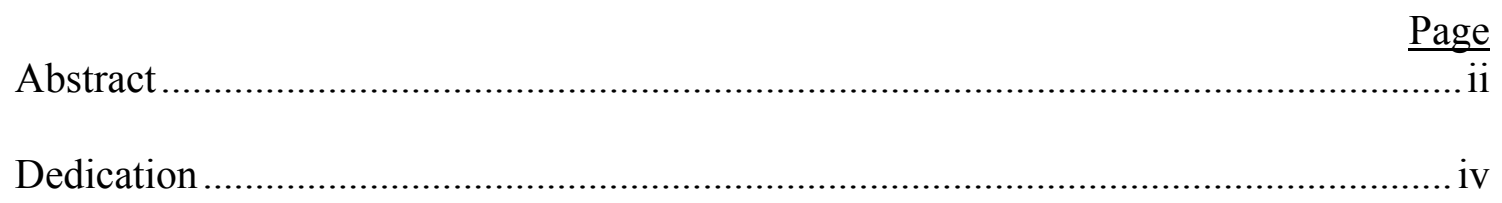

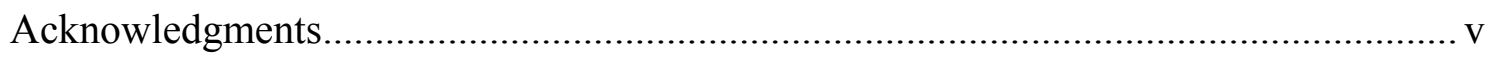

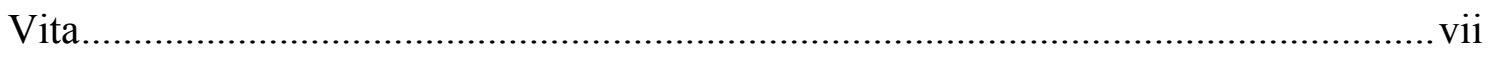

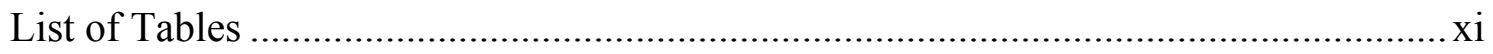

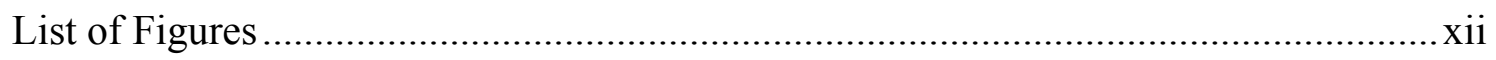

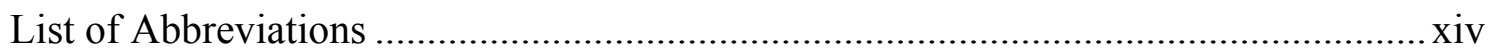

Chapters:

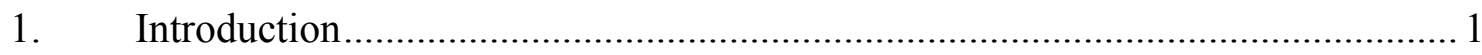

2. Nitric oxide production and nitric oxide synthase type 2 expression by cotton rat (Sigmidon hispidus) macrophages reflect the same pattern as human............................. 24

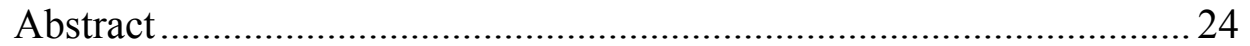

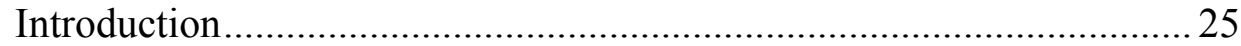

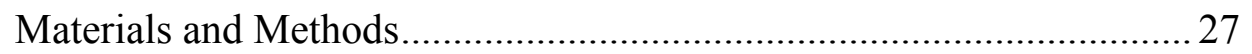

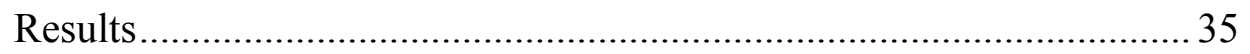

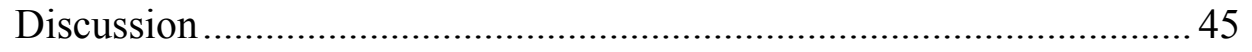

3. Cytokine imbalance after measles virus infection but no correlation to immune

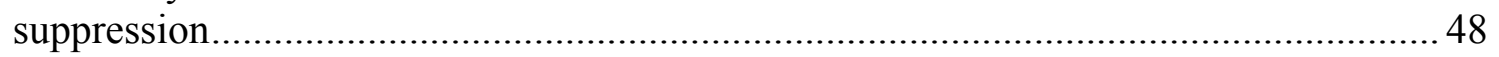

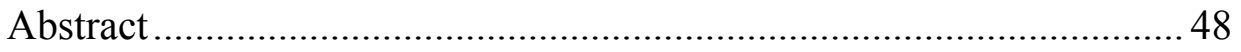

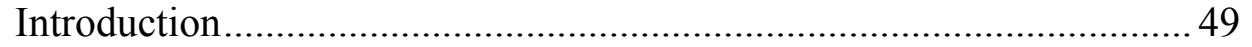

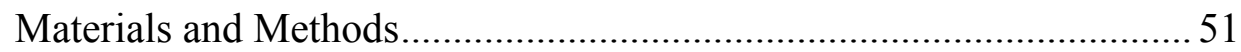

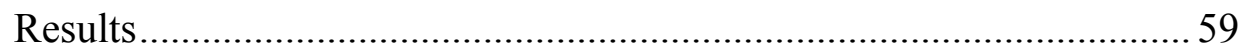




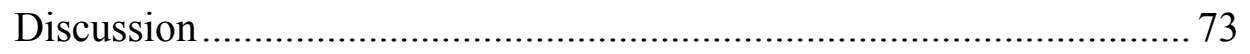

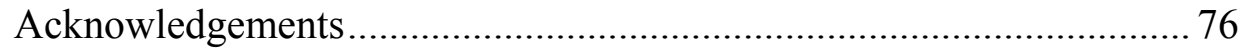

4. Effect of AKT kinase activity on measles virus-infected macrophages ........... 77

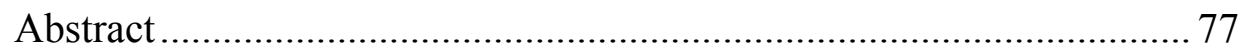

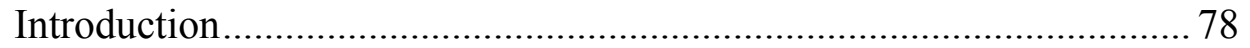

Materials and Methods.................................................................... 80

Results................................................................................ 85

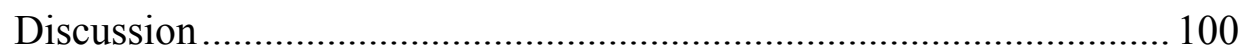

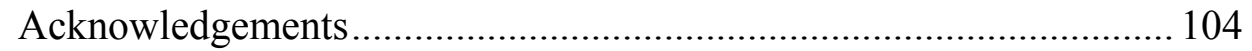

5. Role of AKT kinase in measles virus replication ....................................... 105

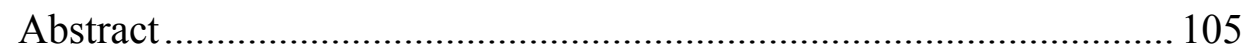

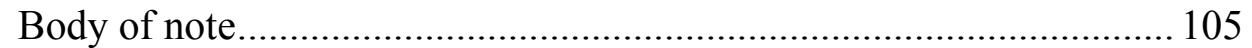

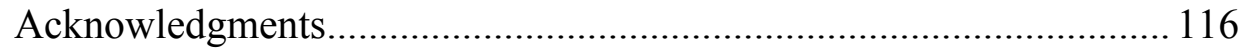

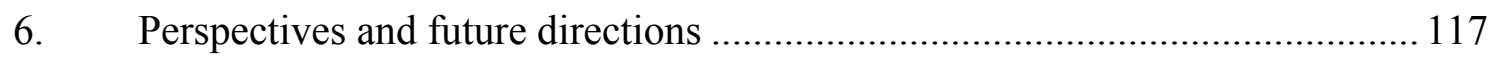

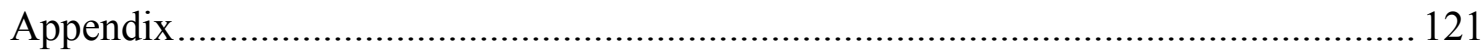

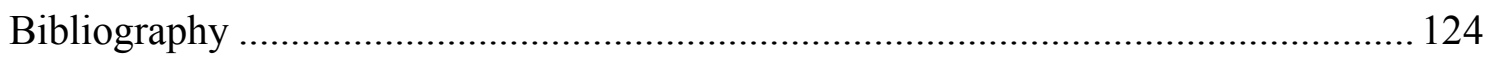




\section{List of Tables}

$\underline{\text { Table }} \quad \underline{\text { Page }}$

2.1 Sequences of primers used for the study of cotton rat macrophages ................ 31

3.1 Sequences of primers used for real-time RT-PCR ......................................... 55

A.1 Optimization of bone marrow-derived macrophage stimulation for cytokine measurement ........................................................................................ 121

A.2 Optimization of bone marrow-derived macrophage stimulation for nitric oxide

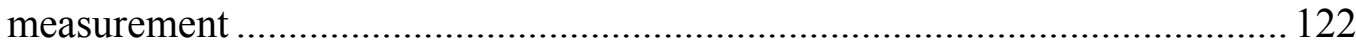

A.3 Sensitivity of real time RT-PCR cytokine assays ....................................... 122 


\section{List of Figures}

Figure $\quad \underline{\text { Page }}$

1.1 Measles virus blocks PI3K-AKT signaling pathway ................................... 12

1.2 Measles virus-induced propagation of aTH2 response ................................... 20

1.3 Measles virus-induced suppression of AKT kinase activity in macrophages..... 22

2.1 Expression of MHCI, MHCII, and CD14 by cotton rat macrophages............... 37

2.2 Levels of IL12p35, IL18, TNF $\alpha$ and TGF $\beta$ mRNA in cotton rat

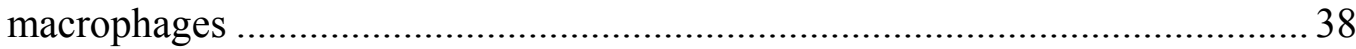

2.3 Secretion of superoxide, hydrogen peroxide and nitric oxide by cotton rat macrophages

2.4 Diaminofluorecein diacetate staining of cotton rat macrophages.................... 43

2.5 Inhibition of bacterial killing by inhibition of nitric oxide ............................ 44

3.1 Inhibition of IL12 secretion by measles virus-infected macrophages .............. 61

3.2 Immune response of cotton rats after measles virus infection ........................ 63

3.3 Interferon $\gamma$ and IL4 secretion by splenocytes from measles virus-infected

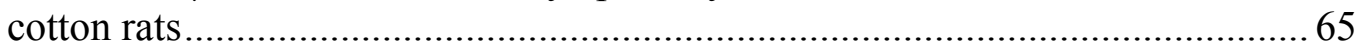

3.4 Growth and production of IL4 by recombinant measles virus ........................ 68

3.5 Changes in pulmonary infiltrates after infection with measles virus expressing IL4

3.6 Proliferation inhibition with measles virus and measles virus expressing IL4 
4.1 Wildtype and vaccine measles virus infection decreases phosphorylation

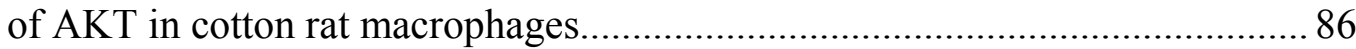

4.2 Measles virus infection leads to a reduction in bacterial uptake and killing

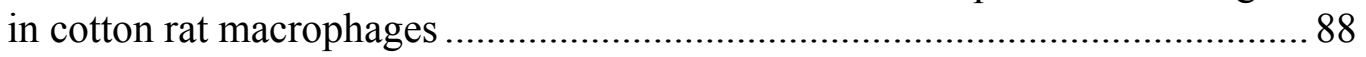

4.3 Increased bacterial burden in cotton rats co-infected with WTF and $S$.

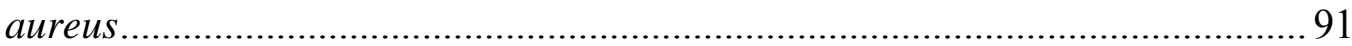

4.4 Cotton rats co-infected with WTF and S. aureus have an increased pulmonary inflammatory response ................................................................... 93

4.5 Lesion score comparison between cotton rats co-infected with WTF and $S$.

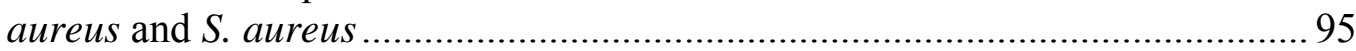

4.6 Expression of constitutively active myr-AKT in measles virus infected

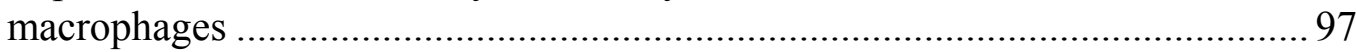

4.7 Bacterial burden of cotton rats co-infected with Ed-NSE or NSE-myrAKT and S. aureus. 98

4.8 Macrophage percentages from bronchoalveolar lavage from cotton rats coinfected with Ed-NSE or NSE-myr-AKT and S. aureus

5.1 Measles virus replication after AKT overexpression in Vero .......................... 109

5.2 No influence of AKT on viral growth in Jurkat............................................... 113

5.3 In vivo growth of measles virus is not influenced by AKT expression.............116

A.1 Standard curve of IL12p35 real time-RTPCR ………................................... 123 


\section{List of Abbreviations}

$\underline{\text { Abbreviation }}$

$\underline{\text { Meaning }}$

BAL Bronchoalveolar Lavage Box-1 Measles Virus Nucleocapsid Protein aa 401-420 cDNA Complementary Deoxyribonucleic Acid

C Celsius

CD Cluster of Differentiation CDV Canine Distemper Virus

ConA Concanavalin A

cpe Cytopathic Effect

CSF Cerebrospinal fluid

CR Cotton Rat

CR3 Complement Receptor 3 DAF-2A Diaminofluoresceine-2 Diacetate DC Dendritic Cell DC-SIGN ..Dendritic Cell-Specific Intercellular Adhesion Molecule-3Grabbing Non-Integrin

DNA Deoxyribonucleic Acid 
IL Interleukin Inducible Nitric Oxide Synthase

IRF1 Interferon Regulatory Factor 1

ITAM Immunoreceptor Tyrosine-Based Activation Motif Keyhole Limpet Hemocyanin

L Measles Virus Large Protein .Lipopolysaccharide M Measles Virus Matrix Protein MCSF Macrophage Colony Stimulating Factor MDLN Mediastinal Lymph Node MHC Major Histcompatibility Complex 

Multiplicity of Infection

mRNA Messenger RNA

MSP Macrophage Stimulating Protein MV Measles Virus myr Myristoyl-group $\mathrm{N}$ Measles Virus Nucleocapsid Protein $\mathrm{NADPH}$ Nicotinamide Adenine Dinucleotide Phosphate-oxidase

$\mathrm{N}_{\mathrm{CORE}}$ Measles Virus N Protein aa 1-400

NO Nitric Oxide NOS2 Nitric Oxide Synthase Type 2 $\mathrm{N}_{\text {TAIL }}$ Measles virus N Protein aa 400-525 $\mathrm{P}$ Measles Virus Phosphoprotein

PBL Peripheral Blood Lymphocytes

PBMC Peripheral Blood Mononuclear Cell

PBS Phosphate Buffered Saline

PCR Polymerase Chain Reaction PDK1 Protein Dependent Kinase 1 pfu Plaque Forming Units PHA Phytohemagglutinin lectin from Phaseolus vulgaris PI3K Phosphoinositide-3-kinase PIP3 Phosphatidylinositol 3,4,5 triphosphate PMA .Phorbol 12-myristate 13-acetate 
PMSF . Phenylmethylsulfonyl fluoride

PTIO 2-phenyl-4,4,5,5-tetramethylimidazoline-1-oxyl-3-oxide RNA Ribonucleic Acid

ROI Reactive Oxygen Intermediate RT-PCR Reverse Transcription Polymerase Chain Reaction SCID Severe Combined Immunodeficiency SDS-PAGE Sodium Dodecyl Sulfacte-Polyacrylamide Gel Electrophoresis

SI Stimulation Index

SLAM Signaling Lymphocytic Activation Molecule (also CD150) SNAP S-nitroso-N-acteyl-penicillamine

SSPE Subacute Sclerosing Panencephalitis

TCID Tissue Culture Infectious Dose

TGF Transforming Growth Factor

TH1 T Helper 1

TH2 T Helper 2

TLR Toll-Like Receptor

TNF Tumor Necrosis Factor UV Ultraviolet Light WTFb Wild Type Strain of Measles Virus 


\section{CHAPTER 1}

\section{Introduction}

\subsection{Background}

Measles virus (MV) is a highly contagious pathogen infecting 2-3 million people annually according to the WHO. Every year, approximately 200,000 thousand people, the majority of which are children under the age of five, die as a result of acute measles. MV causes a multi-systemic infection where symptoms include fever, rash, coryza and immune suppression. MV-induced immune suppression is transient but severe and results in enhanced susceptibility to bacterial infections of the respiratory and gastrointestinal tract leading to increased morbidity and mortality. Encephalitis is a rare sequela to acute MV infection. Measles inclusion body encephalitis (MIBE) and subacute sclerosing panencephalitis (SSPE) are two forms of encephalitis characterized by the presence of viral inclusion bodies in the brain. SSPE is characterized by a prolonged incubation time of 1-15 years, the presence of MV neutralizing antibody in the cerebrospinal fluid (CSF) [1] and failure of neurons to release infective virus [2]. In contrast, MIBE has a short incubation (3-6 months), lacks MV neutralizing antibody in the CSF, and infectious virus can be isolated from the brains of affected individuals [3] 
A third form of encephalitis, postinfectious encephalomyelitis has also been linked to MV infection appearing 5-14 days following acute Measles but is speculated to be an autoimmune disease as MV antigen and RNA are not detectable in brain tissue from affected people $[4,5]$.

\subsection{Measles virus molecular biology}

MV belongs to the Paramyxoviridae family and has a single-stranded, negativesense RNA genome. It encodes two envelope glycoproteins; the hemagglutinin $(\mathrm{H})$ and the fusion (F) proteins which are required for MV cell entry, a matrix protein (M) and three proteins involved in viral genome transcription and replication: the nucleocapsid protein $(\mathrm{N})$, the phosphoprotein protein $(\mathrm{P})$ and the polymerase (large protein; L). The MV genome is encapsidated by $\mathrm{N}$ to form a helical nucleocapsid. The viral polymerase complex, which consists of the $\mathrm{P}$ and $\mathrm{L}$ proteins binds to the N-RNA complex $[6,7]$ and is responsible for replication and transcription of the viral genome.

A molecular DNA clone of the Edmonston vaccine strain of MV, referred to as Ed-NSE, has been generated [8] which allows for the analysis of recombinant MV. This reverse genetic system has been used to analyse the function of MV proteins by exchange [9] or knock-out of viral genes [10], or as a vector system to express exogenous proteins like green fluorescent protein (GFP) [11] and human interleukin 12 [12].

To date three receptors have been identified for MV on human cells. Signalling lymphocyte activation molecule (SLAM), also known as CD150, is expressed on activated leukocytes and mediates high affinity binding and entry of viruses that express the wildtype hemagglutinin glycoprotein [13-15]. After tissue culture adaptation on 
fibroblast cell lines which solely express CD46 (membrane co-factor protein, a regulator of complement activation expressed on all human nucleated cells), vaccine strains use both CD150 and CD46 [16] as receptor molecules. The change in receptor usage has been correlated to a single mutation at position 481 from an asparagine to tyrosine [14, $15,17]$. A third receptor, dendritic cell-specific intercellular adhesion molecule 3grabbing non-integrin (DC-SIGN), does not support MV entry but is crucial as an attachment receptor to enhance CD46/CD150-mediated infection of dendritic cells [18].

A fourth receptor for MV exists which mediates infection in epithelial cells although the respective molecule has not been identified. Though epithelial cells do not express CD150, descriptions of human disease and observations in experimentally infected monkeys have shown that MV antigens and syncytia are detectable in epithelial cells of the skin, oral cavity, pharynx, trachea, esophagus, intestines, and urinary bladder [19-23]. Additional evidence for a fourth MV receptor includes a human lung adenocarcinoma cell line and polarized human epithelial cells lines which can be infected with MV supporting viral entry, replication, and syncytium formation. Infection is not dependant on CD150 or CD46 and monoclonal antibody blocking assays show the receptor-binding site on the $\mathrm{H}$ protein used to infect NCI-H358 cells is different from those used for CD150 and CD46 $[24,25]$. There is evidence that the unidentified epithelial receptor is located in the basolateral membrane of epithelial cells and is primarily associated with MV shedding into the airway lumen. Macaques infected with a selectively epithelial receptor (EpR) blind MV which only binds CD150 developed rash and anorexia but did not shed virus in the airways [26]. 


\subsection{Clinical observations in acute measles virus patients}

Subsequent to exposure, symptoms of acute infection appear after an 8-12 day incubation period. Patients develop fever, conjunctivitis, rhinitis, cough, and Koplik's spots which reach peak severity concurrent with the appearance of a maculopapular rash [27]. The rash typically resolves in 7-10 days and it is during this time that patients develop transient but severe immune suppression. In contrast to patients with acute measles, vaccinees do not demonstrate clinically measurable immunosuppression. MV patients and MV-infected macaques develop a circulating leukopenia characterized by decreased numbers of neutrophils, monocytes, B cells as well as $\mathrm{CD} 4^{+}$and $\mathrm{CD} 8^{+} \mathrm{T}$ cells [28-30]. T cells maintain a normal CD4/CD8 ratio [31] and numbers return to normal levels 10 days after infection. After natural infection of humans a low percentage, $\sim 2 \%$, of T cells, B cells and macrophages have been shown to be infected with MV [32-34] and similar results are seen in the macaque model [35]. MV-induced immune suppression results in enhanced susceptibility to bacterial infections of the respiratory and gastrointestinal tracts leading to increased morbidity and mortality. Of these, bacterial pneumonia is the most common fatal complication, occurring in $56-87 \%$ of fatal cases of Measles [36, 37]. More commonly a mixture of pathogenic bacteria is identified [37] but when a single etiology can be identified the most common pathogens identified include Streptococcus pneumoniae, Haemophilus influenzae, and Staphylococcus aureus [37] [38] [39] [40]. It has also been suggested that MV infection is associated with reactivation of latent Mycobacterium tuberculosis infections [41] and has been linked to reactivation of latent herpes virus infections [42]. 


\subsection{Mechanisms of MV-induced immune suppression}

Due to the low level of viremia it is difficult to explain the extent of immune suppression which cannot be explained by direct infection and contact-mediated inhibition alone. It is therefore reasonable to assume indirect regulatory mechanisms play a major role in the induction of immune suppression. Studies addressing the mechanism of immune suppression have found evidence for a number of possible mechanisms. These include more general mechanisms that affect multiple cells types and direct effects on specific cell types including T cells, macrophages and dendritic cells. It is likely that two or more of the mechanisms operate in concert to induce immune suppression.

General mechanisms contributing to MV-induced immune suppression include unidentified soluble mediators [43, 44], induction of apoptosis and systemic cytokine dysregulation. Fujinami and Sun demonstrated that supernatants from MV-infected T cells but not HeLa or Vero cells could cause inhibition of antigen-specific T-cell proliferation. Though the soluble mediator was not identified they did determine that the proliferation inhibition was not due to infectious virus, IL-10 or TGF $\beta$ or IFN $\alpha / \beta$. MV infection has been shown to induce apoptosis in tissue culture $[45,46]$. Apoptosis is also seen in thymocytes in a SCID-hu mouse model of MV [47]. MV-induced cytokine dysregulation is complex with conflicting reports and will be discussed in detail in section 1.5.

Alternatively, many groups have focused on specific cell types to investigate direct MV effects on their immune modulatory cell functions. There is suppression of recall antigen responses and T-cell delayed-type hypersensitivity reactions, including tuberculin antigen [30, 48-52]. Furthermore, blood monocytes exhibit decreased 
phagocytic and fungicidal capacities ex vivo [53]. These data indicate that both macrophages and $\mathrm{T}$ cells, two important effector cell types which protect against bacterial infection, are dysfunctional during MV infection.

The hallmark feature of MV-induced immune suppression is a reduction in mitogen-stimulation and antigen specific lymphocyte proliferation [54]. Ex vivo mitogen-driven proliferation of both B cells and T cells is inhibited by MV [55-59]. This phenomenon is not restricted to mitogen dependent proliferation and is also seen with Jurkat, BJAB, HL60 and U-937 human cell lines [60].

Macrophages play a central role in the control of bacterial infections due to their innate phagocytic capacity and their ability to stimulate T-cell responses. Individually there are many aspects of macrophage function which are affected by MV infection but the cumulative effect of these changes in vivo is not known. MV-infected monocytes have decreased phagocytic and fungicidal capacities ex vivo [53]. MV also interferes with immune responses of macrophages by altering antigen presentation and cytokine secretion. In vitro, macrophage cell lines infected with MV exhibit reduced secretion of tumor necrosis factor (TNF). Primary MV-infected macrophages increase surface expression of major histocompatibility class (MHC) II antigens and appear to be defective in the presentation of non-MV antigens though presentation of MV antigens remains normal [61]. Macrophages also play a central role in the immune response by secretion of immune mediators which is also altered by MV. Monocytes infected with the Edmonston MV strain secrete reduced amounts of IL12 p40 and IL12 p70 following stimulation through TLR4 [62]. Similar results are seen with UV-inactivated virus, demonstrating viral replication is not required for suppression of IL12. The reduction in 
IL12 secretion is observed in MV-infected patients, where the number of peripheral circulating monocytes increases about threefold [54] however, in comparison to noninfected individuals the same number of macrophages expresses IL12 during infection resulting in a relative reduction of IL12 expressing cells. A reduction in IL12 secretion by peripheral blood lymphocytes after mitogen stimulation has also been observed in MV-infected macaques [63].

Some suggest IL12 reduction results in a shift towards a TH2 response but it is not clear what effect reduction in IL12 has in vivo. In macaques infected with a recombinant vaccine virus that expresses IL12 the inhibition of ex vivo mitogenstimulated T-cell proliferation was not reversed [12, 64].

Although MV-infected dendritic cells (DC) have not been demonstrated in acute Measles patients it has been suggested that they play a critical role in MV-induced immune suppression by transportation of MV from epithelial surfaces to lymphoid organs. MV-infected dendritic cells have been identified in transgenic CD150 [65] and monocyte/macrophage depleted transgenic CD46 mice $[66,67]$ In 2,4 dinitrofluorobenzene (DNFB) sensitized cotton rats, DCs were linked to MV-induced Tcell proliferation inhibition in draining lymph nodes $[52,55,68]$. At epithelial surfaces immature dendritic cells intercalate with epithelial cells surveying the environment for pathogens and once activated they migrate to lymph nodes to present antigens to $\mathrm{T}$ cells and orchestrate an adaptive immune response through cytokine production. Langerhans cells, monocyte-derived dendritic cells and their $\mathrm{CD} 34+$ precursors are susceptible to vaccine and wildtype strains of MV in vitro [9, 46, 69-74]. Immature dendritic cells mature rapidly when exposed to MV. Maturation is signified by upregulation of many 
cell surface markers including MHCI, MHCII, CD40, and co-stimulatory molecules CD80, CD83 and CD86 [70, 72-74]. mRNA levels of IL12 p35, IL12 p40, IL12 p19, IL10, IL1, and IL6 are increased whereas as functional IL12 and IL10 are undetectable in infected dendritic cells $[72,73]$.

\subsection{Development of TH2 responses in humans}

It is reasonable to hypothesize that MV-induced downregulation of IL12 expression by macrophages leads to propagation of a $\mathrm{T}$ helper 2 response and results in T-cell proliferation inhibition. In macaques, this decrease in IL12 correlates with an increase of eosinophils in peripheral blood indicative of increased secretion of IL5 [63].

Results from cytokine analysis from MV-infected patients are conflicting. Prior to and concurrent with the development of rash in patients with acute measles there is upregulation of IFN $\gamma$ and IL2 in the serum or supernatants of peripheral blood lymphocytes stimulated with PMA/ionomycin [75] (or IL2-R [76]). Whereas after development of the rash, a reduction in IL2 and an increase in IL4 [75] and IL10 [63] levels were observed. In contrast, other studies found normal levels of IFN $\gamma$ and IL2 secreted by stimulated PBLs [77] and increased levels of IFN $\gamma$ after the rash secreted by PMA/ionomycin stimulated CD8 T cells [63].

Results from the analysis of cytokines secreted by lymphocytes from MV vaccinees are also conflicting. In contrast to what is seen in patients prior to rash development, some studies have found an increase in IL2 (after mitogen stimulation) [76] or increased IL12 and IFN $\gamma$ (after stimulation with MV antigen) [78]. However, analysis of cytokine mRNA expression in PBLs of vaccinated individuals revealed no difference 
in expression of IL2, IL4, IL5, IL10 or IL12 were found compared to unvaccinated individuals [79].

In one study, IL10 levels were elevated in the serum of patients [80]. In another study high IL10 levels were associated with increased numbers of $\mathrm{CD}^{+} \mathrm{CD} 25^{+}$ regulatory $\mathrm{T}$ cells [81]. These patients also had elevated serum IFN $\gamma$ compatible with a mixed TH1/TH2 type response. Similarly other groups have found results which suggest MV induces a mixed TH1/TH2 type response with up-regulation of IL4 and downregulation of IFN $\gamma$ in the supernatant of PHA stimulated MV-infected PBMCs [82]. Approximately half of the individuals from a cohort of vaccinees had PBMCs which secreted IL4 [83] and when stimulated with MV antigen it was found that the majority of circulating T cells expressed IFN $\gamma$, either alone or in combination with IL4 [84].

Based on these data no clear correlation can be drawn between reduced levels of IL12, the secretion of TH2 type cytokines and the inhibition of lymphocyte proliferation. Furthermore, at least three variables seem to confound the analysis: 1. the use of samples from patients with acute measles (wildtype virus) versus vaccinees (vaccine virus), 2. the method of stimulation of cells and cytokine detection and 3. the individual genetic makeup of the study participants.

\subsection{Mechanism of T-cell proliferation inhibition}

MV-induced immune suppression is likely a complex process involving various immune cells and mechanisms. Despite the belief that the generation of a TH2 response is responsible for $\mathrm{T}$-cell proliferation inhibition there is evidence for a second contributing mechanism. Mitogen-stimulated proliferation of T cells is inhibited in tissue 
culture after infection or direct contact with MV mediated by the F and $\mathrm{H}$ glycoprotein complex [31] [85]. Proliferation inhibition requires both the F and $\mathrm{H}$ glycoprotein and either protein alone does not have an effect on proliferation [60]. This effect is not due to soluble factors and T-cell proliferation inhibition is not reversed after supplementation with IL2 in ex vivo experiments with PBLs from MV patients $[77,86]$ or in splenocytes from MV-infected cotton rats [87]. This effect is independent of the MV receptors CD150 and CD46 and does not require infection [72]. Under normal conditions, crosslinking of either receptor leads to activation of the signaling cascade initiated by phosphorylation of tyrosine residues (ITAMS) in the cytoplasmic tails of the immunoreceptor. These in turn activate the p 85 subunit of phosphoinositide-3 kinase (PI3K). PI3K then generates phosphatidylinositol 3,4,5 triphosphate $\left(\mathrm{PIP}_{3}\right)$ in the inner leaflet of the plasma membrane. The pleckstrin-homology domain of AKT is then attracted to PIP3 and AKT traffics to the membrane. Here AKT is activated by phosphorylation at serine 473 (S473) by the rictor-mTOR complex and threonine 308 by protein dependent kinase 1 (PDK1) (for review [88, 89]). In MV infection of T cells, p85 fails to partition to lipid rafts of the inner membrane (Figure 1.1) [79, 85]. This abrogates $\mathrm{PIP}_{3}$ formation blocking AKT trafficking to the membrane and its phosphorylation at S473.

Additionally, MV induces expression of SIP110, a constitutively active lipid phosphatase that depletes $\mathrm{PIP}_{3}$ (presumably in the lipid raft regions where it is needed to attract AKT to propagate the signaling cascade) [90]. Active AKT kinase blocks trafficking of $\mathrm{p} 27^{\mathrm{kip}}$ to the nucleus by phosphorylation which targets it for ubiquitination and degradation. This blocks p2 $7^{\text {kip }}$ s inhibition of cyclin dependant kinase $2 /$ cyclin E 
and cyclin dependant kinase 4/cyclin D allowing cell cycle progression. Ultimately the MV-induced blockade of PI3K/AKT signaling allows $\mathrm{p} 27^{\mathrm{kip}}$ to enter the nucleus and inhibit cyclin dependant kinase 2/cyclin E and cyclin dependant kinase 4/cyclin D causing $\mathrm{G}_{0} / \mathrm{G}_{1}$ cell cycle arrest.

Over-expression of constitutively active myristoylated AKT leads to reversal of proliferation inhibition of T cells in vitro [79]. Myristoyl-groups are membrane targeting signals that direct AKT to the plasma membrane resulting in constitutive phosphorylation and activation of AKT. It is believed that the upstream kinases required for phosphorylation and activation of AKT have limited basal activity that is sufficient to activate membrane targeted AKT [91] [92] [93].

The MV nucleoprotein has also been shown to contribute to inhibition of T-cell proliferation by causing cell cycle arrest. Nucleoprotein is an approximately $60 \mathrm{kDa}$ protein responsible for encapsidating the viral genome to form nucleocapsid. Nucleoprotein can be divided into two domains, N-CORE and N-TAIL (C terminal 125 amino acids). N-tail (specifically Box 1, a highly conserved region of N-TAIL) binds to a currently unidentified receptor (nucleoprotein receptor) and causes $\mathrm{G}_{0} / \mathrm{G}_{1}$ cell cycle arrest [94]. Nucleoprotein is the most abundant cytosolic MV protein and it has been demonstrated that large amounts of MV nucleoprotein are released into the extracellular milieu after apoptosis or necrosis of MV-infected cells in vitro [95]. This allows $\mathrm{N}$ access to the unidentified nucleoprotein cell-surface receptor expressed on neighboring uninfected cells to mediate cell cycle arrest and proliferation inhibition. Although the mechanism for N-TAIL-mediated cell cycle arrest has not been fully resolved, but it is reasonable to assume that N-TAIL acts via the PI3K/AKT cascade similar to the F and $\mathrm{H}$ 
glycoproteins. The $\mathrm{F}$ and $\mathrm{H}$ glycoprotein complex and nucleoprotein likely have cooperative roles in the Measles virus-induced immunosuppression. The inhibition of AKT kinase by MV infection is a mechanism with potentially far reaching consequences because AKT is a key regulatory molecule for a number of cellular pathways including primary macrophage functions. 
Figure 1.1 In MV infection, p85 fails to partition to the inner membrane, this abrogates PIP3 formation, blocking AKT trafficking to the membrane and its phosphorylation at S473. MV contact also induces expression of SIP110. SIP110 is an isoform of the lipid phosphatase SHIP145 that is generated by transcriptional exon inclusion. SIP 110 is constitutively active and depletes $\mathrm{PIP}_{3}$. Ultimately the MV-induced blockade of PI3K/AKT signaling allows p2 $7^{\text {kip }}$ to enter the nucleus and inhibit cyclin dependant kinase $2 /$ cyclin $E$ and cyclin dependant kinase $4 /$ cyclin D causing $G_{0} / G_{1}$ cell cycle arrest. 


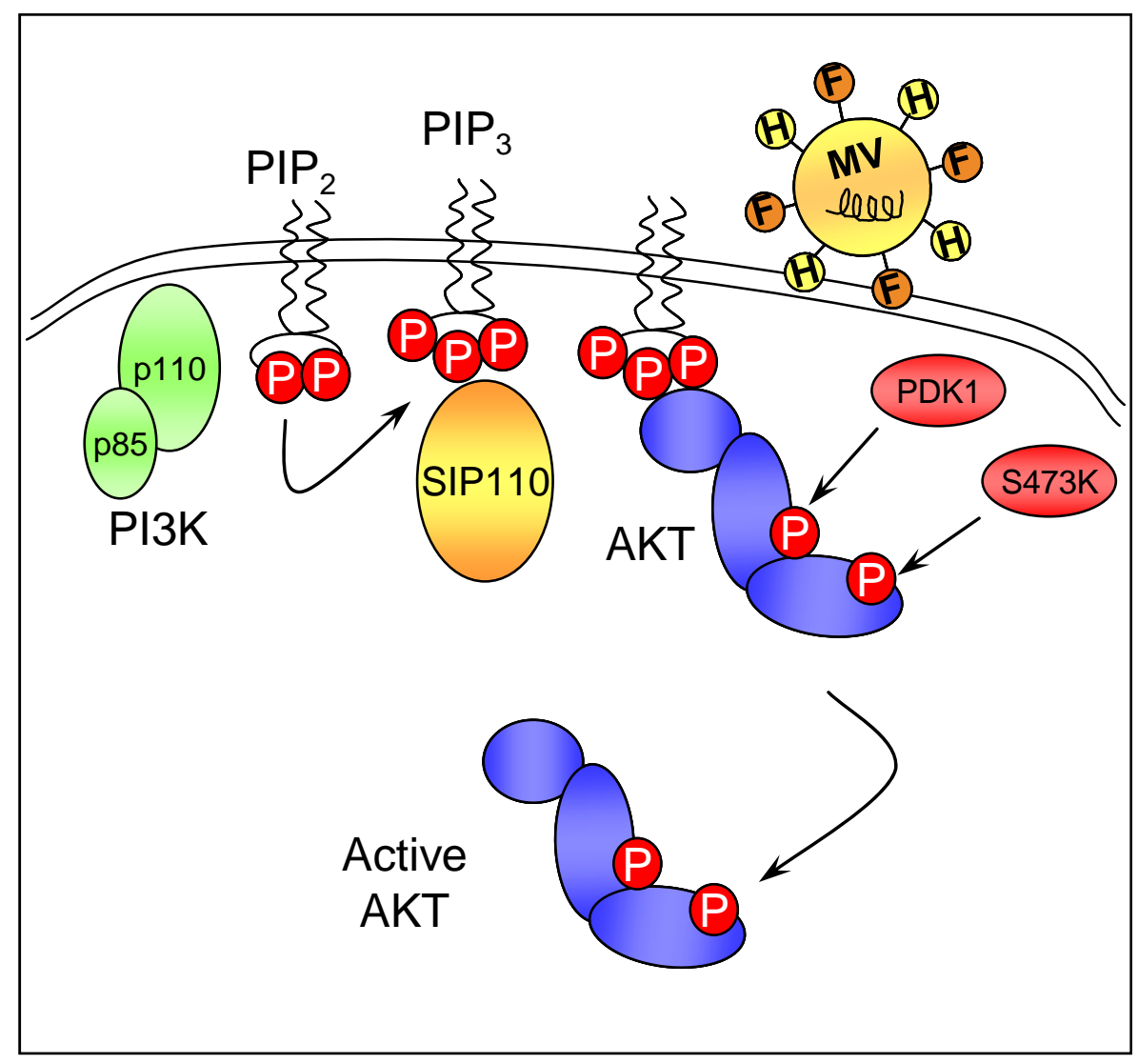




\subsection{Role of AKT kinase in phagocytosis and production of reactive oxygen intermediates}

Though the mechanism has not been identified, it has been demonstrated that MV-infected monocytes have functional defects resulting in decreased phagocytic and fungicidal capacities [53]. There is strong evidence that reduction in AKT kinase activity will severely affect the ability of macrophages to phagocytose and kill bacteria. AKT phosphorylation is critical for receptor mediated phagocytosis using the Fc receptor $(\mathrm{Fc} \gamma \mathrm{R}) \gamma(\mathrm{IgG})$ and complement receptor 3 (CR3 also known as, CD11b/CD18). AKT is specifically phosphorylated in response to Fc $\gamma \mathrm{R}$ clustering and activation of AKT stimulates phagocytosis. This has been shown by transient transfection of constitutively active myr-AKT which significantly increases phagocytic efficiency in mouse macrophage cell lines and murine bone marrow-derived macrophages [96]. In addition, macrophage-stimulating protein (MSP) activates AKT in murine primary peritoneal macrophages [97] and induced rapid phagocytosis of particles via the CR3 receptor [98]. In contrast, transient transfection with dominant negative AKT mutants down-regulates phagocytosis [96]. AKT also influences actin remodeling, a key component of phagocytosis.

There is also evidence for involvement of AKT in the generation of oxygen radicals, a key function of macrophages. The ability to generate toxic oxygen radicals by the multi-enzyme complex, NADPH oxidase, is an important response to invading microorganisms. In resting neutrophils, the NADPH oxidase complex consists of unassembled cytosolic and membrane components. Following activation, the cytosolic components translocate to plasma or phagosome membranes, where they associate to 
form the active oxidase. It has been shown that AKT mediates PI3K-dependent NADPH oxidase activation in human neutrophils and the loss of respiratory burst activity via AKT inhibitory peptide suggests that AKT activity is necessary for NADPH oxidase activity [99].

Taken together these results show that AKT signaling is critical for Fc $\gamma \mathrm{R}$ and CR3-mediated phagocytosis and development of the respiratory burst and the loss of AKT kinase activity will impair macrophage function. We hypothesize that MV induces suppression of AKT activity in macrophages resulting in decreased phagocytic capacity and bacterial killing.

\subsection{Macaque model of measles virus infection}

Several animal models have been used to study MV pathogenesis and immune suppression. Rhesus and cynomolgous macaques are the only animals that develop a disease similar in clinical, immunological and pathological findings to that seen in humans after natural and experimental infection $[100,101]$. The macaque model has been prominently used in experimental vaccine development to assess attenuation as many correlates of humoral and cell-mediated immunity have been standardized [101], however this work has not resulted in a clinical trial or licensing of a new vaccine for human use. Similar to humans, passively transferred maternal antibodies interfere with vaccination in infant macaques [100]. They also provide a model of atypical measles, a condition of exacerbated pneumonia associated with natural MV infection following immunization with a formalin-inactivated vaccine, a model which can be used in safety assessment of vaccines [102]. 


\subsection{Ferret model of Canine Distemper Virus Infection}

While ferrets cannot be naturally infected with MV, they are highly susceptible to a closely related Morbillivirus, Canine Distemper Virus (CDV). Clinical signs of Distemper in ferrets are identical to those of Measles in humans including rash, fever, immune suppression, gastrointestinal disease, respiratory disease and encephalitis [103]. Similar to the rodent models of MV, encephalitis can be modeled in the ferret by intracranial inoculation of subacute sclerosing panencephalitis isolates [104]. Similar to the macaque, ferrets are used as a model for vaccination studies and CDV-induced immune suppression. Interestingly, use of a recombinant CDV that expresses green fluorescent protein has been used to visualize progression of viral dissemination showing initial infection targets B and T cells in lymphoid tissue, followed by massive infection of lymphoid tissue which then spread to the epithelia [105]. This model differs from Measles in that over $70 \%$ of $\mathrm{B}$ and $\mathrm{T}$ cells are CDV positive whereas in humans only $\sim 2 \%$ of $\mathrm{T}$ cells, B cells and macrophages have been shown to be infected.

\subsection{Mouse, rat, and hamster models of Measles virus infection}

Mice [106], hamsters [107] and rats [108] have been used to model encephalitis by intracranial inoculation of a rodent-adapted neurotropic strain of MV but the infection does not spread outside of the central nervous system. The rodent homologs of the MV receptors, CD46 and CD150, do not confer infectivity and therefore mice and rats are naturally resistant to MV [109-112]. Transgenic mice which express human CD46 and CD150 have been used in an attempt to eliminate this barrier and generate a rodent model 
of systemic MV infection. Genetic background of the mouse strain, immunocompetency, the expression promoter, construct composition, and gene integration site determine susceptibility to MV infection [113]. But even with humanized receptor expression, in vitro permissibility of lymphocytes to MV is significantly lower than that of human lymphocytes, suggesting additional intracellular factors which limit MV replication [114]. When CD46, CD150 or dual receptor expression is coupled with immune suppression through a cross with IFN alpha receptor knockout mice MV antigen and RNA can be detected in lymphoid tissue but infectious virus not be cultured $[66,113$, 115, 116]. Transgenic mice have become useful models to study MV-induced neurological disease and strain dependent neuropathogenicity.

\subsection{Cotton rat (Sigmodon hispidus) model of Measles virus infection}

Cotton rats are the only rodents susceptible to intranasal MV infection where wildtype, vaccine and recombinant MV replicate in the respiratory tract [117]. Inbred cotton rats are available as specific pathogen free from several commercial breeders. The cotton rat is a cost-effective, easily accessible animal model for studies which are prohibitive in monkeys due to costs, availability and ethical concerns. Furthermore, the course of MV immune suppression is similar in cotton rats and humans. Histologically, cotton rats develop interstitial pneumonia as seen in the human disease. Immunohistochemistry using a rabbit polyclonal anti-MV nucleoprotein antibody has identified infected bronchial/bronchiolar epithelial cells, pneumocytes and alveolar macrophages (unpublished observations). Vaccine, wildtype and recombinant viruses can be detected by RT-PCR in peripheral blood lymphocytes [118] [119] and spleen [87] 
and by co-cultivation of nasal and lung tissue of cotton rats. Wildtype virus also spreads to the mediastinal lymph nodes and spleen. Similar to humans, the immunosuppressive effect of wildtype virus is much more pronounced than for vaccine viruses, requiring 1000-fold less viral inoculum. The immunosuppressive capacity of wildtype viruses correlates with a more extensive viral spread and higher viral titer in lung tissue [118]. It has also been shown that viral spread to mediastinal lymph nodes is correlated with the use of the CD150 receptor molecule determined by viral expression of wildtype hemagglutinin $(\mathrm{H})$ protein [118] suggesting that receptor usage in cotton rats is similar to that in humans.

The use of the cotton rat model has yielded a number of insights into MV-induced immune suppression. $\mathrm{CD}^{+}(30)$ and $\mathrm{CD} 8^{+} \mathrm{T}$-cells [52] are suppressed by MV infection whereas B-cell responses are not (30). The MV glycoproteins are sufficient and necessary to induce T-cell proliferation in vivo. In vivo contact with the glycoproteins leads to cell cycle arrest [87] which is subsequent to AKT kinase downregulation [79] .

In addition to developing the cotton rat model of MV pathogenesis, necessary reagents have been established to study infectious diseases in cotton rats by producing monoclonal antibodies against cell surface antigens of cotton rat lymphocytes [52, 120128]. Between R\&D Systems, Minneapolis, MN (cytokines and chemokines), Virion Systems, Rockville, MD (gene sequences and antisera) [129] and the Niewiesk laboratory (monoclonal antibodies) all reagents and methods necessary to perform experiments are available.

Cotton rats can be infected with a wide range of human pathogens [130], including measles virus [117], human respiratory syncytial virus [131], HIV [132], 
Helicobacter pylori [133], Staphylococcus aureus [134], and Mycobacterium tuberculosis [135] making the cotton rat an excellent model for polymicrobial disease. The cotton rat is an established model for Staphylococcus aureus nasal colonization where consistent and persistent high-level colonization can be obtained [134]. Following co-infection with influenza A, S. aureus nasal colonization progresses to alveolar and interstitial pneumonia [136].

\subsection{Thesis objectives}

To study MV-induced immune suppression we use the cotton rat, a directly relevant rodent model because the cotton rat is the only rodent shown to replicate MV in the respiratory tract after intranasal infection and to develop T-cell proliferation inhibition (a hallmark of MV-induced immune suppression). Macrophages play a very important role in immune responses through stimulation and modulation of $\mathrm{T}$ helper cell responses through cytokine production and the control of bacterial infections due to their phagocytic and bacterial killing capacity.

In chapter 2, we describe the culture of cotton rat bone marrow-derived macrophages critical for in vitro investigation of macrophage dysfunction in MV infection. Reduction in IL12 expression has been demonstrated in acute MV-patients and macaques. It is reasonable to suggest that the reduction in IL12 results in a shift towards a TH2 response but it is not clear what effect this has in vivo. In chapter 3 , we hypothesize that measles virus infection leads to a decrease in IL12 secretion causing a shift toward a TH2 response and an increase in IL4 secretion will to correlate with immune suppression (Figure 1.2). We will use bone marrow-derived macrophages to 
establish downregulation of IL12 expression in the cotton rat and we will use a recombinant vaccine MV virus that secretes biologically active cotton rat IL4 to experimentally create a $\mathrm{TH} 2$ environment and investigate whether the secretion of IL4 contributes to immune suppression.

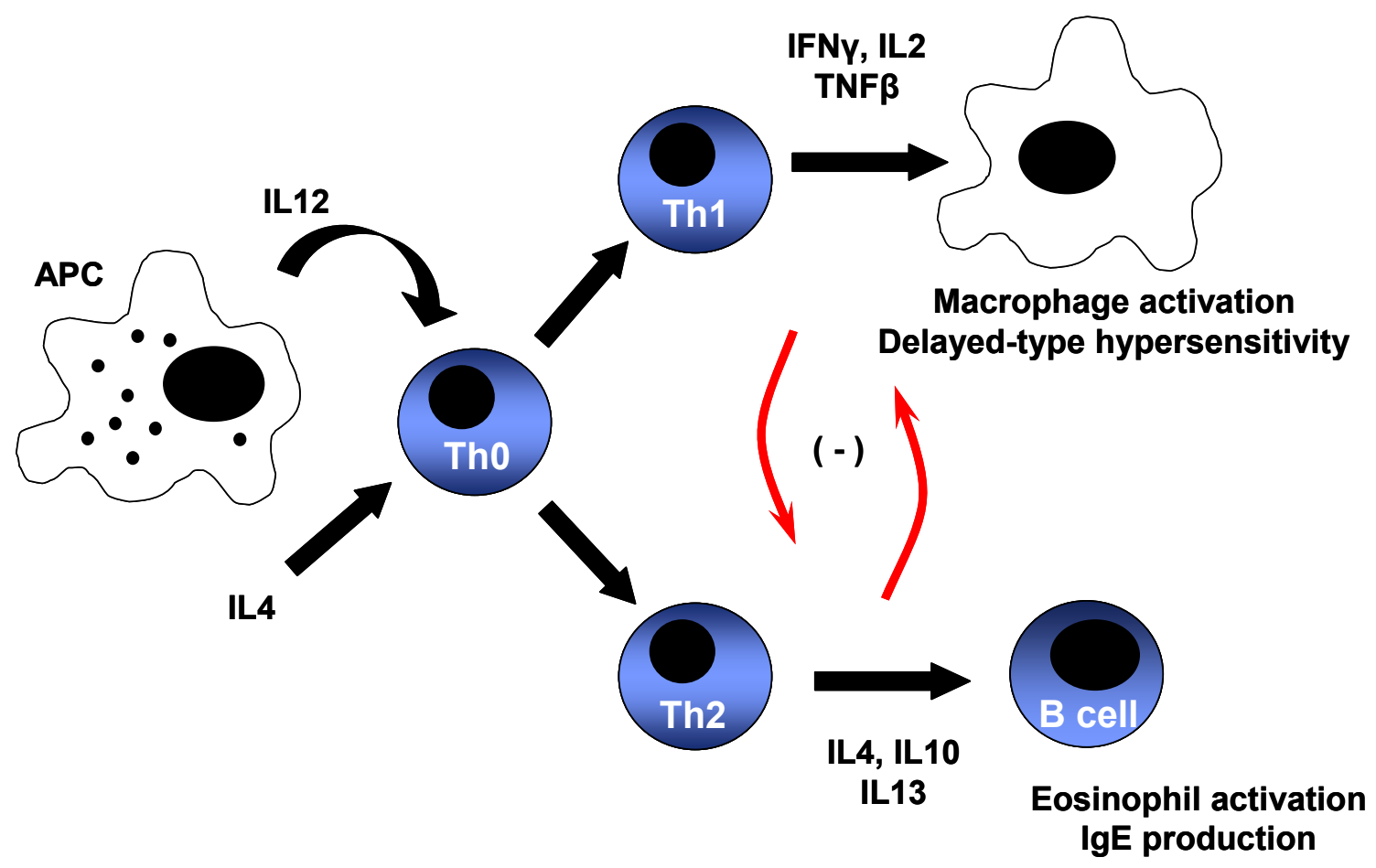

Figure 1.2 Schematic representation of the hypothesis that MV-induced suppression of $\mathrm{T}$-cell proliferation inhibition is due to propagation of a $\mathrm{T}$ helper 2 response characterized by downregulation of IL12 expression by macrophages and increased IL4 production by $\mathrm{T}$ cells. 
A decrease in AKT kinase activity due to MV infection has been demonstrated in a variety of primary and tumor cell lines and is a mechanism with potentially far reaching consequences because AKT is a key regulatory molecule for a number of cellular pathways including macrophage effector mechanisms. In other model systems, reduction in AKT activity has been shown to cause a decrease in macrophage phagocytosis $[96,97$, 137, 138]. Based on these data we hypothesize in chapter 4 that MV infection will lead to downregulation of AKT activity in macrophages resulting in increased susceptibility to S. aureus pneumonia through decrease phagocytosis and bacterial killing (Figure 1.3).

Lastly, the PI3K/AKT pathway is an important mechanism through which viral infection influences various cell functions. Activating the PI3K/AKT signaling pathway is a strategy used by viruses to slow down apoptosis and create a favorable environment for virus replication and virion assembly and release. MV is unusual in that it downregulates AKT kinase activity [139]. Blocking the PI3K/AKT pathway results in lymphocyte proliferation inhibition and supplementation of constitutively active AKT reverses this affect. There is a report that AKT plays a critical role in replication of negative-stranded RNA viruses, including MV. Blocking of the PI3K-AKT pathway with an AKT specific inhibitor resulted in a slight reduction of cell-associated virus and a significant reduction in progeny release from MV infected Vero [139]. This suggests MV requires AKT to enhance synthesis of viral progeny. Higher PI3K/AKT activity might impede viral propagation due to activation of cellular defenses. In chapter 5 , we will investigate the effect of AKT supplementation on viral transcription, replication and progeny release. 
Figure 1.3 Schematic representation of the hypothesis that MV-induced suppression of AKT serine/threonine kinase activity in macrophages will result in decreased phagocytic ability and bacterial killing in vitro (inset) and in vivo. We will also characterize the consequences of AKT kinase inhibition in MV-infected cotton rats intranasally co-infected with S. aureus 


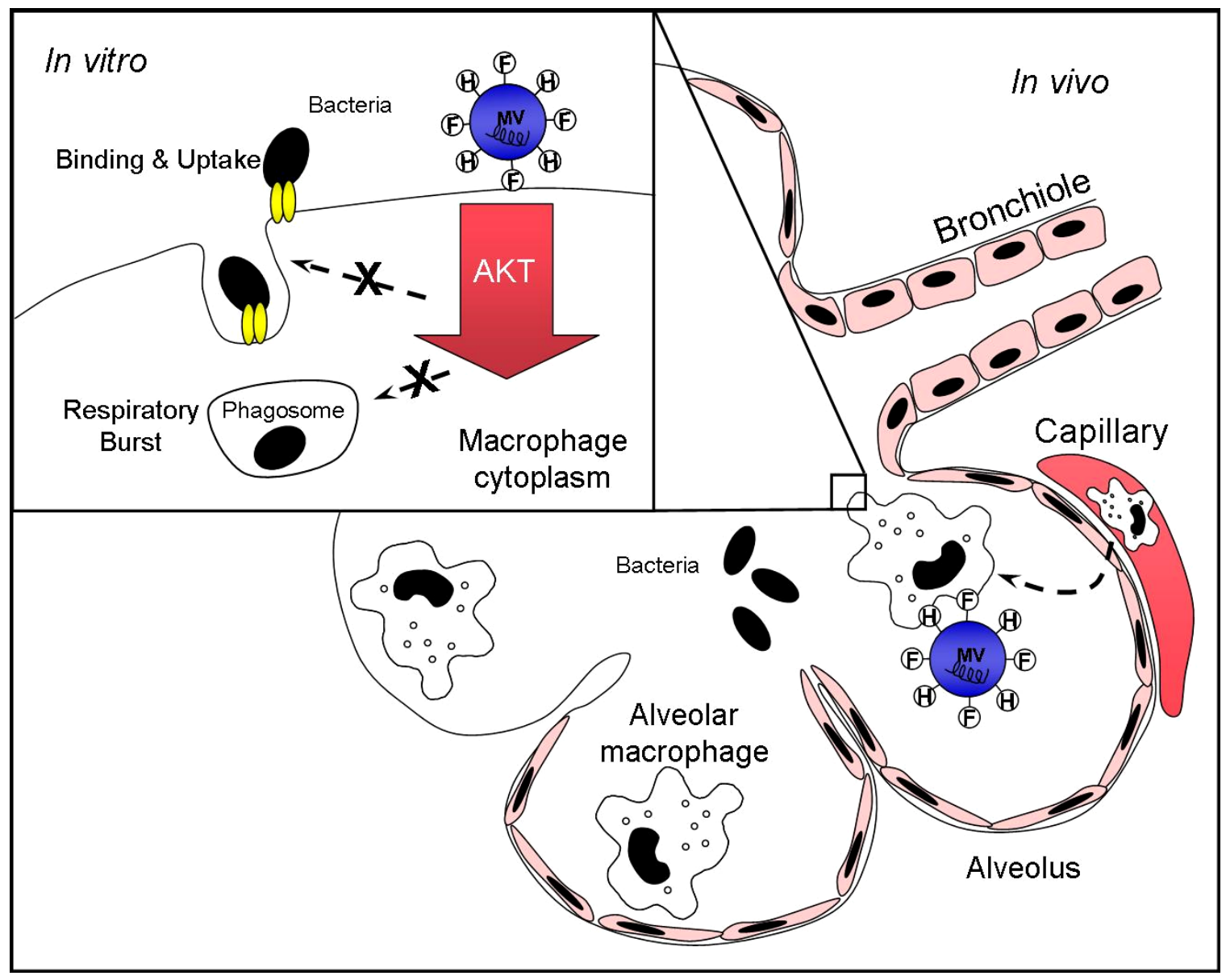




\section{CHAPTER 2}

\section{Nitric Oxide Production and Nitric Oxide Synthase Type 2 Expression by Cotton Rat (Sigmodon hispidus) Macrophages Reflect the Same Pattern as Human Macrophages}

\subsection{Abstract}

Our knowledge of the anti-bacterial role of nitric oxide (NO) during infection is based on studies of murine macrophages, which secrete large amounts of NO. In contrast, human macrophages produce very little NO and its relevance as an anti-bacterial mediator during infection of humans is uncertain. We have defined bone marrow-derived macrophages from cotton rats (Sigmodon hispidus). These macrophages display phenotypical and functional characteristics similar to other rodent and human macrophages. The most interesting finding was the low level of NO production which is in contrast to findings for murine macrophages, but consistent with those of humans. In spite of these low levels, inhibition of NO production led to a decrease in killing of bacteria. Cotton rats are highly susceptible to a variety of human pathogens and therefore offer a rodent model of infectious diseases with similar characteristics to humans in terms of NO production. 


\subsection{Introduction}

Macrophages play a very important role in anti-microbial immunity by linking the innate and adaptive immune responses. As part of the innate immune response, macrophages are able to phagocytose and kill pathogens; as part of the adaptive immune response, they can stimulate antigen-specific immune responses through antigen presentation and secretion of cytokines. For this reason, a variety of pathogens have devised strategies to subvert macrophage functions (for review [140]). Through the study of mouse and rat macrophages it was determined that nitric oxide (NO) is a major antimicrobial molecule and produced in large quantities [141]. NO secretion is generated by nitric oxide synthase type 2 (NOS 2) which in turn is stimulated by a variety of proinflammatory signals like tumor necrosis factor, interferon gamma (IFN $\gamma$ ), and infection with a variety of pathogens. When investigators attempted to apply these findings from rodent macrophages to human mononuclear phagocytes they had difficulties demonstrating NOS2 expression and NO production (for review [142]). With improvements in techniques and reagents, recent studies have shown low levels of NOS2 expression and NO production in human macrophages ([143], [144]). It is currently thought that NO expression in human macrophages is mainly involved in signal transduction rather than anti-microbial activity [142], although antimicrobial activity of NO produced by human macrophages has been established [144]. Whether this difference between human and rodent macrophages is important in the pathogenesis of infectious diseases and therefore constitutes an important aspect in which murine models differ from humans has not been established.

Cotton rats (Sigmodon hispidus) are a very useful animal model for infectious 
disease research due to their susceptibility to a variety of human pathogens (for review [145]). As a model for viral diseases, cotton rats have been used for either acute respiratory infection with measles virus [117, 119], respiratory syncytial virus [146], [147], metapneumovirus [148], [149], [150], parainfluenza virus [151] and influenza A virus [152], [153] or chronic infection with human immunodeficiency virus [154], [132], herpes simplex virus type 1 [155] and 2 [156] and adenovirus [157]. As a model for bacterial diseases cotton rats have been infected with Helicobacter pylori [133], Staphyloccocus aureus [158], Mycobacterium tuberculosis [123], Borrelia burgdorferi [159], [160] and Francisella tularensis [161]. The use of cotton rats as a model of infectious diseases has increased over the last decade, mainly due to commercially available inbred animals and the development of methods and reagents for the analysis of the immune system [145], [162]. In this study, we have defined the phenotypical and functional characteristics of bone marrow-derived macrophages from cotton rats. This allows for the analysis of macrophage-pathogen interaction during infection of cotton rats with human pathogens. In contrast to other rodent and similar to human macrophages, cotton rat macrophages demonstrate low levels of NOS2 expression and NO production. The similarities between human and cotton rat macrophages might help to explain the high susceptibility of this rodent to human pathogens. 


\subsection{Material and Methods}

Animals

Inbred cotton rats and $\mathrm{C} 3 \mathrm{H}$ mice were obtained from Harlan, Indianapolis. Female animals from six to ten weeks of age were used. The animals were bought specific pathogen free according to the breeder's specification and were maintained in a barrier system. Animals were kept under controlled environmental conditions of $22 \pm 1^{\circ} \mathrm{C}$ and a twelve-hour light cycle. All animals were euthanized by $\mathrm{CO}_{2}$ inhalation.

\section{Bone marrow derived macrophages}

Bone marrow was aspirated aseptically from the femoral diaphyseal marrow cavity of female cotton rats and cells were isolated after centrifugation. Bone marrow cells were then cultured in $10 \mathrm{~cm}$ perfluoroalkoxy polymer resin dishes for seven days in the presence of $100 \mathrm{ng} / \mathrm{ml}$ recombinant mouse M-CSF (R\&D Systems) in RPMI 1640 supplemented with $10 \%$ FCS, $1 \%$ non essential amino acids, $1 \%$ sodium pyruvate, 2 mmol/L glutamine, 50 I.U. penicillin, $50 \mathrm{mg}$ streptomycin/L and $5 \times 10^{-5} \mathrm{M} \beta$ mercaptoethanol. After seven days in culture plastic adherence of cells is characteristic of macrophage differentiation. Macrophages were primed in RPMI/10 (RPMI 1640 with $10 \% \mathrm{FCS}, 1 \%$ non essential amino acids, $1 \%$ sodium pyruvate, $2 \mathrm{mmol} / \mathrm{L}$ glutamine, 50

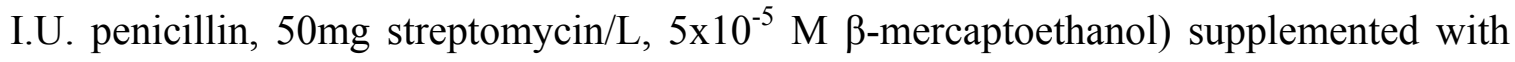
$20 \%$ tissue culture supernatant from Concanavalin A stimulated spleen cells (containing IFN $\gamma$ ). To produce this supernatant, $5-10 \times 10^{7}$ cotton rat splenocytes were cultured in RPMI $/ 10$ containing $2.5 \mathrm{ug} / \mathrm{mL}$ Concanavalin A at $37^{\circ} \mathrm{C}$. After 36 hours, $10 \mathrm{mg} / \mathrm{mL}$ methyl- $\alpha$-mannopyranoside was added and supernatant obtained by centrifugation. The 
supernatant was filtered prior to use.

\section{Non-specific esterase staining}

Macrophages were stained for cytoplasmic non-specific esterase activity using $\alpha$ naphthyl acetate (non-specific esterase) (Sigma) according to the manufacturer's instructions.

\section{Cloning of cotton rat CD14 and production of antiserum}

Isolation of the CD14 gene was performed by screening cDNA libraries constructed from LPS-stimulated cotton rat macrophages using standard recombinant DNA techniques. cDNA libraries were constructed using the SuperScriptTM Plasmid System for cDNA synthesis and plasmid cloning (Invitrogen) and transformed into DH5a maximum efficiency E. coli (Invitrogen). To clone cotton rat CD14, sense and anti-sense degenerated primers based on the sequence homology of CD14 for various species (mouse, rat, rabbit and human) were synthesized. With these primers (see table 1) a probe of $938 \mathrm{bp}$ was amplified from cotton rat macrophage cDNA and used for screening of a cotton rat macrophage library. The full length cotton rat CD14 gene was cloned into pcDNA-3. This plasmid was used to stably transfect L929 cells using lipofectin, and

gentamycin was used as the selection agent. $\mathrm{C} 3 \mathrm{H}$ mice were inoculated with $10^{7} \mathrm{CD} 14$ transfected L929 cells in weekly intervals for three weeks intraperitoneally. Three weeks later mice were euthanized and serum was obtained by cardiac puncture. 


\section{Flow cytometry}

Spleen cells or macrophages were incubated with primary antibodies MHC I [163] (clone W6/32), MHC II [164] (clone 13/4) cotton rat-CD4 [127] or a mouse serum specific for cotton rat CD14. The secondary donkey anti-mouse serum labeled with FITC was pre-absorbed with cotton rat serum. Subsequently cells were analyzed by flow cytometry (Facscan, Becton Dickenson).

\section{Reverse transcriptase polymerase chain reaction}

Macrophages were primed with 20\% supernatant from Concanavalin A stimulated spleen cells and stimulated further with 100 ng/mL LPS (E. coli 0127:B8; Sigma). RNA was isolated using the Qiagen RNeasy kit (Ambion). Culture permutations used during optimization can be found in Table A.1 of the appendix. RNA concentration was calculated using 260/280nm light absorbance (ND-1000 Spectrophotometer, Nano Drop Technologies). To ensure RNA sample integrity, each sample was probed for the housekeeping gene $\beta$ actin. All reactions were also performed without reverse transcriptase to verify the absence of genomic DNA contamination. Standard RT-PCR was performed using M-MLV reverse transcriptase (Invitrogen). NOS2 was amplified by standard RT-PCR (table 1 for primer sequences). Samples were analyzed by $2.0 \%$ agarose gel electrophoresis and stained with ethidium bromide.

Real time RT-PCR was performed using the LightCycler RNA Amplification Kit SYBR Green I (Roche) for IL12p35, IL18, TGF $\beta$, TNF $\alpha$ and $\beta$ actin (table 1 for primer sequences). Total SYBR Green fluorescence was measured at conditions that preserve specific gene product amplicons but not nonspecific amplification products. A 
representative standard curve for IL12p35 is shown in Figure A.1 of the appendix. Data were analyzed using LightCycler Software Version 3. Quantification was based upon fit points analysis with arithmetic baseline adjustment. Melting peak and melting curve analyses were performed using the polynomial calculation method. RT-PCR standards were generated by in vitro transcription. Template for these transcription reactions was an expression plasmid containing the complete mRNA sequence. Plasmid was linearized to introduce a consistent transcription stop site. The transcripts were treated with DNase (Ambion) to remove the template plasmid. Nucaway columns (Ambion) were used to remove free nucleotides. RNA transcripts were quantified by optical density. Serial dilutions of the RNA transcripts were made for use as standards for the real time RTPCR; samples were also analyzed by agarose gel electrophoresis $(2.0 \%)$ and stained with ethidium bromide. 
Table 2.1 Sequences of primers used for the study of cotton rat macrophages. The sequences for the primers used to amplify gene products from cotton rat macrophages by PCR and the expected size of the amplicon are shown. 


\begin{tabular}{|l|l|l|l|}
\hline Gene & Sense primer & Anti-sense primer & $\begin{array}{l}\text { Size of } \\
\text { amplicon } \\
\text { in base } \\
\text { pairs }\end{array}$ \\
\hline CD14 & $\begin{array}{l}\text { C/A AGC G/T/C T/C G/A T/C } \\
\text { C/T C/T C/T } \\
\text { G/TGCTTTGTTGCTG }\end{array}$ & $\begin{array}{l}\text { ACCT G/A T C/T CAG C/T C/T } \\
\text { TGTTG T/C A A/G CT }\end{array}$ & 938 \\
\hline IL12p35 & GGACCATAATCGGAAGCAGA & TGGAGGAGAATGCAGAGCTT & 162 \\
\hline IL18 & CACCAGAAGAAGGCTCTTGC & CTGGTCTGGGCTTCATTAGC & 235 \\
\hline TGF $\beta$ & GCCTTGTCCCTACATTTGGA & & 182 \\
\hline TNF $\alpha$ & TTGAGTGACAAGCCTGTAGC & CAAAGTAGACCTGCCCGGAT & 433 \\
\hline$\beta$ actin & CACCAGAAGAAGGCTCTTGC & CTGGTCTGGGCTTCATTAGC & 246 \\
\hline NOS2 & $\begin{array}{l}\text { CCTCCAGGCACACAGTTTGG } \\
\text { TGG }\end{array}$ & $\begin{array}{l}\text { GCCAAGAACGTGTTCACCAT } \\
\text { GAG }\end{array}$ & 229 \\
\hline
\end{tabular}




\section{Bacterial killing}

Cotton rat bone marrow-derived macrophages were incubated with Escherichia coli $(\mathrm{MOI}=1)$ in glass tubes containing $\mathrm{PBS} / 10 \%$ normal cotton rat serum. Tubes were rotated end-over-end at $\sim 8 \mathrm{rpm}$ for $20 \mathrm{~min}$ at $37^{\circ} \mathrm{C}$ in a hybridization oven. The cells were washed to remove extracellular bacteria. Cell lysates were harvested at times zero and 120 minutes post infection. Serial dilutions of the homogenates were plated in duplicate on LB agar plates to determine the number of viable intracellular bacteria. After incubation overnight at $37^{\circ} \mathrm{C}$, colonies were counted. In some experiments $1400 \mathrm{~W}$ (Sigma), an inhibitor of NOS2, was added to the macrophage media for 30 minutes prior to and during the 15 minutes incubation with E. coli.

\section{Nitric oxide detection by Griess reaction}

Cotton rat bone marrow-derived macrophages were plated in 96-well plates in triplicates and primed with RPMI containing 20\% supernatant of Concanavalin A stimulated spleen cells (containing IFN $\gamma$ ). Macrophages were triggered with $100 \mathrm{ng} / \mathrm{mL}$

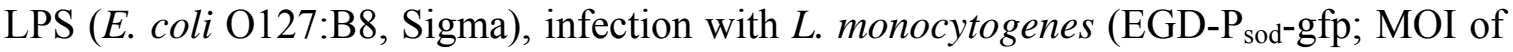
10), PMA $100 \mathrm{ng} / \mathrm{ml}$ or TNF- $\alpha 10 \mathrm{pg} / \mathrm{mL}$ (R\&D Systems). Culture permutations used during optimization can be found in Table A.1 of the appendix. At 24, 36 and 48 h, 50 $\mu \mathrm{L}$ of culture supernatant was collected and transferred to a 96-well plate. Serial dilutions of a $2 \mathrm{mM}$ stock of $\mathrm{NaNO}_{2}$ solution were used to generate a standard (1.25 $\mu \mathrm{M}$ through $100 \mu \mathrm{M}) .50 \mu \mathrm{L}$ of $0.1 \%(\mathrm{w} / \mathrm{v}) \mathrm{N}-(1$-naphthyl) ethylenediamine dihydrochloride (in $2.5 \%$ phosphoric acid) and $50 \mu \mathrm{L}$ of $1 \%(\mathrm{w} / \mathrm{v})$ sulfanilamide (in $2.5 \%$ phosphoric acid) were added to each well. The absorbance was measured at $550 \mathrm{~nm}$ in a microwell plate reader. 


\section{Nitric oxide detection by electron paramagnetic resonance $(E P R)$ spectroscopy}

The nitric oxide generated by macrophages was measured using Fe-MGD complex $\left(1 \mathrm{mM} \mathrm{Fe}{ }^{2+}, 5 \mathrm{mM} \mathrm{N}\right.$-methyl-D-glucaminedithiocarbamate (MGD) in PBS, $\mathrm{pH}$ 7.4). Stimulated bone marrow-derived macrophages were incubated with Fe-MGD for 30 min, and then EPR spectra were recorded in a quartz flat cell at room temperature with a Bruker ER 300 spectrometer operating at X-band with $100 \mathrm{kHz}$ modulation frequency and a TM110 cavity as described [165] [166]. S-nitroso- N-acetyl-penicillamine (SNAP, $10 \mu \mathrm{M})$ was used as NO standard. NO scavenger, 2-phenyl-4,4,5,5tetramethylimidazoline-1-oxyl 3-oxide (PTIO, Sigma), (50 $\mu \mathrm{M})$ was used to verify the specificity of the EPR signal.

\section{Nitric oxide detection by DAF fluorescence}

The intracellular NO production was determined using diaminofluoresceine-2 diacetate (DAF-2A) fluorescence. Macrophages grown on glass cover slips were preloaded with DAF-2A $(10 \mu \mathrm{M})$ for $30 \mathrm{~min}$, washed to remove excess fluorophore and then stimulated with $100 \mathrm{ng} / \mathrm{mL}$ LPS for six hours. SNAP $(100 \mu \mathrm{M})$ was used as a positive control which releases nitric oxide under physiological conditions. NO scavenger, 2-phenyl-4,4,5,5-tetramethylimidazoline-1-oxyl 3-oxide (PTIO, Sigma), (50 $\mu \mathrm{M})$ was used to verify the specificity of the DAF fluorescence. Macrophages were rinsed with PBS and examined using a Leica TCS SP2 AOBS Confocal Laser Scanning Microscope under a magnification of $40 \mathrm{X}$ at $490 \mathrm{~nm}$ and $520 \mathrm{~nm}$. The fluorescence intensity was quantitatively determined using Leica Confocal Software Lite. 


\section{Superoxide and hydrogen peroxide detection}

Bone marrow-derived macrophages were plated in a black, clear-bottomed 96well plate $\left(10^{6}\right.$ cells/well $)$ in replicates of six. Macrophages were primed with $10 \mathrm{U} / \mathrm{mL}$ recombinant cotton rat IFN $\gamma$ (R\&D Systems) for $48 \mathrm{~h}$ and then washed with Hank's balanced salt solution (HBSS). Subsequently, lucigenin $(10 \mu \mathrm{M})$ or luminol $(100 \mathrm{mM})$ was added to the each well and macrophages were stimulated with PMA $(100 \mathrm{ng} / \mathrm{mL})$ or Zymosan A (100 $\mu \mathrm{g})$. Luminescence measurements were taken immediately (PMA) or after centrifugation (Zymosan A) and then for every 5 min in the Microbeta Scintillation Counter (Perkin Elmer). Cells were maintained at $37^{\circ} \mathrm{C}$ between the readings.

\subsection{Results}

\section{Culture conditions for the generation of cotton macrophages from bone marrow}

In order to determine the antimicrobial activity of cotton rat macrophages, we established a method to culture a homogenous cell population from bone marrow and defined these cells as macrophages by phenotypical and functional criteria. These macrophages were used for phagocytosis assays and tested for their secretion of reactive oxygen and nitrogen intermediates. Based on protocols for the generation of mouse macrophages from bone marrow, we plated $5 \times 10^{6}$ bone marrow cells in a $10 \mathrm{~cm}$ Petri dish in RPMI medium supplemented with $10 \% \mathrm{FCS}$ and $5 \times 10^{-5} \mathrm{M} \beta$-mercaptoethanol. As a growth promoter L929 supernatant (which contains mouse M-CSF), recombinant mouse or human M-CSF was added. The best growth of cells from bone marrow was observed after the addition of recombinant mouse M-CSF that yielded $7.5 \times 10^{6}$ to $1 \times 10^{7}$ macrophages per plate (twice as much as after addition of human M-CSF). After the 
addition of L929 supernatant, cells grew poorly. The cells growing after seven days in culture had a homogenous phenotype of large cells adherent to plastic and contained granules expressing non-specific esterase, an enzyme typically expressed by macrophages (data not shown).

\section{Expression of cell surface markers on cotton rat macrophages}

In order to define cotton rat macrophages, further, they were stained with antibodies against MHC class I (clone W6/32; [163]), MHC class II (clone 13/4; [164]), CD14 and CD4 (clone CR-CD4; [127]). W6/32 is an antibody specific for human MHC I and is cross-reactive with cotton rat MHC I by immunoprecipitation (data not shown). It demonstrates a typical pattern of MHC I expression by flow cytometry on spleen cells and macrophages obtained by peritoneal lavage (Figure 2.1). 13/4 is an antibody specific for mouse MHC II; it did not immunoprecipitate cotton rat MHC II (data not shown). However, it inhibited the proliferation of measles virus specific CD4 $\mathrm{T}$ cells in tissue culture [127], and demonstrated a typical pattern of expression by flow cytometry on spleen cells and macrophages obtained by peritoneal lavage (Figure 2.1). Staining with these two antibodies revealed that bone marrow-derived macrophages of cotton rats express MHC I, but little MHC II. In order to increase MHC II expression, macrophages were treated with recombinant IFN $\gamma$ for $48 \mathrm{~h}$, and this treatment increased MHC II expression (Figure 2.1). For staining against CD14, L929 cells stably transfected with cotton rat CD14 were used to produce a mouse polyclonal antiserum specific for cotton rat CD14. All cells derived by culture from bone marrow expressed CD14 (Fig. 2.1). It has been shown that rat and human macrophages express CD4 but staining with CR-CD4 
(a monoclonal antibody specific for cotton rat CD4 [127] demonstrated no CD4 expression on cotton rat macrophages (data not shown).
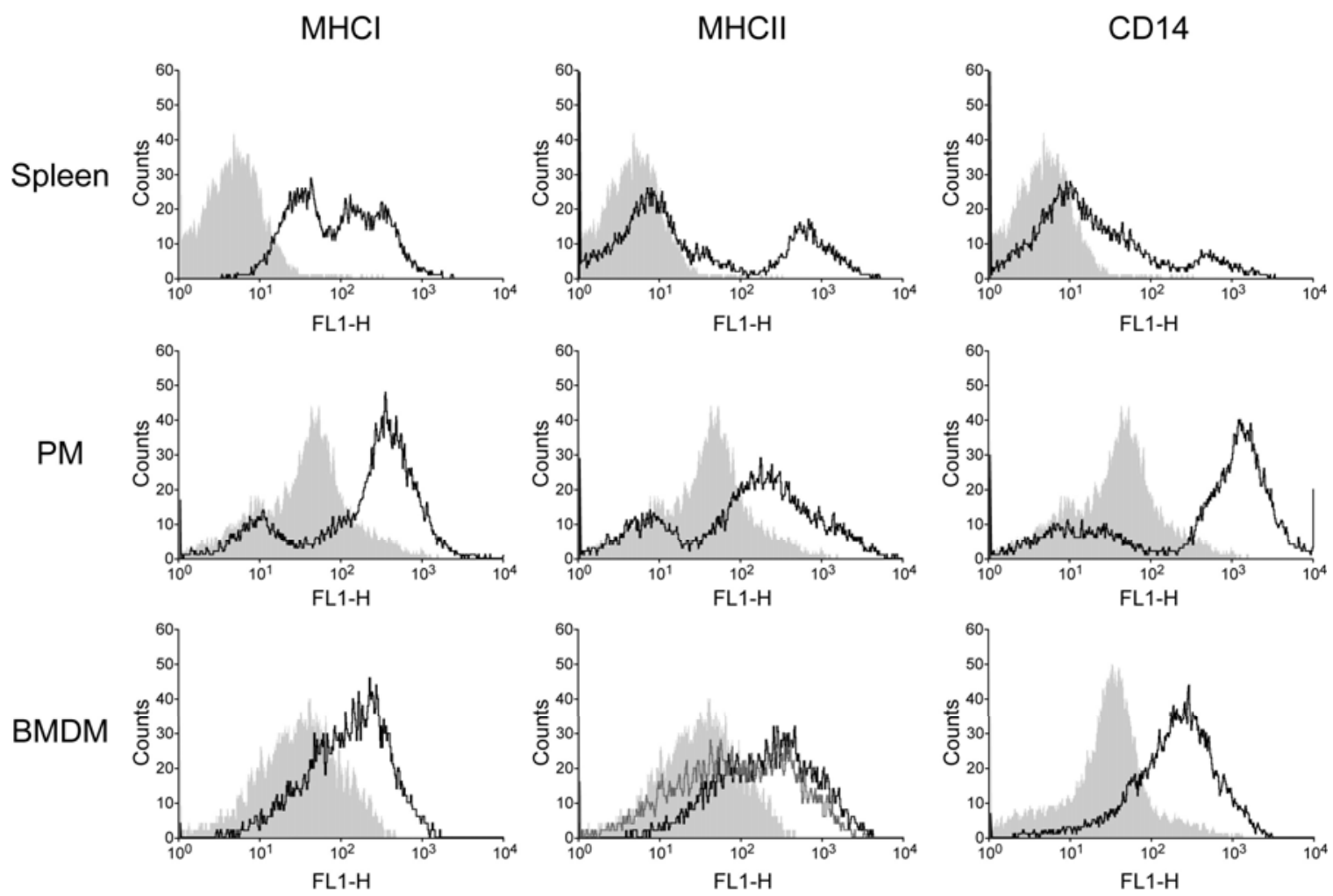

Figure 2.1 Expression of MHC I, MHC II and CD14 by cotton rat macrophages. Expression of MHCI, MHCII and CD14 on spleen cells, peritoneal macrophages and bone marrow-derived macrophages. MHC class II expression increased with stimulation of the bone marrow-derived macrophages for $48 \mathrm{~h}$ with recombinant cotton rat IFN $\gamma$ prior to staining (gray no IFN $\gamma$ treatment, black IFN $\gamma$ treatment). Bone marrow-derived macrophages were stained with hybridoma tissue culture supernatant containing mouse anti-cotton rat monoclonal antibodies. These data are representative of three independent trials. 


\section{Cytokine expression of bone marrow-derived macrophages}

Macrophages typically express TNF $\alpha$, TGF $\beta$, IL12 and IL18. The expression of these cytokines by bone marrow-derived cotton rat macrophages was determined by real time RT-PCR. TNF $\alpha$, TGF $\beta$ and IL18 were expressed in both stimulated and unstimulated bone marrow-derived macrophages (Figure 2.2), and the expression of both TNF $\alpha$ and TGF $\beta$ increased after stimulation. In contrast, IL12 p35 expression was found only after stimulation with IFN $\gamma$ and LPS (Figure 2.2).

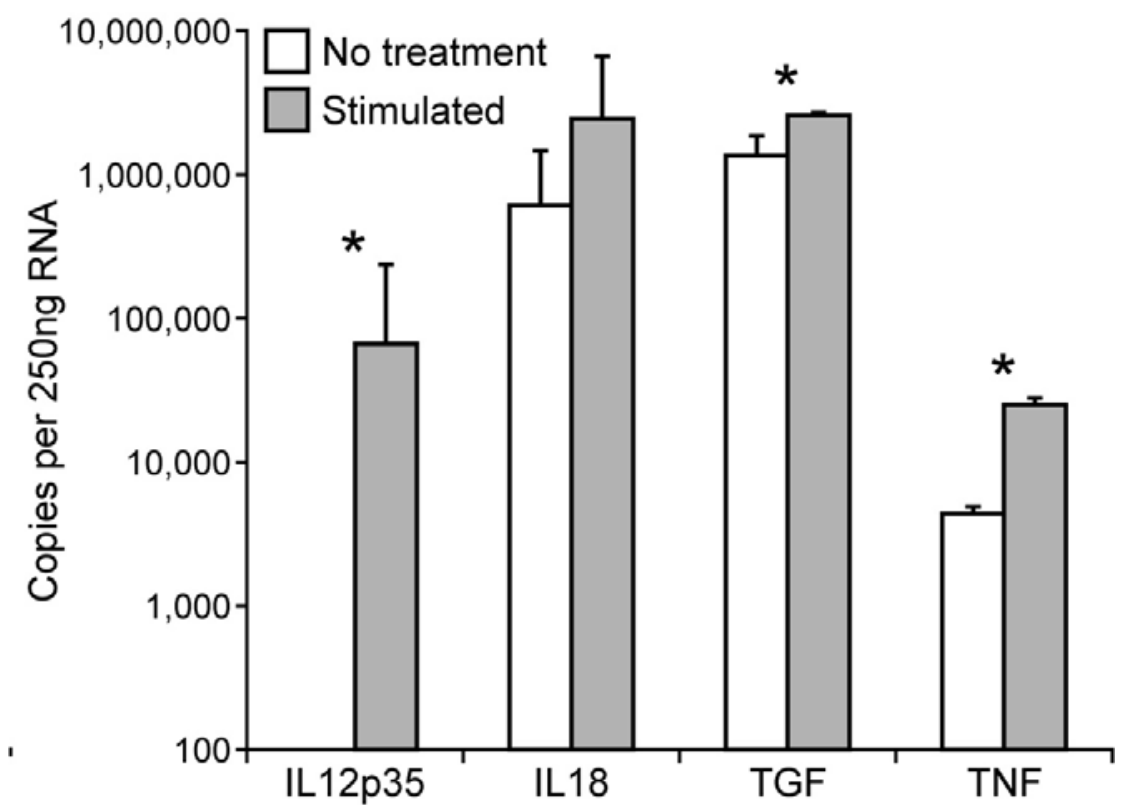

Figure 2.2 Levels of IL12p35, IL18, TNF $\alpha$ and TGF $\beta$ mRNA in cotton rat macrophages. Expression levels of IL12p35, IL18, TNF $\alpha$ and TGF $\beta$ mRNA were determined in untreated (white bars) and stimulated macrophages (gray bars) by SYBR green real time RT-PCR. The differences for mRNA expression in untreated versus stimulated macrophages were statistically significant for IL12p35 $(p<0.001)$, TNF $\alpha$ $(p<0.001)$ and TGF $\beta(p<0.05)$ whereas the difference in IL18 mRNA expression was not. Data represent mean of duplicates $+/$ - standard deviation. 


\section{Phagocytosis of L. monocytogenes by cotton rat macrophages}

A hallmark of macrophage function is its antimicrobial activity through phagocytosis. Phagocytosis is defined as the binding, up-take and killing of bacteria in lysosomal compartments. In order to observe these different steps, we established both a confocal microscopy assay to visualize intracellular compartments of infected macrophages and a bacterial killing assay. For infection of macrophages a $L$. monocytogenes mutant was used in which the gene for superoxide dismutase ( $\operatorname{sod} A)$ was replaced by green fluorescent protein (GFP) [167]. This mutant constitutively expresses GFP, is fully functionally in tissue culture and easily visible by UV-light microscopy (data not shown). In order to visualize different cellular compartments of macrophages and to follow the route of infection by the Listeria mutant, dyes staining DNA in the nucleus (Hoechst stain 33258), the F actin skeleton (Alexa Fluor 633 phalloidin) and the phagolysosome (LysoTracker Red) were used. Infected cells were analyzed at different time points by confocal microscopy. As previously published for mouse macrophages, infection with L. monocytogenes lead to binding and uptake of bacteria. Listeria infection stimulated the generation of phagolysosomes (containing bacteria) and disrupted the regularly structured cytoskeleton (actin F filaments, data not shown). In order to demonstrate bactericidal activity, macrophages were incubated with $L$. monocytogenes and lysates were prepared directly or after two hour incubation. Cotton rat macrophages reduced the number of intracellular L. monocytogenes by $>0.2 \log 10$ (difference between $\mathrm{T}_{0}$ and $\mathrm{T}_{2}$ hours) which is considered to be bactericidal activity [168] although the difference did not reach statistical significance. As a facultative intracellular bacterium, L. monocytogenes is relatively resistant to killing by macrophages. Relative to $L$. 
monocytogenes, activated cotton rat bone marrow-derived macrophages killed E. coli (Figure 2.5) more efficiently and E. coli was used for further phagocytosis assays.

\section{ROI and NO generation in cotton rat macrophages}

Killing of bacteria after phagocytosis by macrophages is typically achieved by a combination of methods including vesicle acidification, enzymatic digestion and reactive oxygen (ROI) and nitrogen intermediates. As a marker of antibacterial activity, the generation of superoxide, hydrogen peroxide and nitric oxide by cotton rat macrophages were measured. To stimulate the production of these molecules, cotton rat macrophages were primed with IFN $\gamma(2,4,6,8$ or $10 \mathrm{U} / \mathrm{mL})$ or supernatant from Concanavalin A stimulated spleen cells (containing IFN $\gamma$ ), and triggered with 100ng/mL LPS and Listeria monocytogenes $(\mathrm{MOI}=10$ ), PMA $100 \mathrm{ng} / \mathrm{mL}$ or $\mathrm{TNF} \alpha 10 \mathrm{pg} / \mathrm{mL}$. After the stimulation, there was an increase in the generation of superoxide and hydrogen peroxide by macrophages (Figure 2.3A). However, no nitric oxide production by cotton rat macrophages was observed (Figure 2.3B). In contrast, mouse bone marrow-derived macrophages secreted high amounts of nitric oxide (Figure 2.3B). In order to exclude the possibility that the lack of NO secretion was specific for bone marrow-derived macrophages, peritoneal macrophages were obtained and tested with various stimuli. However, no secretion of NO was found (data not shown). The Griess reaction used to measure nitrite (a stable product of $\mathrm{NO}$ ) has a limit of detection in the low micromolar range. Furthermore, we tested the production of $\mathrm{NO}$ in supernatants of cotton rat macrophages by electron paramagnetic resonance (EPR) spin trapping. Even with this sensitive technique, no nitric oxide production was observed (data not shown). 
Figure 2.3 Secretion of superoxide, hydrogen peroxide and nitric oxide by cotton rat macrophages. Addition of zymosan to IFN $\gamma$ primed cotton rat bone marrow-derived macrophages $\left(10^{6}\right.$ per well $)$ leads to secretion of extracellular superoxide $\left(\mathrm{O}_{2}{ }^{-}\right)$and hydrogen peroxide $\left(\mathrm{H}_{2} \mathrm{O}_{2}\right)$ detected by lucigenin and luminol luminescence, respectively. Production of superoxide and hydrogen peroxide reaches a peak at $30 \mathrm{~min}$ post-trigger. Nitric oxide, measured as nitrite with the Griess reaction, was not detectable in the supernatant of IFN $\gamma$ primed, LPS (E. coli) stimulated cotton rat bone marrow-derived macrophages. In contrast, nitrite was detectable in the supernatant of stimulated mouse bone marrow-derived macrophages. These data represent mean of six replicates +/standard deviation and are representative of two independent trials. 

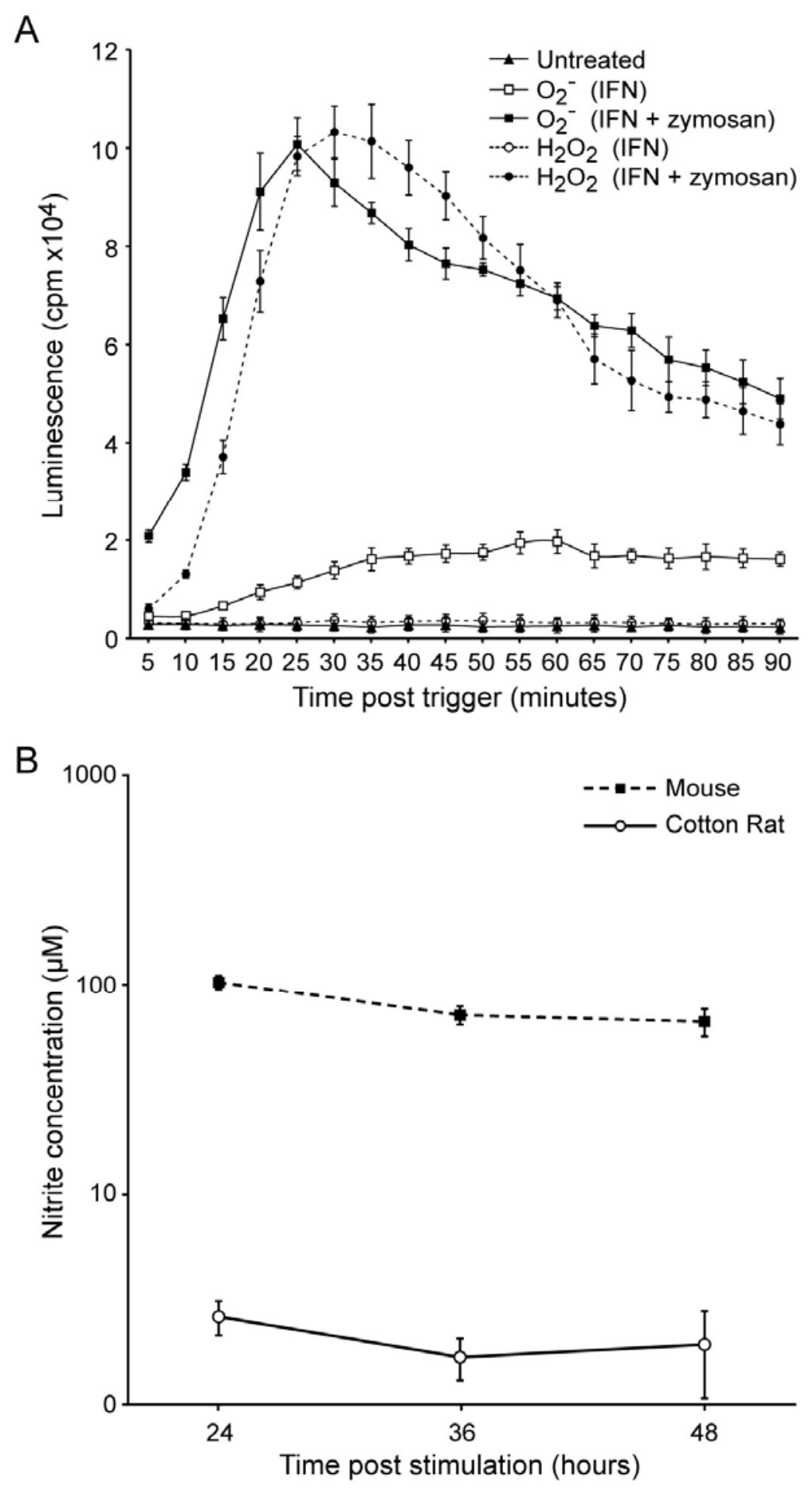
To test for the presence of intracellular nitric oxide, cells were preloaded with the NO-specific intracellular fluorophore, diaminofluorescein-2 diacetate (DAF-2A), and results indicated the production of intracellular NO (Figure 2.4).

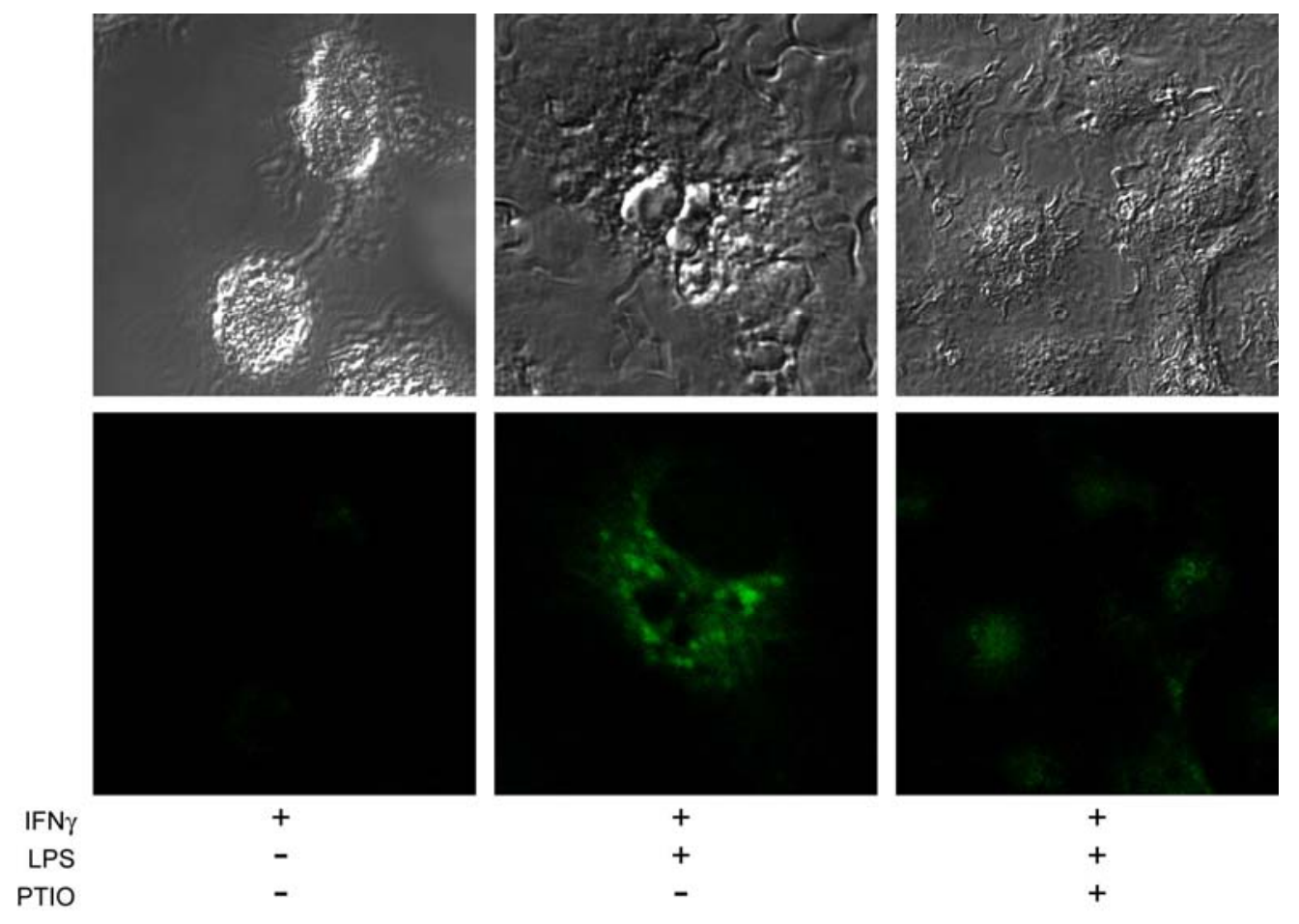

Figure 2.4 Fluorescent microscopy of diaminofluorescein diacetate (DAF2A) stained cotton rat bone marrow-derived macrophages. Cotton rat macrophages were treated with the fluorophore DAF2A which can be detected by UV light (bottom) after reaction with nitric oxide as green fluorescence. The integrity of cotton rat macrophages is seen by light microscopy (top). Priming with IFN $\gamma$ does not stimulate secretion of nitric oxide (bottom left). Stimulation of IFN $\gamma$ primed macrophages with LPS (E. coli) causes secretion of low levels of intracellular nitric oxide (bottom center, green fluorescence). Addition of 2-phenyl-4,4,5,5-tetramethylimidazoline-1-oxyl 3-oxide (PTIO), a nitric oxide scavenger, reduces nitric oxide specific fluorescence (bottom right). These data are representative of two independent trials 
In addition, mRNA for inducible nitric oxide synthase 2 (NOS2) was detected by PCR from these macrophages (data not shown). These data indicate that cotton rat macrophages are very similar to human macrophages in that they express very little NO (in contrast to mouse macrophages).

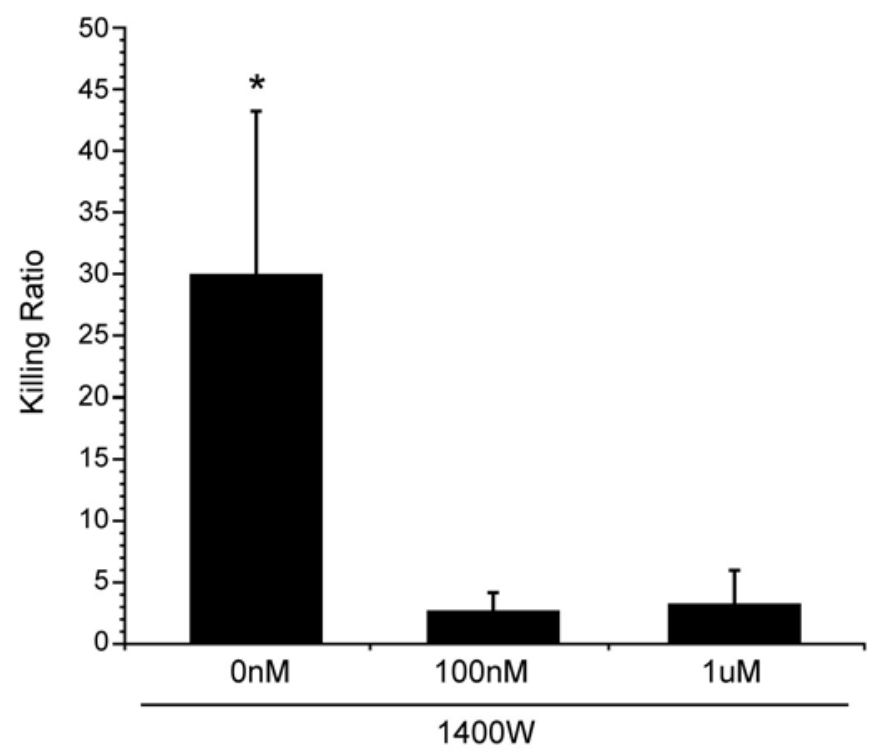

Figure 2.5 Inhibition of bacterial killing assay by inhibition of nitric oxide. Bone marrow-derived macrophages $\left(5 \times 10^{5} /\right.$ well $)$ were plated in 24 -well plates and primed for $48 \mathrm{~h}$ with $0.5 \mu \mathrm{g} / \mathrm{ml}$ recombinant cotton rat IFN $\gamma$. Wells were incubated with $1400 \mathrm{~W}$ for $30 \mathrm{~min}$, and then all wells were infected with $E$. coli in the presence or absence of $1400 \mathrm{~W}$. Total CFUs were determined after $2 \mathrm{~h}$. Killing ratio = initial viable intracellular bacterial at T0/viable intracellular bacteria at T2 $\mathrm{h}$. *Significant difference between IFN and $1400 \mathrm{~W}$ treatment groups $(p<0.001)$. These data represent mean of duplicates $+/$ standard deviation and are representative of two independent trials. 
However, even low amounts of NO produced by human macrophages may have the antibacterial activity [144]. In order to determine whether this was also true for cotton rat macrophages, an inhibitor of NO production was used. Macrophages treated with the NOS2 inhibitor $1400 \mathrm{~W}$, demonstrated increased growth of bacteria as compared to bacterial growth in mock-treated macrophages (Figure 2.5).

\subsection{Discussion}

In the present study, we have described the culture of bone marrow-derived macrophages from cotton rats and characterized them phenotypically and functionally. Culture conditions used for the generation of mouse bone marrow-derived macrophages proved to be satisfactory for cotton rat bone marrow-derived macrophages, too. Cotton rat macrophages display typical characteristics of macrophages including plastic adherence, the presence of granules containing non-specific esterase, expression of MHC I, MHC II, CD14, and production of TNF $\alpha$, TGF $\beta$, IL12 and IL18 mRNA. One difference to other rodent macrophages was the expression of MHC II. In mouse and rat BMDM expression levels of MHC II molecules are high (60\% [169] and 30\% [170], respectively) whereas in cotton rat macrophages expression is low although it can be stimulated with IFN $\gamma$. Cotton rat macrophages also do not express CD4, similar to the mouse, but in contrast to rat and human macrophages [171]. In functional assays, cotton rat macrophages ingest bacteria into lysosomes and are able to kill them. In contrast to macrophages from a variety of rodents like mouse [172], gerbil, mastomys [173] and rats [141], cotton rat macrophages express low amounts of nitric oxide. Previous studies have shown that the induction of interferon regulatory factor 1 (IRF1) by IFN $\gamma$ up-regulates the NOS2 promoter and this stimulation is counteracted by TGF $\beta$ [174]. Constitutive 
TGF $\beta$ mRNA expression is found in cotton rat macrophages. However, further studies have to elucidate whether this is the mechanistical reason for the low level of NO expression.

The apparent difference between mouse and cotton rat is of particular interest for the study of infectious diseases. Mice have been used to study a variety of infectious diseases, as they are genetically and immunologically well-defined animal model. However, the increasing body of evidence demonstrate a large difference in the immune system of mouse and humans [175]. Of interest in the current study is to investigate in the differences in NO generation. The production of NO by mouse macrophages in culture have been demonstrated and correlated with its antibacterial effects [172]. Further, the role of NO in the antibacterial actions have been confirmed with use of NO inhibitors and the deletion of the NOS2 gene [172]. In contrast, human macrophages secrete very little NO [176]. A large number of studies have demonstrated that the detection of NO production by human macrophages (peritoneal, alveolar or bone marrow-derived) is very difficult and often relies on the detection of NOS2 mRNA by PCR or Northern blotting or by immunohistochemistry in lung tissue [142]. These data have been interpreted as NO having more of a signal transduction function in human macrophages whereas reactive oxygen intermediates (like superoxide and hydrogen-peroxide) are thought to be the effector molecules for antibacterial function. This seems to be true for the killing of a variety of bacteria, protozoa and helminthes, if chemokines, cytokines and bacterial products are used to activate macrophages [142]. However, activation of human macrophages with surfactant protein A resulted in NO production and killing of Klebsiella by human macrophages [144]. Interestingly enough, NO secretion by human 
macrophages is enhanced when alveolar macrophages are obtained from patients with lung injury, chronic lung inflammation [142] or patients with tuberculosis [177-179]. In the latter case, killing of mycobacteria in vitro by these macrophages was inhibited by NO inhibitors, thus indicating an antimicrobial role for NO, possibly also in humans during mycobacterial infection [180]. Currently, the mouse is an often-used animal model for the study of tuberculosis, and whether the differences in the antibacterial properties of human and mouse macrophages are relevant to study outcomes in the mouse has not been determined. Recently, it has been shown that cotton rats are an excellent model for infection studies with Mycobacterium tuberculosis [123]. As cotton rat macrophages display a NO secretion pattern similar to humans it would be of interest to study the role of NO in M. tuberculosis immunity in these animals. 


\section{Chapter 3}

\section{Cytokine Imbalance After Measles Virus Infection But No correlation with immune suppression}

\subsection{Abstract}

Measles virus infection leads to immune suppression. A potential mechanism is the reduction of IL12 secretion during acute measles resulting in a TH2 response. Studies in humans have reported conflicting results in detecting either a TH2 or a TH1 response. We have investigated the correlation between a $\mathrm{TH} 2$ response and immune suppression in specific pathogen free inbred cotton rats which were infected with measles vaccine and wildtype virus. After infection of bone marrow-derived macrophages with wildtype virus, IL12 secretion was reduced in contrast to infection with a vaccine virus. In bronchoalveolar lavage cells, IL12 secretion was suppressed after infection with both wildtype and vaccine virus on day 2, 4 and 6 , and detectable on day 8 and 10. After stimulation of mediastinal lymph node and spleen cells with UV-inactivated measles virus at various time points after infection, interferon $\gamma$ but no IL4 was found. After stimulation with PMA/ionomycin, high interferon $\gamma$ and low IL4 levels were detected. To investigate whether the secretion of IL4 contributes to immune suppression, a recombinant vaccine virus was created which secretes cotton rat IL4. After infection with 
this recombinant virus IL4 secretion was enhanced. However, neither inhibition of Concanavalin A stimulated nor KLH-specific proliferation of spleen cells was altered after infection with the recombinant virus in comparison to the parental virus. Our data indicate that measles virus infection leads to a decrease in IL12 secretion and an increase in IL4 secretion but this does not seem to correlate with immune suppression.

\subsection{Introduction}

Acute measles is caused by infection with measles virus and associated with high morbidity and mortality. The main reason for these is thought to be immune suppression due to measles virus infection. Studies addressing the mechanism of immune suppression have found evidence for a number of possible mechanisms. These include unidentified soluble mediators [43], [181], [182], interference with the type I interferon system (for review [183]), apoptosis [45], impaired lymphoproliferation [184], [60], [185], interleukin 12 downregulation [62], [54] and impaired dendritic cell (DC) function [186]. Some of the mechanisms may operate in conjunction with each other; e.g. it is possible that the downregulation of IL12 might lead to the development of a T helper 2 response that results in impaired lymphoproliferation. The evidence for this line of argument is that human macrophages after stimulation through toll like receptor 4 (TLR-4) secrete less IL12 when infected with measles virus [62]. In measles virus infected humans the percentage of IL12 expressing macrophages is reduced [54] and in Rhesus macaques lower serum levels of IL12 have been found during measles virus infection [63]. In macaques, this correlates with an increase of eosinophils in peripheral blood indicative of increased secretion of IL5 [63]. 
In serum or supernatants of peripheral blood lymphocytes stimulated with PMA/ionomycin from patients with acute measles an up-regulation of IFN $\gamma$ and IL2 [75] (or IL2-R [76]) was found before and during the rash, whereas after the rash a reduction in IL2 and an increase in IL4 [75] or IL10 [63] levels were observed. In contrast, other studies found normal levels of IFN $\gamma$ and IL2 secreted by stimulated PBLs [77] and increased levels of IFN $\gamma$ after the rash secreted by PMA/ionomycin stimulated CD8 T cells [63].

Results from the analysis of cytokines secreted by lymphocytes from measles virus vaccinees were also conflicting. In one study, an up-regulation of IL4 and downregulation of IFN $\gamma$ was found in the supernatant of PHA stimulated cells [32]. In another study, increased IL12 and IFN $\gamma$ were detected after stimulation with MV antigen [78]. In a third study, no differences in expression of IL4, IL5 or IL12 were found between vaccinated and unvaccinated individuals by ex vivo hybridization for cytokine mRNA in PBLs [79]. However, when PBLs from vaccinees were stimulated with MV and analyzed on a per cell basis by limiting dilution, it was found that nearly all $\mathrm{T}$ cells expressed IFN $\gamma$, either alone or in combination with IL4 [84]. In a similar cohort of vaccinees it could demonstrated by a IL4-receptor blocking ELISA that PBLs from about half of the individuals secreted IL4 ([83]; (IFN $\gamma$ secretion was not addressed). This might be explained by a recent report suggesting that the secretion of IFN $\gamma$ and IL4 after MV stimulation is linked to the haplotye of human MHC class I molecules (HLA) [187].

Based on these data no clear correlation can be drawn between reduced levels of IL12, the secretion of TH2 type cytokines and the inhibition of lymphocyte proliferation. Furthermore, at least three variables seem to confound the analysis: 1 . the use of samples 
from patients with acute measles (wildtype virus) versus vaccinees (vaccine virus), 2. the method of stimulation of cells and cytokine detection and 3. the individual genetic makeup of the study participants.

In this report, we have used inbred cotton rats to compare the ability of wildtype and vaccine measles virus to inhibit IL12 secretion and have compared the secretion of T helper 1 and 2 cytokines after stimulation with MV antigen versus PMA/ionomycin. In addition, we tested a recombinant MV expressing cotton rat IL4 for its ability to suppress the immune system.

\subsection{Materials and Methods}

\section{Animals}

Inbred cotton rats and $\mathrm{C} 3 \mathrm{H}$ mice were obtained from Harlan, Indianapolis, USA. Female animals from six to ten weeks of age were used. The animals were purchased specific pathogen free according to the breeder's specification and were maintained in a barrier system. Animals were kept under controlled environmental conditions of $22 \pm 1^{\circ} \mathrm{C}$ and a twelve-hour light cycle. All animals were euthanized by $\mathrm{CO}_{2}$ inhalation.

\section{Infection and virus titration}

For intranasal (i.n.) infection MV was given in PBS to isofluorane anesthetized cotton rats. I.n. inoculations of virus were administered in a volume of not more than $100 \mu 1$. Animals were asphyxiated using $\mathrm{CO}_{2}$ and lungs were removed and weighed. Lung tissue was minced with scissors and dounced with a glass homogenizer. Serial tenfold dilutions of virus containing supernatant were assessed for the presence and levels of 
infectious virus in a 48-well microassay using Vero cells with cytopathic effect (cpe) as an end point. Plates were scored microscopically for cpe after 7 days. The amount of virus in inocula was expressed as the quantity of virus that could infect $50 \%$ of inoculated tissue culture monolayers (TCID50). TCID50 was calculated according to methods described by Reed and Muench [188].

\section{Bronchoalveolar lavage}

The trachea was aseptically isolated and a canula was sutured in place in a $\mathrm{CO}_{2}$ asphyxiated cotton rat. The lungs were lavaged with ten milliliters of $37^{\circ} \mathrm{C}$ PBS with $0.1 \%$ EDTA $(\mathrm{w} / \mathrm{v})$ and $10 \%$ FCS (v/v) at $\mathrm{pH}$ 5.6. Lavage fluid was transferred to a siliconized tube and cells were isolated by centrifugation. Lung lavage cells were stained with Wright Giemsa and counted.

\section{Bone marrow-derived macrophages}

Bone marrow was flushed aseptically from the femoral diaphyseal marrow cavity of female cotton rats and cells were isolated after centrifugation. Bone marrow cells were then cultured in perfluoroalkoxy polymer resin dishes $(10 \mathrm{~cm}$ diameter) for seven days in the presence of $100 \mathrm{ng} / \mathrm{mL}$ recombinant mouse M-CSF (R\&D Systems) in RPMI 1640 supplemented with $10 \%$ FCS, $1 \%$ non essential amino acids, $1 \%$ sodium pyruvate, 2 $\mathrm{mmol} / \mathrm{L}$ glutamine, $50 \mathrm{I} . \mathrm{U}$. penicillin, $50 \mathrm{mg}$ streptomycin/L and $5 \times 10^{-5} \mathrm{M} \beta-$ mercaptoethanol. After seven days in culture macrophages were infected at a multiplicity of infection of one with either wildtype or vaccine MV for 24 hours before analysis. 


\section{Cell lines and viruses}

Vero cells (African green monkey) and Vero-huCD150 (transfected with human CD150; [168]) were grown in minimal essential medium (MEM) with $10 \%$ fetal calf serum (FCS) and BJAB cells were grown in RPMI 1640 containing 10\% FCS, 1\% non essential amino acids, $1 \%$ sodium pyruvate, $2 \mathrm{mmol} / \mathrm{L}$ glutamine, 50 I.U. penicillin and $50 \mu \mathrm{g}$ streptomycin/mL (referred to as RPMI/10). Measles virus strains MV Edmonston B vaccine/60s (Edm) and MV Erlangen.DEU/90 (WTFb), Edm and recombinant viruses based on the molecular clone Ed-NSE [12] were grown and titered on Vero cells [118]. WTFb was grown on BJAB cells and titered on Vero-huCD150 cells.

The cotton rat IL4 gene (accession no. AF421390) was inserted in forward and reverse (IL4r) orientation between the MV H and L genes in the MluI and SpeI sites of $\mathrm{p}(+)$ MV-NSE [12]. For the recombinant virus rescue, Hep-2 cells were co-transfected with 5ug of MV genome plasmids $\mathrm{p}(+)$ MV-NSE-IL4 or $\mathrm{p}(+)$ MV-NSE-IL4r, and 1.5ug pT7-MV-N, 1.5ug pT7-MV-P and 0.5ug pT7-MV-L [8]. To express T7 polymerase, Hep2 cells were additionally infected (MOI 2) with a modified vaccinia virus Ankara (MVAGKT7) [189]. After 72 hours these transfected Hep-2 were co-cultured with Vero cells and recombinant virus was purified from plaques. Insert integrity was verified by sequence analysis of rescued clones. Kinetic growth curves and IL4 cytokine ELISA (R\&D Systems) of tissue culture supernatant were performed for each recombinant virus. The molecular clone Ed-NSE has been shown to differ in vitro from its parent Edm B in its failure to inactivate the type I interferon system [190]. 


\section{In vitro assays for IL4 detection}

To test IL4 induced proliferation of B cells, $5 \times 10^{5}$ spleen cells/well were plated in triplicate in a 96-well-plate in RPMI 1640 with $2 \%$ cotton rat serum in the presence of $10 \mu \mathrm{g} / \mathrm{mL}$ LPS and increasing dilutions of tissue culture supernatant from NSE-IL4 or NSE-IL4r infected Vero cells. After 48 hours $0.5 \mu \mathrm{Ci} 3 \mathrm{H}$-thymidine/well was added and 24 hours later cells were harvested onto glass filters and counted with a Betaplate Counter (Wallac, Turku, Finnland). The stimulation index (SI) was calculated as the mean of proliferation of IL4 stimulated cells in counts per minute (cpm)/ proliferation of cells in medium (cpm). To test for the induction of MHC II expression on B cells, spleen cells were incubated with tissue culture supernatant from NSE-IL4 or NSE-IL4r infected Vero cells for 24 hours. A donkey-anti mouse IgG FITC labeled cross-reactive antiserum was used to detect B cells and a mouse monoclonal against MHC II (clone 13/4) [127] was used to measure MHC II expression. The donkey anti-mouse serum labeled with FITC was pre-absorbed with cotton rat serum before being used as secondary antibody specific for 13/4. Cells were analyzed by flow cytometry (Facscan, Becton Dickinson). IgG positive cells were gated and MHC II was evaluated.

\section{Reverse transcriptase polymerase chain reaction}

Bone marrow-derived macrophages were infected with WTFb and Ed-NSE (MOI 1) for 24 hours. Total cellular RNA was isolated using the Qiagen RNeasy kit (Qiagen), DNase treated with Turbo DNA-free (Ambion) and RNA concentration was calculated using 260/280nm light absorbance ratio (ND-1000 Spectrophotometer, Nano Drop Technologies). To ensure RNA sample integrity, each sample was probed for the 
housekeeping gene $\beta$-actin. All reactions were also performed without reverse transcriptase to verify the absence of genomic DNA contamination. Standard RT-PCR was performed using M-MLV reverse transcriptase (Invitrogen). IL-4 and IL-10 were amplified by standard RT-PCR [162]. Samples were analyzed by $2.0 \%$ agarose gel electrophoresis and stained with ethidium bromide.

Real time RT-PCR was performed using the LightCycler RNA Amplification Kit SYBR Green I (Roche) for IL12p35, IL18 and $\beta$-actin [191] and measles virus nucleoprotein [192]; see Table 1 for primer sequences.

\begin{tabular}{|l|l|l|l|}
\hline Gene & Sense primer & Anti-sense primer & $\begin{array}{l}\text { Amplicon, } \\
\text { bp }\end{array}$ \\
\hline IL12p35 & $\begin{array}{l}\text { GGACCATAATCGGAAGC } \\
\text { AGA }\end{array}$ & $\begin{array}{l}\text { TGGAGGAGAATGCAGAG } \\
\text { CTT }\end{array}$ & 162 \\
\hline IL18 & $\begin{array}{l}\text { CACCAGAAGAAGGCTCT } \\
\text { TGC }\end{array}$ & $\begin{array}{l}\text { CTGGTCTGGGCTTCATTA } \\
\text { GC }\end{array}$ & 235 \\
\hline$\beta$ actin & $\begin{array}{l}\text { CACCAGAAGAAGGCTCT } \\
\text { TGC }\end{array}$ & $\begin{array}{l}\text { CTGGTCTGGGCTTCATTA } \\
\text { GC }\end{array}$ & 246 \\
\hline MV-N & $\begin{array}{l}\text { AAACTATGTATCCTGCTC } \\
\text { TTG }\end{array}$ & $\begin{array}{l}\text { CTCCCATGGAGTTTTCAA } \\
\text { GT }\end{array}$ & 212 \\
\hline
\end{tabular}

Table 3.1 Sequences of primers for real time RT-PCR.

Total SYBR Green fluorescence was measured at conditions that preserve specific gene product amplicons but not nonspecific amplification products. Data were analyzed using LightCycler Software Version 3. Quantification was based upon fit point analysis with arithmetic baseline adjustment. Melting peak and melting curve analyses were performed 
using the polynomial calculation method. RT-PCR standards were generated by in vitro transcription. Template for these transcription reactions were expression plasmids containing the complete mRNA sequence: IL12p35-pPCR Script Amp, IL18 pSport1, and $\beta$-actin pSport1. Plasmid was linearized to introduce a consistent transcription stop site with KpnI for IL12p35 and NotI for IL18 and $\beta$-actin. IL12p35 transcription was driven by T3 in the pPCR-Script Amp plasmid. IL18 and $\beta$-actin transcription was driven by $\mathrm{T} 7$ in the pSPORT Amp plasmid. The transcripts were treated with DNA Free (Ambion) to remove the template plasmid. Nucaway columns (Ambion) were used to remove free nucleotides. RNA transcripts were quantified by optical density. Serial dilutions of the RNA transcripts were made for use as standards for the real time RTPCR; samples were also analyzed by agarose gel electrophoresis (2.0\%) and stained with ethidium bromide.

\section{Cytokine ELISA}

ELISA detection of cotton rat IL4 and IFN $\gamma$ was performed following the vendor's protocol (R\&D Systems). Briefly, Maxisorb (NUNC) ELISA plates were coated with capture antibody in $100 \%$ PBS overnight at room temperature. Plates were washed between each subsequent step with $0.05 \%$ Tween-20. Plates were blocked with $1 \%$ BSA and sequentially incubated for two hours at room temperature with samples/standards and detection antibody diluted in 1\% BSA. The plate was developed using streptavidin-HRP and substrate solution (R\&D Systems). Color development was stopped by addition of $2 \mathrm{~N} \mathrm{H}_{2} \mathrm{SO}_{4}$. The optical density of each well was immediately determined, using a Tecan microplate reader set to $450 \mathrm{~nm}$ with subtraction of 
wavelength correction at $570 \mathrm{~nm}$. Linear regression analysis was used to determine the concentration of unknown samples.

\section{Antibody ELISA}

For the detection of MV-specific antibodies, $10 \mu \mathrm{g} / \mathrm{mL}$ gradient purified, UVinactivated MV was coated in $200 \mathrm{mM} \mathrm{NaCO} 3$ buffer ( $\mathrm{pH} 9.6$ ) at $4{ }^{\circ} \mathrm{C}$ overnight, blocked with PBS $/ 10 \% \mathrm{FCS} / 0.05 \%$ Tween 20 and incubated with dilutions of cotton rat serum at $4^{\circ} \mathrm{C}$ for 1 hour. After washing, the plate was incubated with rabbit serum specific for cotton rat IgG (Virion Systems, Rockville, USA) for 1 hour at room temperature. After washing, the plate was incubated with horseradish-peroxidase coupled goat serum specific for rabbit IgG (Zymed, San Francisco,USA) for 45 minutes at room temperature and developed with $0.5 \mathrm{mg} / \mathrm{ml}$ ortho-phenyl-diamine in buffer (35 mM citrate, $\mathrm{Na}_{2} \mathrm{HPO}_{4}$ 66mM, pH:5.2) and $0.01 \% \mathrm{H}_{2} \mathrm{O}_{2}$.

\section{Neutralization assay (NT)}

To assay for neutralizing antibodies twofold serum dilutions were incubated with $50 \mathrm{pfu}$ Edmonston B strain for 1 hour at $37^{\circ} \mathrm{C}$ and plated in duplicate onto $10^{4}$ Vero cells/ well (96 well plate). 5 days later titers were determined microscopically.

\section{Proliferation assay}

For proliferation assays $50 \mu \mathrm{L} /$ well $(10 \mu \mathrm{g} / \mathrm{mL})$ of gradient purified, UVinactivated MV or keyhole limpet hemocyanin was coated in $200 \mathrm{mM} \mathrm{NaCO} 3$ buffer $(\mathrm{pH}$ 9.6) at $4^{\circ} \mathrm{C}$ overnight in 96 -well-plates. After washing twice with PBS, $5 \times 10^{5}$ cells/well 
spleen or lymph node cells were plated in triplicate in a 96-well-plate in RPMI 1640 with $2 \%$ cotton rat serum in the presence or absence of antigen (medium control). After 40 hours $0.5 \mu \mathrm{Ci} 3 \mathrm{H}$-thymidine/well was added and 16 to 20 hours later cells were harvested onto glass filters and counted with a Betaplate Counter (Wallac, Turku, Finnland). The stimulation index (SI) was calculated as the mean of proliferation of measles virus antigen stimulated cells in counts per minute $(\mathrm{cpm}) /$ proliferation of cells in medium (cpm). To control for the specificity of the assay, spleen cells from infected animals were tested against Vero cell antigen and naive animals against MV. In controls, proliferation did not exceed a stimulation index of 2 indicating the threshold of the assay. Gradient purified, UV-inactivated MV was derived from Vero cells infected with the vaccine strain Edmonston B. This virus has the same sequence in the four epitopes defined for CD4 T cells in cotton rats [127] as Ed-NSE. Based on published sequences and (where not available) our own sequencing all epitopes in WTFb were identical to Ed-NSE except amino acid 564 in the $\mathrm{H}$ protein where an isoleucine was replaced by a valine.

\section{Statistical analysis}

Analysis of variance (ANOVA) was performed using the GraphPad Instat version 3 software. 


\subsection{Results}

\section{Measles virus infection inhibits interleukin 12 secretion by macrophages in vitro and}

in vivo

In order to test the effect of measles virus infection on IL12 secretion by cotton rat macrophages, bone marrow-derived macrophages were infected with either vaccine strain (Ed-NSE) or wildtype virus (WTFb) at a multiplicity of infection of 1 . Without stimulus, IL12 mRNA was not detectable in cotton rat macrophages. After stimulation with IFN $\gamma$ and LPS, uninfected macrophages secreted IL12 as did macrophages infected with Ed-NSE (Figure 3.1a). In contrast, macrophages infected with WTFb did not secrete IL12. It is of interest to note that the copy number of $\mathrm{N}$ mRNA was hundred-fold increased in wildtype (about $10^{7}$ copies per 250ng RNA) versus vaccine virus (about $10^{6}$ copies per 250 ng RNA) infected macrophages. In contrast to IL12, levels of mRNA for IL18 were not affected by either treatment or infection. In order to test the effect of measles virus infection on IL12 secretion in vivo, cotton rats were infected with either vaccine strain (Ed-NSE) or wildtype virus (WTFb). On day 2, 4, 6, 8 and 10 bronchoalveolar lavage (BAL) was performed. The percentage of macrophages in BAL was determined to be $40 \%$ by a differential count of a Wright Giemsa stained cytospin preparation of lavage fluid. After co-cultivation of BAL cells with indicator cells virus was readily obtained (data not shown). On day 2, 4 and 6 after infection no IL12 mRNA was detectable by real time RT-PCR; on day 8 and 10 IL12 mRNA was detectable in both vaccine and wildtype virus-infected animals (Figure 3.1b). Viral RNA (for the nucleocapsid protein) was detectable from day 2 to 8 but not on day 10 (data not shown), consistent with viral titers obtained from lung tissue previously [185], [118]. IL18 mRNA 
was low in both groups from day 2 to 10 (data not shown). At the virus doses used for inoculation, suppression of Concanavalin A-stimulated proliferation of spleen cells in cotton rats is most severe between day 2 and 6 for wildtype infection but no inhibition is seen after vaccine virus infection [118]. The difference in suppression of IL12 production seen between vaccine and wildtype virus in vitro could not be reproduced in vivo. Although the time-frame for the lack of IL12 secretion correlates with proliferation inhibition for wildtype virus infection, a similar effect is seen after infection with the non-suppressive vaccine virus.

\section{Comparison of $T$ helper responses after wildtype and vaccine virus infection}

To determine whether the lack of IL12 production has biological consequences, the type of $\mathrm{T}$ helper response after wildtype and vaccine virus infection was determined by assessing the antibody response, and proliferation and cytokine secretion by CD4 T cells. It was shown previously that infection with WTFb leads to higher titers in lung tissue and mediastinal lymph nodes than infection with Edmonston B (Edm) [118]. Within the first two weeks after infection with WTFb antibody titers (measured by ELISA and neutralization assay) rose faster than after infection with Edm (Figure 3.2a and b). However, four weeks after infection antibody titers were indistinguishable between wildtype and vaccine virus infected animals. MV-specific T-cell proliferation was higher in WTFb infected than in Edm infected animals but this difference was not statistically significant (Figure 3.2c). In MDLN, however, a T-cell response was detectable on day four after infection with WTFb (stimulation index of 2.6 \pm 1.2 ) but not in Edm infected animals (data not shown). In summary, these data indicate that both wildtype and vaccine 


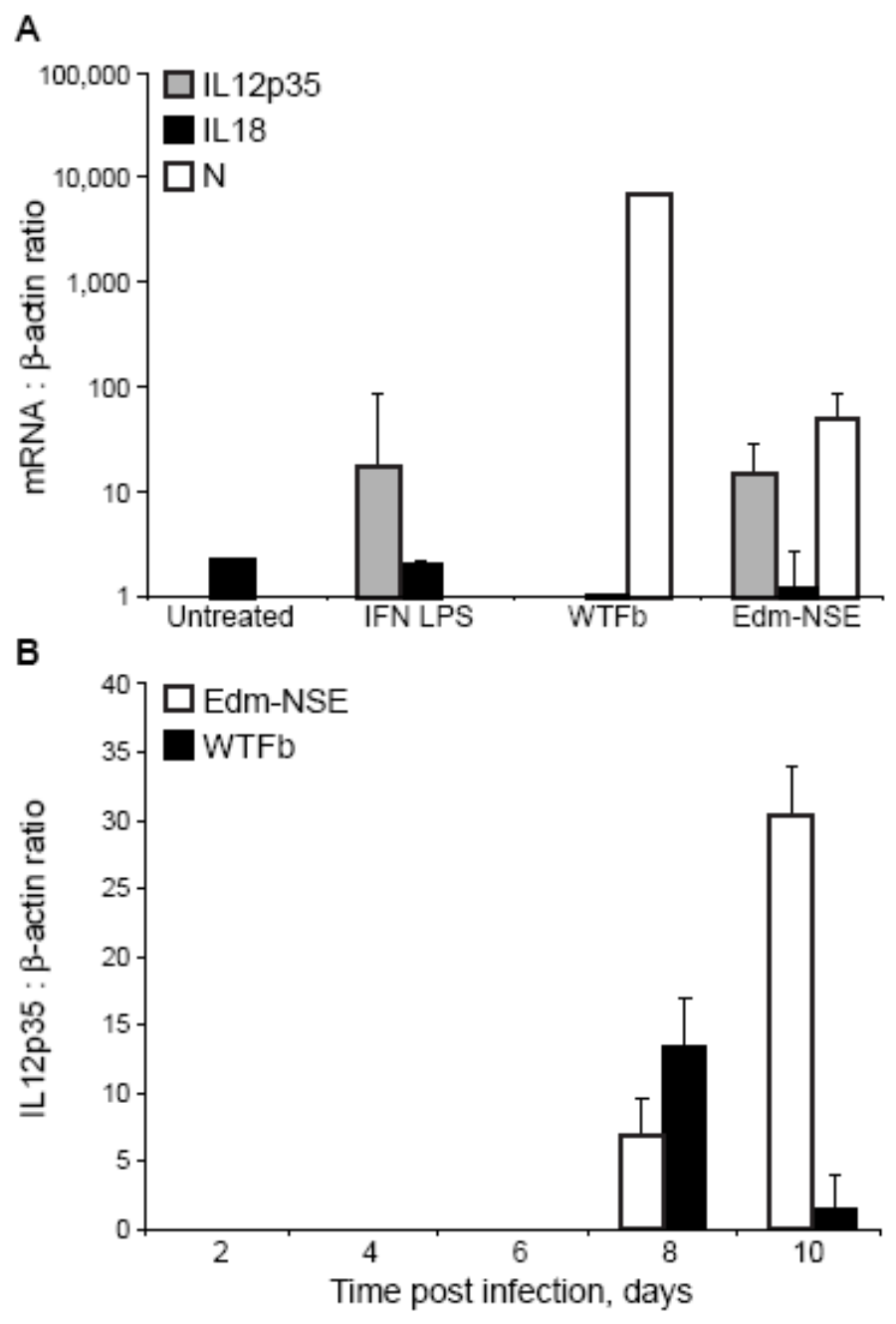

Figure 3.1 Inhibition of IL12 secretion by measles virus infected macrophages in vitro and in vivo. Bone marrow-derived macrophages (A) were stimulated with IFN $\gamma$ for 48 hours and subsequently with LPS for 24 hours. Macrophages were then infected with WTFb or Ed-NSE strain of MV at an MOI 1 and RNA harvested at 24 hours postinfection. Cotton rats were infected intranasally with either the Ed-NSE or WTFb strain MV (B). Pulmonary macrophages were harvested by bronchoalveolar lavage (BAL) at the time points indicated and total RNA was isolated. Data represent the mean ratio of cytokine specific mRNA expression over $\beta$-actin mRNA expression \pm standard deviation. Viral titers obtained from lung homogenates on day 2, 4 and 6 were comparable with published data [118] with peak titers for Edmonston B at $10^{3} \mathrm{TCID}_{50} / \mathrm{g}$ lung tissue and for $\mathrm{WTFb}$ at $10^{4} \mathrm{TCID}_{50} / \mathrm{g}$ lung tissue. On day 8 no infectious virus but similar levels of $\mathrm{N}$ mRNA was detectable by PCR in both groups. On day 10 neither virus nor N mRNA was detectable. Data represent the mean ratio of IL12p35 mRNA expression over $\beta$-actin mRNA expression \pm standard deviation ( 5 animals/group). 
virus induce MV specific B-cell and T-cell responses but activation of the B-cell response is faster after wildtype virus infection.

To determine the type of $\mathrm{T}$ helper response induced by measles virus infection, spleen and MDLN cells were stimulated with UV-inactivated MV antigen or PMA/ionomycin and the supernatant was tested for IFN $\gamma$ and IL4 by ELISA. In addition, eosinophil numbers (as a marker of IL5) in blood were determined over the course of infection. After stimulation of spleen or lymph node cells with MV antigen, only IFN $\gamma$ was detected (Figure 3.3a). In the supernatants of spleen cells from MV-infected animals, levels of IFN $\gamma$ were two to ten-fold higher in WTFb infected animals ( 5 to $15 \mathrm{ng} / \mathrm{mL}$ ) in comparison to animals infected with Edm ( 2 to $5 \mathrm{ng} / \mathrm{mL}$ ) after stimulation with UVinactivated MV antigen. In contrast, no IL4 secretion was detected. After stimulation with PMA/ionomycin, both IFN $\gamma$ and IL4 were detectable in supernatants of naive animals $(30 \pm 6 \mathrm{ng} / \mathrm{mL}$ IFN $\gamma$ and $24 \pm 5 \mathrm{pg} / \mathrm{mL}$ IL4). However, levels of both cytokines were higher in supernatants of spleen cells from MV-infected cotton rats. In the supernatants of spleen cells from animals infected with wildtype virus, both levels of IFN $\gamma$ and IL4 were higher $(71.5 \pm 6.2 \mathrm{ng} / \mathrm{mL}$ IFN $\gamma$ and $142 \pm 43 \mathrm{pg} / \mathrm{mL}$ IL4) than in supernatants of spleen cells from vaccine virus infected animals $(21 \pm 1.9 \mathrm{ng} / \mathrm{mL}$ IFN $\gamma$ and $85 \pm 11 \mathrm{pg} / \mathrm{mL}$ IL4) (Figure 3.3b and c).

To verify and extend these findings, RT-PCR for IFN $\gamma$, IL4 and IL10 was performed on spleen cells four days after stimulation with $\mathrm{MV}$ antigen or PMA/ionomycin. Expression of IFN $\gamma$ and IL4 followed the same pattern as found by ELISA, and no expression of IL10 was detected (data not shown). 
Figure 3.2 Immune response of cotton rats after infection with either wildtype or vaccine measles virus. Groups of cotton rats (4 animals/group) were infected intranasally with $10^{5}$ pfu of Edmonston B or WTFb strain. Serum and spleens were obtained on day 4, week 1, 2 and 4. With sera an ELISA (A) and a neutralization assay (B) were performed. The threshold for detection was determined by comparison with sera from naïve animals and is indicated as a dashed line for the ELISA and is NT $<10$ for the neutralization assay. Measles virus specific $\mathrm{T}$-cell proliferation (C) was measured using $\mathrm{H}_{3}$-thymidine incorporation. The threshold for this assay is a stimulation index of 2 . 

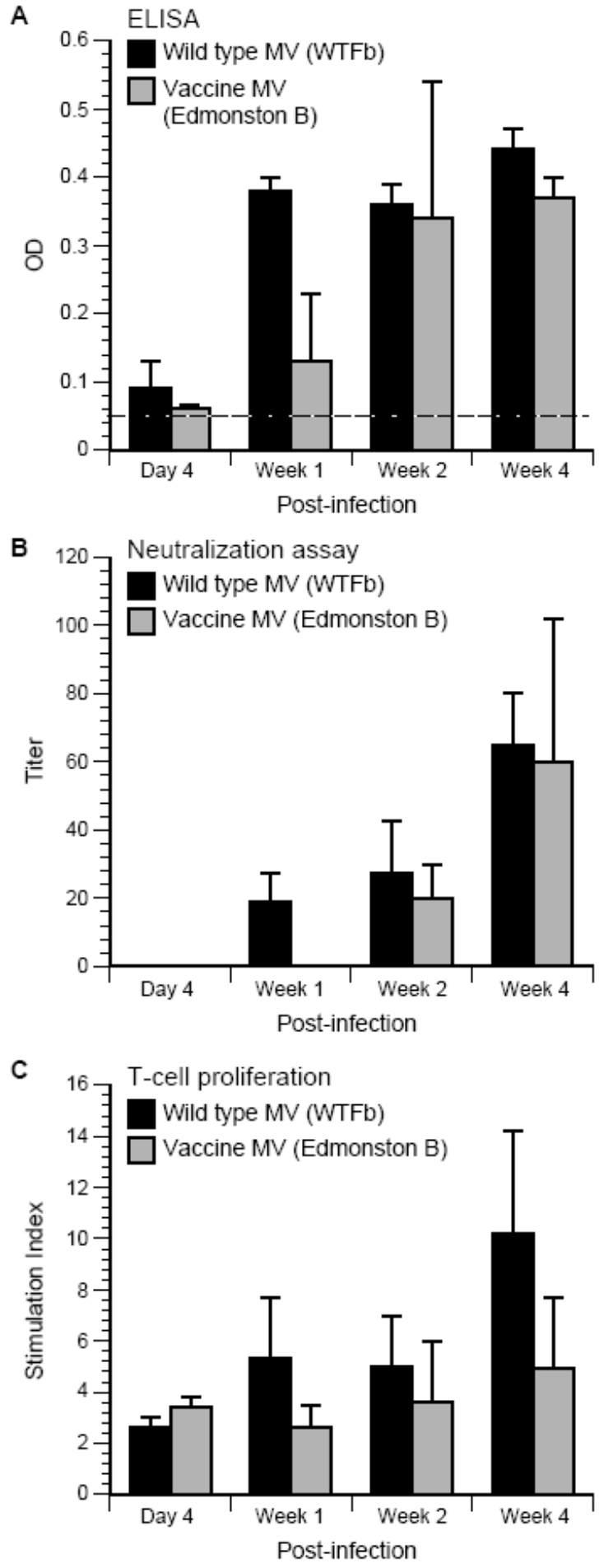
Figure 3.3 Interferon $\gamma$ and IL4 secretion by splenocytes from measles virus infected cotton rats. Groups of cotton rats (4 animals/group) were infected intranasally with $10^{5}$ pfu of Edmonston B or WTFb strain. Spleens were obtained on day 4, week 1, 2 and 4. After stimulation with UV-inactivated measles virus antigen, splenocytes secreted IFN $\gamma$ (A) but no IL-4. After stimulation with PMA/ionomycin splenocytes secreted both IFN $\gamma$ (B) and IL-4 (C). The dashed line in B and C indicates the level of cytokine secretion by splenocytes from naïve animals. 
A UV-MV

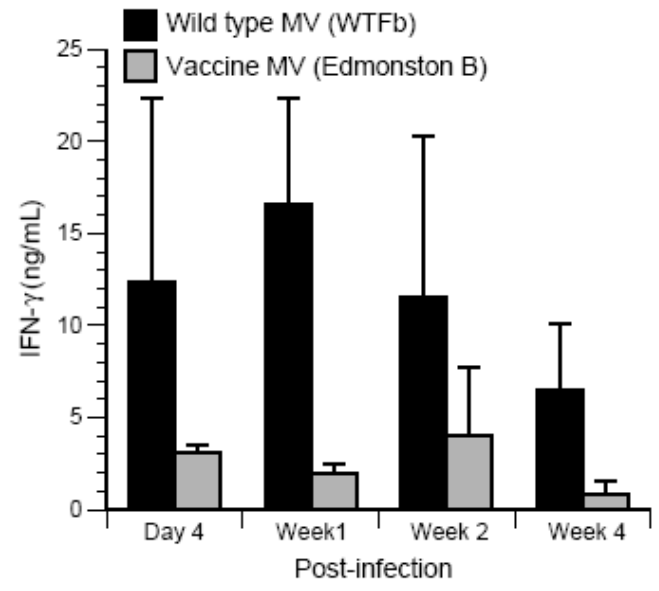

B
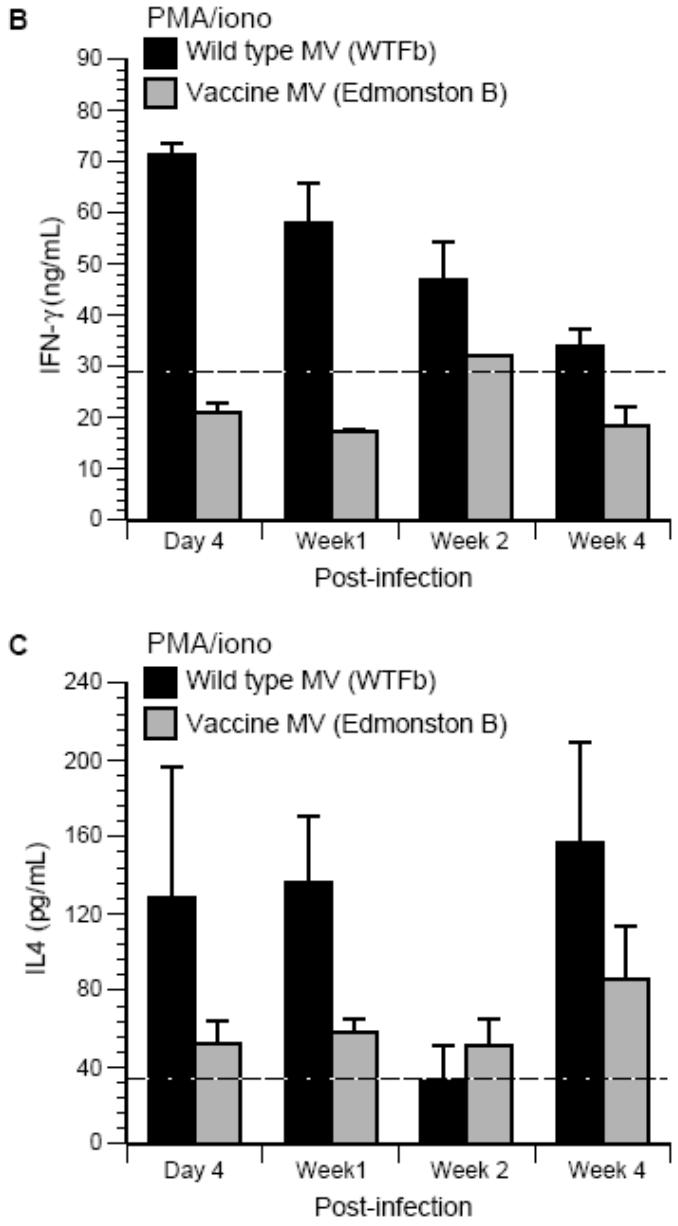
In MDLN, IFN $\gamma$ secretion was detected on day 4 and 8 in wildtype virus infected animals and on day 4 in vaccine virus infected animals. Stimulation of MDLN cells with PMA/ionomycin did not result in cytokine secretion from naive animals but in secretion of IFN $\gamma$ and IL4 for both wildtype and vaccine virus infected animals (data not shown).

After infection, the percentage of eosinophils was determined by differential count of blood smears as a marker of IL5 secretion. The percentage was between 5 and $10 \%$ and did not vary over four weeks or between animals infected with the two different viruses and control animals.

In summary, these data indicate that immune activation is stronger after wildtype virus infection but that the generation of a MV-specific T helper type 1 response occurs after infection with both wildtype and vaccine virus. However, MV infection leads to enhanced IL4 secretion after antigen-independent stimulation with PMA/ionomycin.

\section{No immune suppression through recombinant measles virus expressing IL4}

If IL4 expression and therefore the induction of a $\mathrm{TH} 2$ response plays a critical role in inhibition of lymphocyte proliferation, then expression of IL4 by the molecularly cloned measles vaccine virus Ed-NSE should increase its immunosuppressive potential. To test this hypothesis a recombinant measles virus was produced which carried the cotton rat IL4 gene before the polymerase gene (NSE-IL4) similar to a previously generated virus expressing human IL12 [12]. A virus containing the IL4 gene in reverse orientation (IL4r) served as control virus (NSE-IL4r). In tissue culture there was no difference in either cell associated virus (not shown) or virus progeny release into the supernatant between the parental Ed-NSE virus, NSE-IL4 or NSE-IL4r (Figure 3.4a). 
Only supernatants from Vero cells infected with NSE-IL4 contained IL4 measurable by ELISA (Figure 3.4b). These supernatants also induced MHC II expression (2 fold increase in mean fluorescence intensity) and growth of spleen B cells (up to 15-fold stimulation; data not shown); these values are comparable with data obtained for mouse IL4 [193], [194].

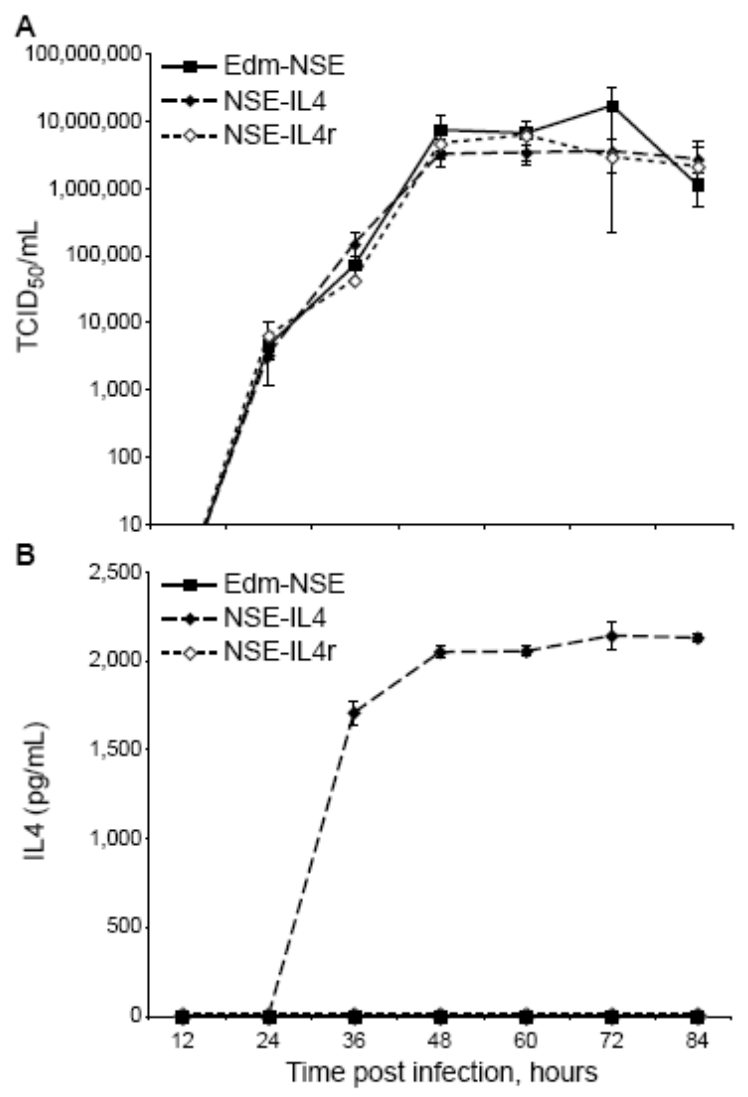

Figure 3.4 Growth and production of IL-4 by recombinant measles virus. Vero cells were infected with Ed-NSE ( $\bullet$ ), NSE-IL4 $(\bullet)$ and NSE-IL4r $(\diamond)$ at an MOI of 0.02 for the time points indicated. Progeny release is expressed as $\mathrm{TCID}_{50} / \mathrm{mL}$ tissue culture supernatant (upper panel). Production of cotton rat IL4 was assayed by ELISA of tissue culture supernatant (lower panel). Data represent mean of duplicates $+/$ - standard deviation and are representative of two independent trials. 
Figure 3.5 Changes of pulmonary infiltrates after lung infection with measles virus expressing IL-4. Four days after intranasal infection with NSE-IL-4 or NSE-IL-4r lung lavage cells were analyzed for the total number of leukocytes/ $\mu$ l and the percentage of mononuclear cells and eosinophils. Data represent mean \pm standard deviation from five animals. ${ }^{*} p<0.001$, the differences between animals infected with either virus were statistically significant $(* * \mathrm{p}<0.0001)$. 

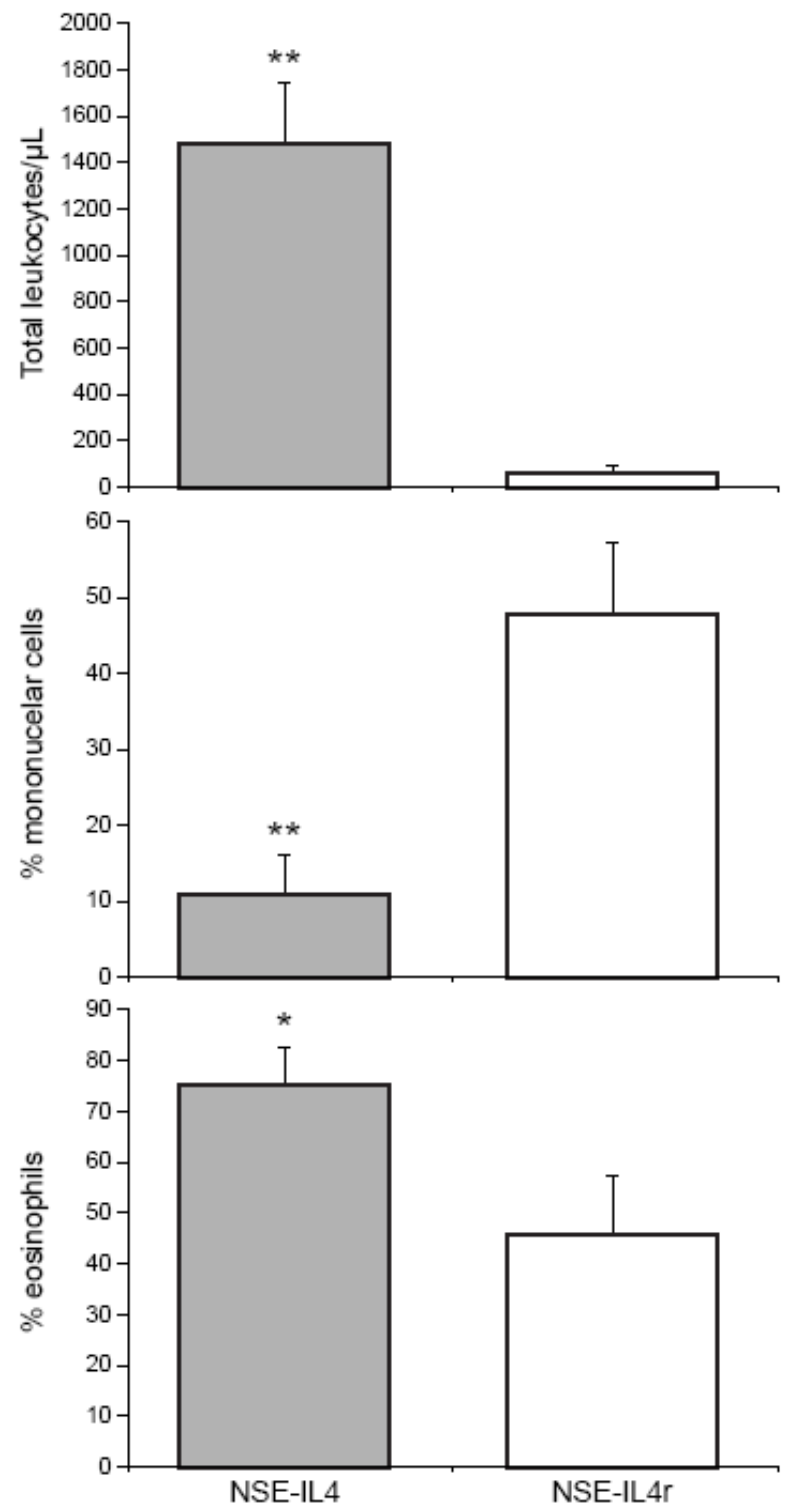
In lung tissue of cotton rats NSE-IL4 and NSE-IL4r grew to comparable titers after inoculation of either $5 \times 10^{5}$ or $10^{6}$ pfu. However, the composition of bronchial alveolar lavage cells was different between the two groups. Animals infected with NSEIL4 displayed a higher influx of leukocytes into the lungs with a higher proportion of eosinophils and reduced proportion of macrophages (Figure 3.5).

To test the MV-specific immune responses after infection with either NSE-IL4 or NSE-IL4r, spleen cells were harvested 28 days after infection and tested for MV-specific proliferation and cytokine secretion. Similar to previous results, stimulation with PMA/ionomycin of spleen cells from animals infected with either NSE-IL4 or NSE-IL4r led to secretion of both IL4 and IFN $\gamma$. After stimulation with UV-inactivated MV, spleen cells secreted IFN $\gamma$. but no IL4. We have shown previously that inoculation of $10^{5} \mathrm{pfu}$ vaccine virus does not suppress Concanavalin A stimulated proliferation of spleen cells whereas inoculation with $10^{6}$ pfu does [118], [185]. To demonstrate a difference between NSE-IL4 and NSE-IL4r both viruses were used at $5 \times 10^{5}$ pfu and $10^{6}$ pfu per inoculum. After inoculation of $5 \times 10^{5} \mathrm{pfu}$, proliferation of spleen cells after stimulation with Concanavalin A was not inhibited whereas infection with $10^{6}$ pfu suppressed mitogen stimulated proliferation (Figure 3.6). However, no difference was seen between animals infected with NSE-IL4r and NSE-IL4.

To test the immunosuppressive potential of NSE-IL4 against a third party antigen, cotton rats were infected with $10^{6} \mathrm{pfu}$ of virus. On day 4 when immune suppression is most marked animals were immunized with keyhole limpet hemocyanin (KLH). 28 days after infection spleen cells were stimulated with KLH. No differences in KLH specific proliferation was detected between uninfected animals, or animals infected with NSE- 
IL4r or NSE-IL4 (data not shown). In addition, the cytokine profile of KLH-specific T cells from these animals also indicated a TH1 response (no IL4 but IFN $\gamma$ ).

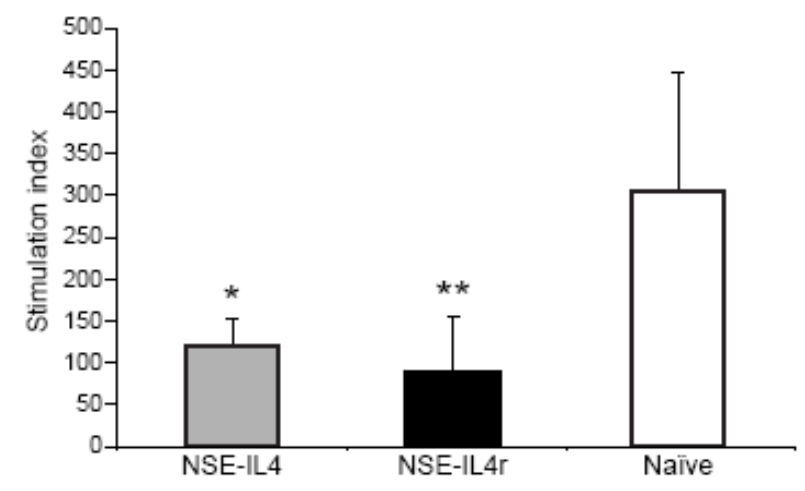

Figure 3.6 No difference in proliferation inhibition between measles virus and measles virus expressing IL-4. Spleen cells were harvested from naïve cotton rats and cotton rats infected with either NSE-IL-4 or NSE-IL-4r at 4 days post infection (5 animals/group) and stimulated with Concanavalin A. Stimulation indices correspond to the ratio of $\mathrm{H}_{3}$-thymidine incorporation for stimulated versus unstimulated splenocytes. The differences between infected and naive animals were statistically significant $\left({ }^{*} \mathrm{p}<\right.$ $0.01, * * \mathrm{p}<0.05)$. 


\section{Discussion}

During studies of measles virus pathogenesis a number of observations have been made which have led to a putative mechanism of measles virus-induced immune suppression. Measles virus infection of macrophages leads to a reduction in IL12 secretion which might induce a $\mathrm{T}$ helper 2 response with proliferation inhibition of $\mathrm{T}$ cells thus contributing to immune suppression. The experimental evidence demonstrates that TLR-4 mediated IL12 induction is inhibited by the measles virus P protein [62], [65], [195]. Interestingly, this inhibition is seen in macrophages but not in epithelial cells. In patients, a reduction in the percentage of IL12 expressing macrophages is also found [54]. However, in rhesus macaques infected with a genetically modified measles vaccine virus which expressed human IL12 no change in proliferation inhibition of peripheral blood lymphocytes induced by the vaccine virus was seen [64]. The current study in cotton rats demonstrated also a strong reduction in the production of IL12 mRNA by alveolar macrophages. The reduction in IL12 production coincided with the time frame of proliferation inhibition of cotton rat spleen cells after measles virus infection. In contrast to tissue culture results, no difference could be detected between vaccine and wildtype virus infection.

Apart from the macrophage, the other main source of IL12 is the dendritic cell (DC). Recently, it has been reported that $\mathrm{C}$ type selectin DC-SIGN is an adhesion receptor for measles virus [18]. In this context it is of interest that after TLR-induced activation of NF- $\mathrm{kb}$, DC-SIGN activates serine and threonine kinase Raf-1 which leads to activation of the NF- $\mathrm{kb}$ subunit $\mathrm{p} 65$. Acetylation of $\mathrm{p} 65$ prolongs and increases IL10 transcription [196] and in monocyte-derived dendritic cells this signal synergizes with 
$\mathrm{TNF} \alpha$ to lead to prolonged IL10 secretion [197] potentially resulting in a TH2 response. In contrast to this mechanistic insight, however, human measles virus infected DCs drive T-cell development towards a TH1 response when infected with vaccine virus in vitro, and a TH1/0 response when infected with wildtype virus [198].

In humans, numerous studies have generated contradictory results as to whether a $\mathrm{T}$ helper 1 or 2 response is generated after either measles virus infection or vaccination. In these studies, expression of cytokines was measured with a variety of methods (ELISA, PCR, in situ hybridization), from different biological samples (serum or peripheral blood lymphocytes) and after different types of stimulation (with PMA/ionomycin or measles virus antigen). For this study, cytokines were measured by ELISA and data subsequently verified by PCR. Cytokine levels in serum samples were below the threshold of detection (data not shown), and therefore cytokines were measured in supernatants of lymphocytes from the lung draining mediastinal lymph nodes and spleen. Lymphocytes were stimulated with either PMA/ionomycin or measles virus antigen. No differences between the methods to measure cytokines and between the two different origins of lymphocytes were found. However, the mode of stimulation of lymphocytes influences their cytokine expression. Stimulation with measles virus antigen resulted in a clear TH1 response independent of whether animals were infected with the vaccine virus or wildtype virus. However, in contrast to humans the level of virus replication might play a role. A recent study reported that IL4 mRNA was detectable in cotton rat lung tissue when these animals were infected with up to $5 \times 10^{7} \mathrm{pfu}$ of measles virus (about 500-fold more virus than used in this study) [199]. These data from the cotton rats correlate with a number of studies performed in humans. 
A potential explanation for conflicting results in human studies might be the presence of co-infections [63]. Although, a recently published report also indicates the importance of the genetic makeup of individuals in directing preferentially a measles virus specific TH1 or 2 response [187]. In addition, the mode of stimulation might be able to influence cytokine composition. Whereas stimulation with MV antigen leads to IFN $\gamma$ secretion, stimulation with PMA/ionomycin only leads to a strong increase in levels of IFN $\gamma$ and IL4 secretion. When mouse IL4 was expressed by ectromelia virus, the secretion of IL4 in the microenvironment of virus infected cells led to a TH2 response [200]. This resulted in increased susceptibility of mice and subsequent death. A similar recombinant measles virus expressing cotton rat IL4 clearly had a biological effect by skewing the percentages of bronchial alveolar lavage cells. However, this virus did not induce a TH2 response against either measles virus or a third party antigen (keyhole limpet hemocyanin). This indicates that $\mathrm{T}$-cell proliferation inhibition during measles virus-induced immune suppression can occur in the absence of a TH2 response.

In this study we chose to measure cytokines as direct parameters of the $\mathrm{T}$ helper response but we also investigated indirect parameters including serum anti-MV antibody isotype and eosinophil infiltration of the lung. In measles patients, IgG antibodies are the main neutralizing and protective antibodies. Specific anti-MV IgG isotype subclasses are similar in naturally infected and vaccinated individuals where IgG1 and IgG4 are the predominant isotypes, though IgG2 and IgG3 are also present [220, 221]. Though less clear in humans, the IgG2a isotype is seen in TH1 responses [222] and TH2 IgG1, IgG2b, IgE are predominant in $\mathrm{TH} 2$ responses in mice [223-225]. Attempts to evaluate antibody isotype in serum from cotton rats infected with NSE IL4 and NSE IL4r using a 
mouse antibody isotyping ELISA kit were unsuccessful. In the cotton rat four immunoglobulins have been identified ( $\operatorname{IgM}, \operatorname{IgG} 1, \operatorname{IgG} 2$, and $\operatorname{IgA}$ ) but their expression has not been correlated to $\mathrm{TH} 1$ and $\mathrm{TH} 2$ responses. Eosinophilia has been used as a marker of a TH2 cytokine environment in humans [226]. We show a significant increase in eosinophils in lungs of cottons rats infected with NSE IL4 which produces cotton rat IL4, suggesting a pulmonary TH2 environment. It is worth noting that naïve cotton rats have elevated numbers of circulating eosinophils, $5.7+/-3.84$ in males and $4.4+/-2.3$ in females (C.B. Spainhour oral communication) and eosinophils in BAL (45.20 +/- 12.83 unpublished data). Human parainfluenza virus 3 and respiratory syncytial virus infection of cotton rats also leads to increased numbers of eosinophils in BAL fluid (unpublished

data). Appropriately, following intranasal infection of cotton rats with S. aureus there is a significant increase in BAL neutrophils and a reduction in eosinophils (unpublished data).

Abnormalities in the production of IL12 and increased ability to produce IL-4 were seen in the cotton rat model thus confirming the notion that measles virus infection disturbs cytokine production. Although this has no direct impact on the development of the $\mathrm{T}$ helper response, cytokine imbalances might play an important role in the pathogenesis of measles virus-induced immune suppression.

\section{Acknowledgements}

M.E.C was supported by NIH Training Grant RR007073 and the NIH Pediatric Loan Repayment Program. 


\section{Chapter 4}

\section{Effect of AKT Kinase Activity on Measles Virus-Infected Macrophage Function}

\subsection{Abstract}

Measles virus (MV) infection induces severe immune suppression which results in enhanced susceptibility to bacterial infections making MV a major cause of morbidity and mortality in children in the developing world. This is partly due to inhibition of $\mathrm{T}$ cell proliferation by the MV glycoproteins (hemagglutinin and fusion protein) which interfere with the AKT signaling pathway. Macrophages, important effector and regulatory cells linking innate and adaptive immunity have been shown to be infected during MV infection and seem to play a central role in MV-induced immune suppression. The present work tested the hypothesis that MV infection induces decreased AKT activity in macrophages resulting in a decrease in antibacterial activity of macrophages.

In tissue culture, interferon $\gamma$-primed bone marrow-derived macrophages lose their bactericidal activity after infection with MV. This correlates with an approximately two-fold reduction in phosphorylation of AKT after infection with both MV wildtype and vaccine strain when compared to uninfected controls. In vivo, MV infection with wildtype WTFb leads to an increased bacterial burden and inflammatory infiltrates in cotton rats co-infected with Staphylococcus aureus. To prove a causal relationship, we 
generated a recombinant MV that expresses constitutively active myristoylated AKT, NSE-myr-AKT. In contrast to WTFb, the parental Ed-NSE vaccine virus does not lead to increased susceptibility to bacterial infection. There is no significant difference between bacterial burdens or pulmonary infiltrates in Ed-NSE or NSE-myr-AKT infected cotton rats. Future studies will focus on the development and use of a recombinant wildtype virus that overexpresses AKT.

\subsection{Introduction}

MV-induced immune suppression results in increased susceptibility to bacterial infections of the respiratory and gastrointestinal tracts leading to increased morbidity and mortality. Of these, bacterial pneumonia is the most common fatal complication, occurring in $56-87 \%$ of fatal cases of Measles [36, 37]. When a single etiology can be identified the most common pathogens in nosocomial and MV-associated pneumonia identified include Streptococcus pneumoniae, Haemophilus influenzae, and Staphylococcus aureus [37] [38] [39] [40], but more often a mixed culture of pathogenic bacteria is identified [37].

Macrophages play a central role in the control of bacterial infections due to their innate phagocytic capacity and their ability to stimulate T-cell responses and have been shown to be infected in acute MV-infected patients [32-34]. MV interferes with the immune responses of macrophages by altering antigen presentation and cytokine secretion. Primary MV-infected macrophages upregulate major histocompatibility class (MHC) II antigen expression and appear to be defective in the presentation of non-MV antigens $[61,201]$. Alterations in cytokine production have also been demonstrated in macrophage cell lines and monocyte-derived macrophages [62, 202]. There is a report 
suggesting MV-infected monocytes have functional defects resulting in decreased phagocytic and fungicidal capacities ex vivo [53]. Individually there are many aspects of macrophage function which are affected by MV infection but the cumulative effect of these changes in vivo is not known.

MV inhibits mitogen-stimulated proliferation of $\mathrm{T}$ cells after infection or by direct contact with the $\mathrm{F}$ and $\mathrm{H}$ glycoprotein complex $[31,57,60]$ and is due to a reduction in AKT kinase activity and subsequent cell cycle arrest $[79,90]$. There is strong evidence that reduction in AKT kinase activity will severely affect the ability of macrophages to phagocytose and kill bacteria. AKT phosphorylation is critical for receptor mediated phagocytosis using the $\mathrm{Fc}$ receptor $(\mathrm{Fc} \gamma \mathrm{R}) \gamma(\mathrm{IgG})$ and complement receptor 3 (CR3 also known as, CD11b/CD18). This has been shown by transient transfection of constitutively active myr-AKT which significantly increases phagocytic efficiency in mouse macrophage cell lines and murine bone marrow-derived macrophages [96]. In addition, macrophage-stimulating protein (MSP) activates AKT in murine primary peritoneal macrophages [97] and induced rapid phagocytosis of particles via the CR3 receptor [98]. In contrast, transient transfection with dominant negative AKT mutants down-regulates phagocytosis [96].

There is also evidence for involvement of AKT in the generation of oxygen radicals, a key effector function of macrophages. The ability to generate toxic oxygen radicals by a multi-enzyme complex, NADPH oxidase, is an important response to invading microorganisms. It has been shown that AKT mediates PI3K-dependent NADPH oxidase activation in human neutrophils and the loss of respiratory burst activity via AKT inhibitory peptide suggests that AKT activity is necessary for NADPH oxidase 
activity [99].

Taken together these results show that AKT signaling is critical for phagocytosis and development of the respiratory burst and the loss of AKT kinase activity will impair macrophage function.

To study MV-induced suppression we use the cotton rat because the cotton rat is the only rodent shown to replicate MV in the respiratory tract after intranasal infection and to develop T-cell proliferation inhibition (a hallmark of MV-induced immune suppression). Cotton rat bone marrow-derived macrophages are phenotypically and functionally similar to other rodent and human macrophages. We will use the cotton rat to examine the effects of concurrent MV infection on the host immune response to a $S$. aureus infection.

\subsection{Materials and Methods}

Animals

Inbred cotton rats were obtained from Harlan, Indianapolis. Female animals from six to ten weeks of age were used. The animals were bought specific pathogen free according to the breeder's specification and were maintained in a barrier system. Animals were kept under controlled environmental conditions of $22 \pm 1^{\circ} \mathrm{C}$ and a twelve-hour light cycle. All animals were euthanized by $\mathrm{CO}_{2}$ inhalation. 


\section{Cell lines and viruses}

Vero cells (African green monkey) and Vero-huCD150 (transfected with human CD150) were grown in minimal essential medium (MEM) with $10 \%$ fetal calf serum (FCS), $2 \mathrm{mmol} / \mathrm{L}$ glutamine, 50 I.U. penicillin and $50 \mu \mathrm{g}$ streptomycin $/ \mathrm{mL}$. BJAB cells were grown in RPMI 1640 containing 10\% FCS, 1\% non essential amino acids, 1\% sodium pyruvate, $2 \mathrm{mmol} / \mathrm{L}$ glutamine, 50 I.U. penicillin and $50 \mu \mathrm{g}$ streptomycin $/ \mathrm{mL}$. The molecular clone Ed-NSE [12] and the recombinant virus (NSE-myr-AKT) based on this clone were grown and titered on Vero cells. MV Erlangen.DEU/90 (WTFb) was grown on BJAB cells and titered on Vero-huCD150 cells.

To produce the myrAKT expressing Ed-NSE recombinant virus the pcDNA myrAKT-EE plasmid encoding a bovine AKT with a membrane targeted Src myristoylation signal was kindly provided by Susheela Tridandapani (The Ohio State University, Columbus, Ohio). The bovine AKT gene (GenBank AY781100) was inserted in forward orientation between the MV $\mathrm{H}$ and L genes in the MluI and SpeI sites of $\mathrm{p}(+)$ MV-NSE [12]. For the recombinant virus rescue, Hep-2 cells were co-transfected with 5ug of MV genome plasmis $\mathrm{p}(+) \mathrm{MV}-\mathrm{NSE}-\mathrm{myrAKT}$, and 1.5ug pT7-MV-N, 1.5ug pT7-MV-P and 0.5ug pT7-MV-L. To express T7 p-olymerase, Hep-2 cells were additionally infected (MOI 2) with a modified vaccinia virus Ankara (MVAGKT7) [189]. After 72 hours these transfected Hep-2 were co-cultured with Vero cells and recombinant virus was purified from plaques. 


\section{Bone marrow-derived macrophages}

Bone marrow-derived macrophages were derived as described in [125]. Briefly, bone marrow was aspirated aseptically from the femoral diaphyseal marrow cavity of female cotton rats and cells were isolated after centrifugation. Bone marrow cells were then cultured in $10 \mathrm{~cm}$ perfluoroalkoxy polymer resin dishes for seven days in the

presence of $100 \mathrm{ng} / \mathrm{ml}$ recombinant mouse M-CSF (R\&D Systems) in RPMI 1640 supplemented with $10 \%$ FCS, $1 \%$ non essential amino acids, 1\% sodium pyruvate, 2 mmol/L glutamine, 50 I.U. penicillin, $50 \mathrm{mg}$ streptomycin/L and $5 \times 10^{-5} \mathrm{M} \beta-$ mercaptoethanol for seven days. Macrophages were primed with $0.5 \mathrm{ug} / \mathrm{mL}$ of recombinant cotton rat IFN $\gamma$ (R\&D Systems) for 48 hours prior to use in bacterial killing assays.

\section{AKT kinase phosphorylation}

$4 \times 10^{6}$ cotton rat bone marrow-derived macrophages were plated per well in a $6-$ well plate and infected at a multiplicity of infection (MOI) of one with WTFb, Ed-NSE or NSE-myr-AKT for 24 hours at. $37^{\circ} \mathrm{C}$. Macrophages were then cultured in $10 \mathrm{mM}$ pervanadate PBS to stimulate AKT kinase phosphorylation. Protein cell lysates were collected after a five minute incubation. Cells were lysed in 1X RIPA cell lysis buffer (Cell Signaling) with 2mM PMSF (Sigma) and protein concentration of the lysates was quantified by BCA (Pierce). Proteins were separated by SDS-PAGE (Invitrogen NuPAGE pre-cast gel system), transferred to nitrocellulose filters, probed with antibody, and developed by enhanced chemiluminescence (Pierce). Each lysate is probed with rabbit polyclonal antibodies against AKT and pAKT serine 473 (Cell signaling) and a 
monoclonal antibody against gapdh (Invitrogen). Densitometry is used to quantify expression in each sample compared to the gapdh control.

\section{Growth of bacteria}

One day prior to use DH5 $\alpha$ Escherichia coli was grown overnight in LB broth, washed three times and resuspended in PBS and used to infect bone marrow-derived macrophages at an MOI of 100-200, verified by serial dilution of the inoculum and overnight culture on LB agar.

One day prior to use Staphylococcus aureus aureus (ATCC 49521) was grown in tryptic soy broth followed overnight growth on Columbia agar to induce capsule formation. Prior to intranasal infection a solution of OD 0.9 at $600 \mathrm{nn}$ in PBS is produced that corresponds to approximately $1 \times 10^{9} \mathrm{cfu} / \mathrm{ml}$.

\section{Bacterial killing}

$1-5 \times 10^{6}$ cotton rat bone marrow-derived macrophages were plated per well of a 24-well plate and infected at a multiplicity of infection (MOI) of one, five or ten with $\mathrm{WTFb}$ for 24 hours at. $37^{\circ} \mathrm{C}$. This was followed by infection with Escherichia coli or Staphylococcus aureus $(\mathrm{MOI}=100-200)$ in Hank's balanced salt solution (HBSS) 10\% normal cotton rat serum. Plates were incubated for $20 \mathrm{~min}$ at $37^{\circ} \mathrm{C}$ to allow binding and phagocytosis. The cells were washed to remove remaining extracellular bacteria. Cell lysates were harvested at times zero and two hours post infection. Serial dilutions of the homogenates were plated in duplicate on LB agar plates (E. coli) or Tryptic soy agar plates (S. aureus) to determine the number of viable intracellular bacteria. After 
incubation overnight at $37^{\circ} \mathrm{C}$, colonies were counted.

\section{Cotton rat infection}

For intranasal (i.n.) infection MV was given in PBS to isofluorane anesthetized cotton rats. I.n. inoculations of virus were administered in a volume of not more than $150 \mu 1$

\section{Lung viral and bacterial titrations}

Animals were asphyxiated using $\mathrm{CO}_{2}$ and lungs were removed and weighed. Lung tissue was minced with scissors and dounced with a glass homogenizer. Serial tenfold dilutions of lung homogenates were assessed for the presence and levels of infectious virus in a 48-well microassay using Vero cells with cytopathic effect (cpe) as an end point. Plates were scored microscopically for cpe after 7 days. The amount of virus in inocula was expressed as the quantity of virus that could infect $50 \%$ of inoculated tissue culture monolayers (TCID50). TCID50 was calculated according to methods described by Reed and Muench [188]. Serial tenfold dilutions of lung homogenates were also assessed for the presence of S. aureus. Homogenates were plated in duplicate on LB agar plates (E. coli) or Tryptic soy agar plates to determine the number of viable intracellular bacteria. After incubation overnight at $37^{\circ} \mathrm{C}$, colonies were counted. 


\section{Bronchoalveolar lavage}

The trachea was aseptically isolated and a canula was sutured in place in a $\mathrm{CO}_{2}$ asphyxiated cotton rat. The lungs were lavaged with ten milliliters of $37^{\circ} \mathrm{C}$ PBS with $0.1 \%$ EDTA (w/v) and $10 \%$ FCS (v/v) at $\mathrm{pH}$ 5.6. Lavage fluid was transferred to a siliconized tube and cells were isolated by centrifugation. Lung lavage cells were stained with Wright Giemsa and counted.

\subsection{Results}

\section{MV-induced reduction of pAKT in infected bone marrow-derived macrophages}

Reduction in AKT kinase activity has been demonstrated in a variety of human, mouse, and rat primary and tumor cell lines and in primary cotton rat blood cells infected with Measles. The effect of MV on AKT kinase activity in macrophages has not been investigated even though, there are many aspects of macrophage function which are affected by MV infection and there is strong evidence that a reduction will severely affect the ability of macrophages to phagocytose and kill bacteria. To correlate MV infection with reduced AKT phosphorylation in macrophages, bone marrow-derived macrophages were infected with vaccine or wildtype MV for 24 hours. Macrophages were then treated with $10 \mathrm{mM}$ pervanadate to inhibit phosphatase activity. There is a two-fold reduction in pAKT Ser 473 levels in the WTFb and Ed-NSE infected cell lysates compared to the uninfected control as measured by net signal intensity (Figure 4.1). 


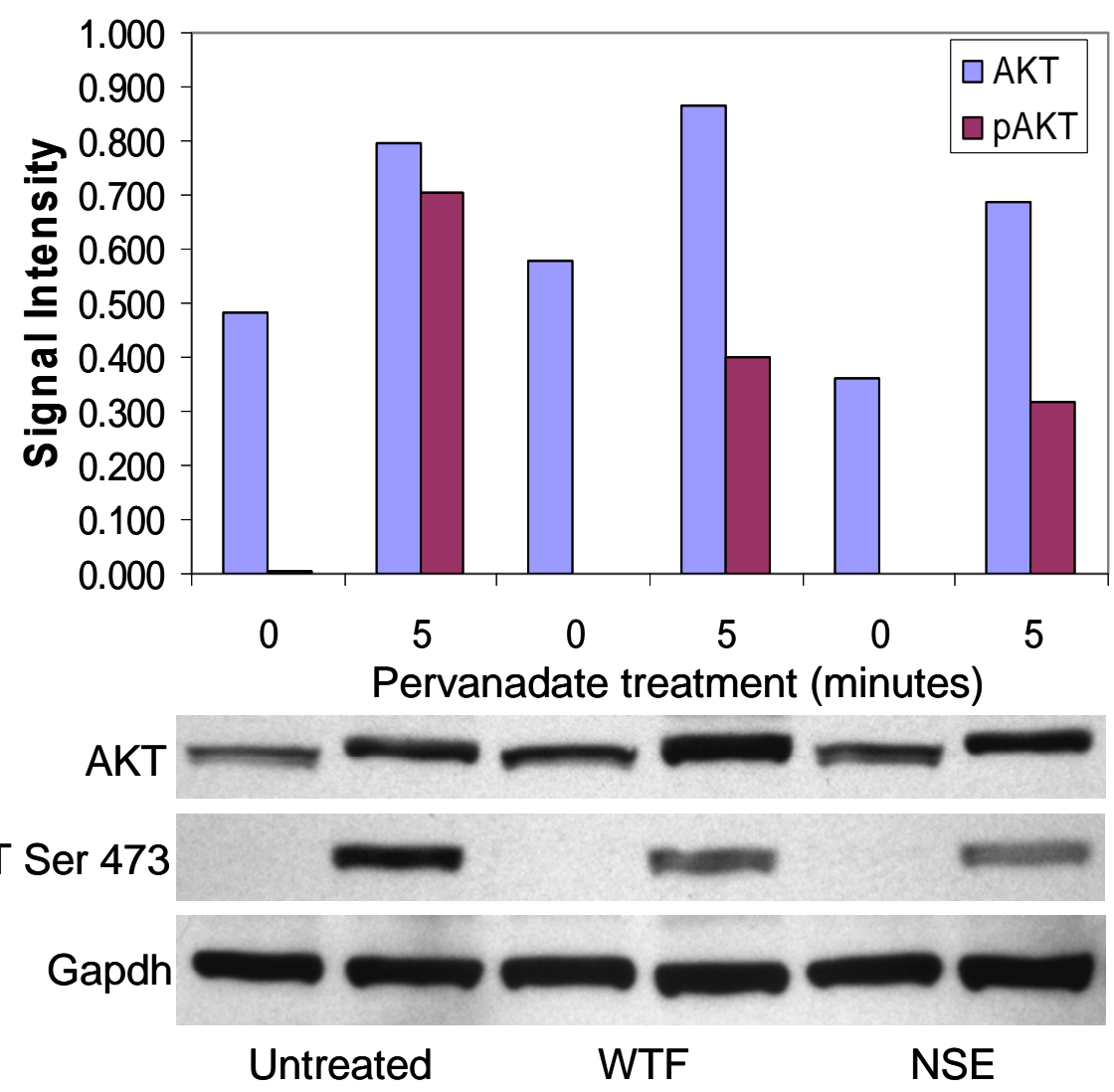

Figure 4.1 Wildtype and vaccine $\mathrm{MV}$ infection decreases phosphorylation of AKT in cotton rat macrophages when compared to uninfected controls. Bone marrow derived-macrophages were infected with WTFb or Ed-NSE $(\mathrm{MOI}=1)$. Macrophages were then treated with pervanadate at 24 hpi to inhibit phosphatase activity. There is a two-fold reduction in pAKT Ser 473 levels in wildtype and vaccine infected cell lysates compared to the uninfected control as measured by net signal intensity. Data is representative of three independent trials.

\section{MV-induced reduction in bacterial uptake and killing}

There is a report suggesting MV-infected monocytes have functional defects resulting in decreased phagocytic and fungicidal capacities ex vivo [53] which may contribute to the enhanced susceptibility to bacterial infections reported in acute Measles patients. To evaluate phagocytosis and bacterial killing in vitro, bone marrow-derived macrophages 
were infected with wildtype MV (WTFb) at various MOIs for 24 hours and then were used in a bacterial killing assay. With E. coli, MV infected macrophages showed a decrease in bacterial uptake at all MOIs (Figure 4.2a). After the two hour killing period there was a two-fold reduction in viable E. coli in the non-MV infected macrophages, whereas in the MV-infected macrophages there was an approximately 1.5 -fold decrease in viable E. coli (Figure 4.2b). These data indicate MV infection in cotton rat macrophages reduces phagocytosis and killing of bacteria as has been previously demonstrated in monocytes from MV infected patients [53] and in alveolar macrophages in Sendai infected mice [203] [204]. 
Figure 4.2 MV infection leads to a reduction in bacterial uptake and killing. Bone marrow-derived macrophages were infected with WTFb at an MOI of 1,5 and 10 for 24 hours. After co-infection with DH5a E. coli there is a two-fold reduction in bacterial uptake by MV infected macrophages compared to non-MV infected macrophages (* vs. uninfected $\mathrm{p}<0.05)(\mathrm{a})$. At two hours post DH5 $\alpha$ E. coli infection there is also a reduction in bacterial killing by MV infected macrophages, $p>0.10$ (b). The killing ratio is the bacterial count after the two hour incubation /bacterial count at time zero. Data represents an average of triplicates $+/-$ standard deviation. Analysis of variance (ANOVA) was performed using the GraphPad Instat version 3 software. 
a

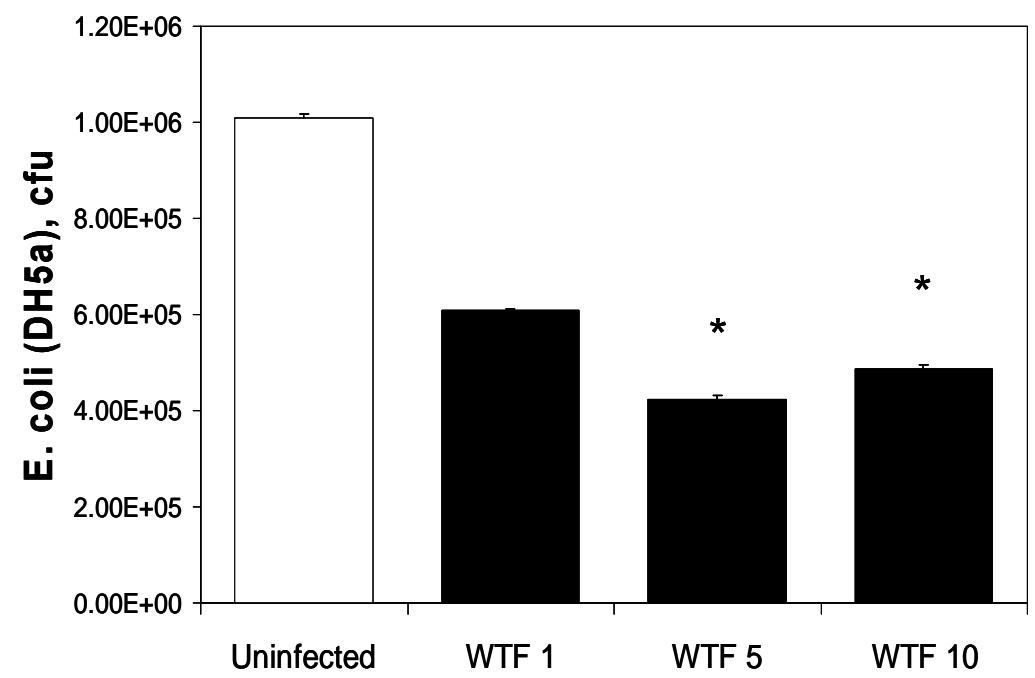

b

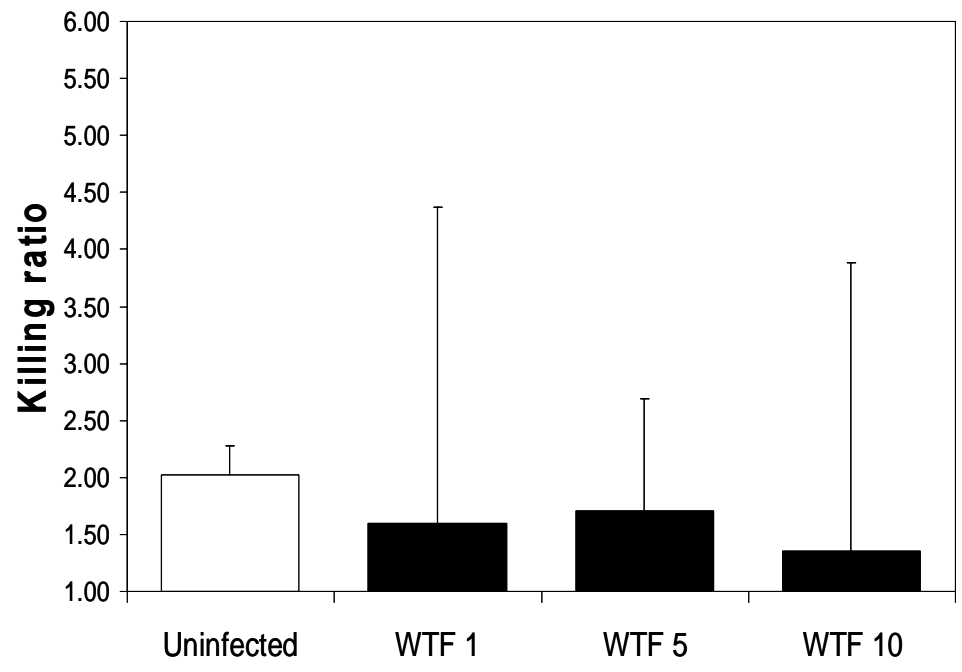




\section{MV-induced reduction in bacterial killing is associated with increased bacterial burden and inflammation in the cotton rat lung}

Bacterial pneumonia is the most common fatal complication following acute MV infection and Staphylococcus aureus is one of the most common etiologic pathogens identified. To evaluate the effect of MV infection on phagocytosis and bacterial killing in vivo, cotton rats were infected intranasally with $1 \times 10^{6} \mathrm{TCID}_{50} \mathrm{WTFb}$. At four days post MV infection cotton rats were co-infected with $1 \times 10^{9} \mathrm{pfu}$ S. aureus. At four hours post $S$. aureus infection the cotton rats were euthanized and their lungs were harvested. Viral titers from the WTFb and co-infected animals were not significantly different, Figure 4.3a. S. aureus titers were significantly higher in the WTFb co-infected animals compared to the cotton rats infected with $S$. aureus alone ( $\mathrm{p}$ value $=0.05)$ Figure $4.3 \mathrm{~b}$.

Additionally, the WTFb S. aureus animals had more severe inflammatory changes in the lung characterized by increased number and size of inflamed foci, increase severity of interstitial alveolar infiltration by neutrophils, eosinophils and macrophages (Figure 4.4 and 4.5). Infection of cotton rats with wildtype MV (WTFb) prior to co-infection with $S$. aureus leads to a reduction in bacterial killing and an increase in pulmonary inflammatory infiltrates. 
Figure 4.3 Cotton rats co-infected with WTFb and $S$. aureus have an increased bacterial burden compared to $S$. aureus infected controls. Cotton rats were intranasally inoculated with WTFb and at 4dpi we co-infected with S. aureus. At 4 hours post $S$. aureus infection lung tissue was homogenized and serial dilutions were plated to determine $\mathrm{TCID}_{50}$ and cfu/gram lung tissue. Viral titers were comparable between the groups (a). There is a two-fold increase in bacteria in cotton rats co-infected with WTFb and $S$. aureus $(\mathrm{p}=0.05)(\mathrm{b})$. Data represents an average of five animals $+/-$ standard deviation. Analysis of variance (ANOVA) was performed using the GraphPad Instat version 3 software. 
a

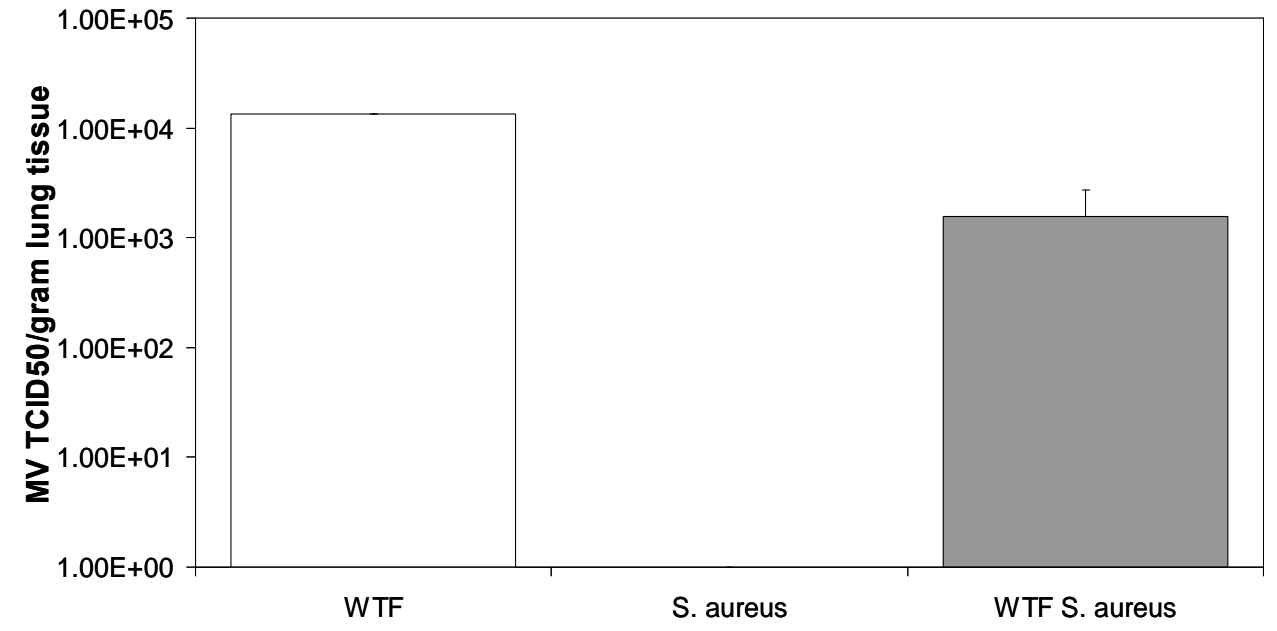

b

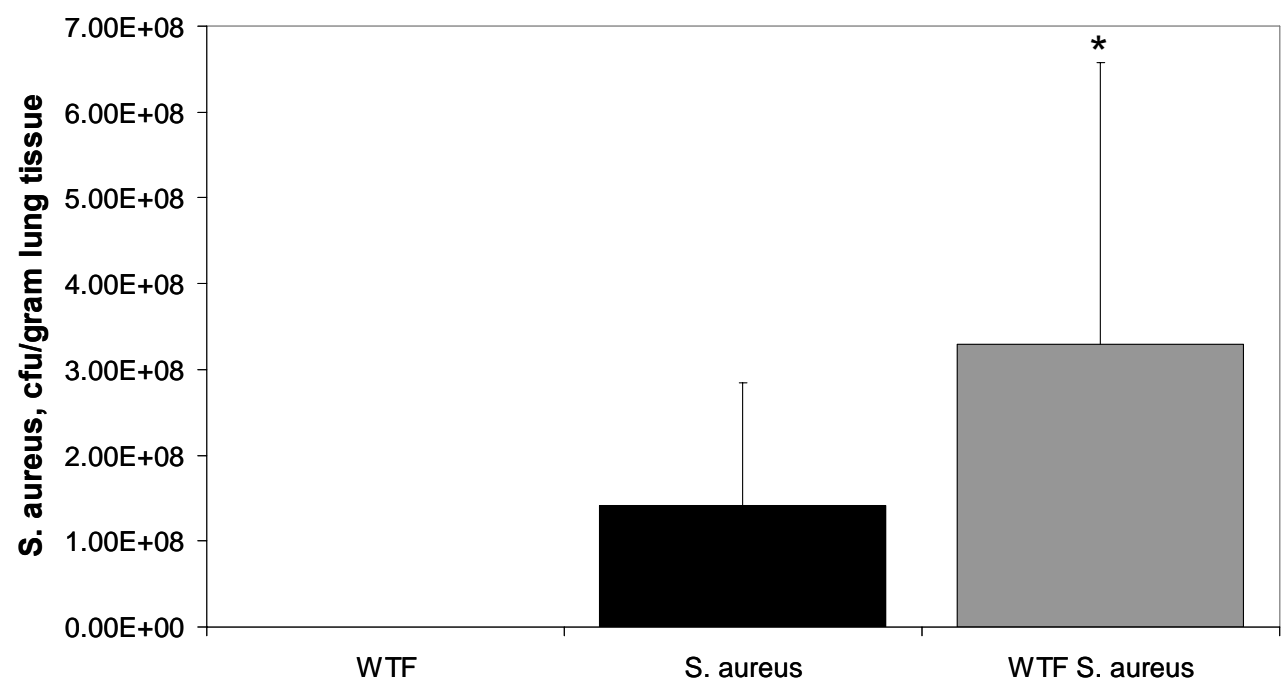


Figure 4.4 Cotton rats co-infected with WTFb and S. aureus have an increased inflammatory response compared to $S$. aureus infected controls. Overall, there was an increase in number and size of pneumonic foci in the WTFb S. aureus co-infected rats. Within each affected focus there was an increase in interstitial, bronchiolar and alveolar infiltration by neutrophils, macrophages and eosinophils. Lesions were quantified as described in the methods section and results are seen in Figure 4.5. Data represents an average of five animals $+/$ - standard deviation. 


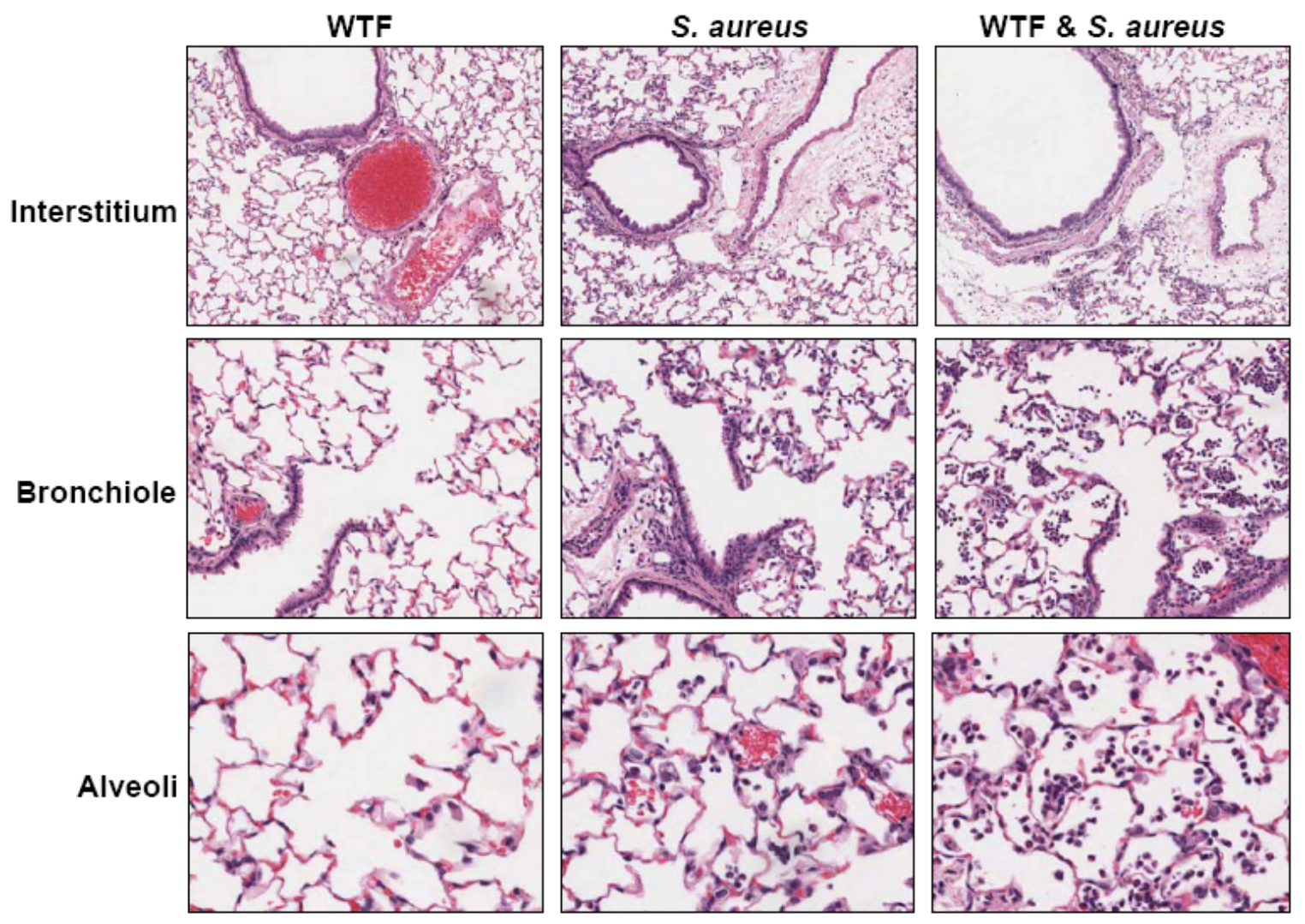




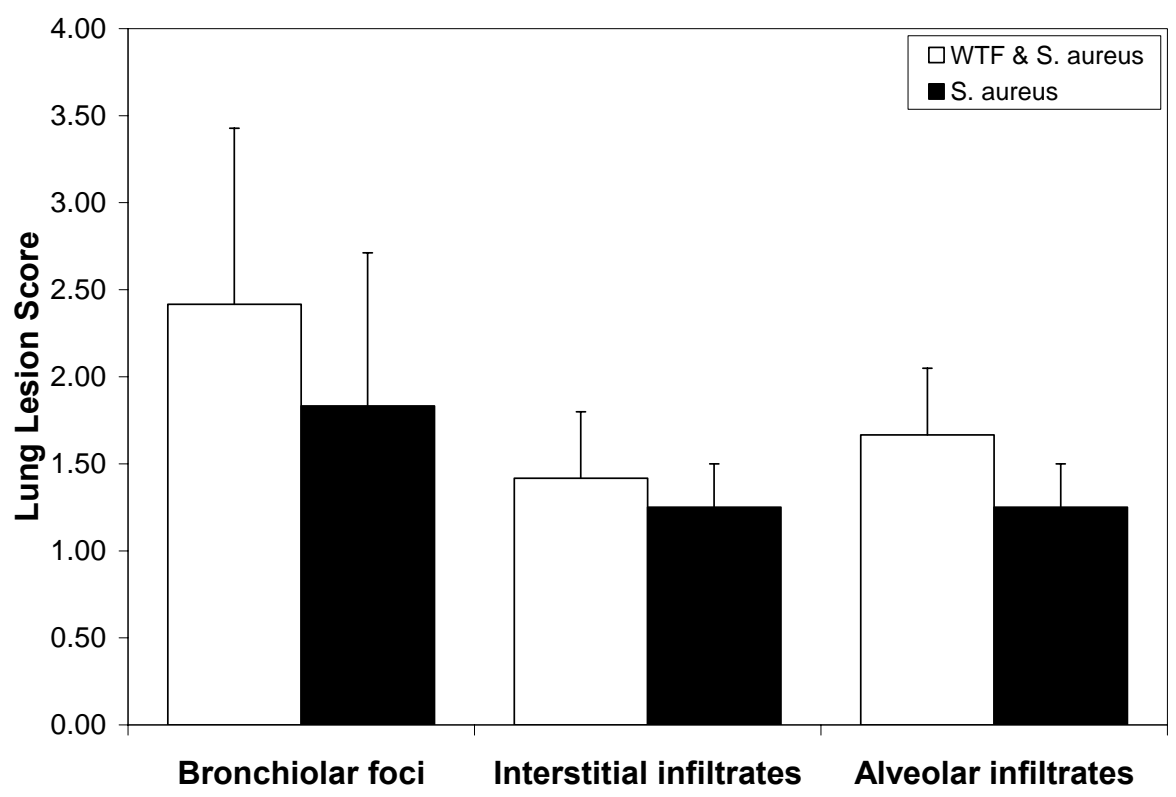

Figure 4.5 Comparison of lung lesion scores between cotton rats co-infected with WTFb and S. aureus (white bars) and S. aureus alone (black bars). Inflammatory foci within each lung lobe were counted. Then for each lobe lesion severity was quantified (0-4) on the basis of the characteristic lesions of acute suppurative bronchopneumonia: The lesion scores are based on severity of characteristic lesions of acute suppurative pneumonia: (i) interstitial peribronchial and perivascular accumulation of edema fluid, neutrophils, eosinophils and macrophages and (ii) inflammatory cell infiltration in alveoli. The trend in all parameters evaluated is an increased inflammatory response compared to $S$. aureus infected controls. Overall, there was an increase in number and size of pneumonic foci in the WTFb S. aureus co-infected rats. Within each affected focus there was an increase in interstitial and alveolar infiltration by neutrophils, macrophages and eosinophils. Data represents an average of five animals $+/$ - standard deviation. Two-tailed student's T-test was performed using the GraphPad Instat version 3 software.

\section{Restoration of pAKT levels in NSE-myr-AKT infected cotton rat macrophages}

It has already been shown that overexpression of constitutively active myristoylated AKT leads to reversal of proliferation inhibition of $\mathrm{T}$ cells in vitro [79]. To test whether overexpression of myristolated AKT would rescue bacterial uptake and killing in 
macrophages we have produced a recombinant MV that expresses constitutively active myristoylated AKT. In order to increase the level of pAKT production at the site of infection a molecularly cloned MV was produced by inserting the bovine myristoylated AKT gene $(98 \%$ homology to mouse and rat AKT) between the hemagglutinin glycoprotein (H) and polymerase (L) using the MV reverse genetics system [205]. This bovine myristoylated AKT construct is functional in mouse bone marrow-derived macrophages proving interspecies applications of AKT are successful. The myr-AKT gene was inserted between the MV H and L genes where insertion of a foreign gene does not disrupt in vivo viral replication (unpublished observation).

Expression of constitutively active myr-AKT in a recombinant MV returns pAKT to uninfected control levels as measured by net signal intensity. Cotton rat bone marrowderived macrophages were infected with vaccine Ed-NSE or NSE-myr-AKT and incubated for 24 hours. Macrophages were then treated with pervanadate to activate AKT. There is a two-fold reduction in pAKT Ser 473 levels in vaccine (Ed-NSE) infected cell lysates compared to the uninfected control as measured by net signal intensity. Infection with NSE-myr-AKT which expresses a constitutively active AKT rescues pAKT levels and returns it to levels comparable to the uninfected control (Figure 4.6). 

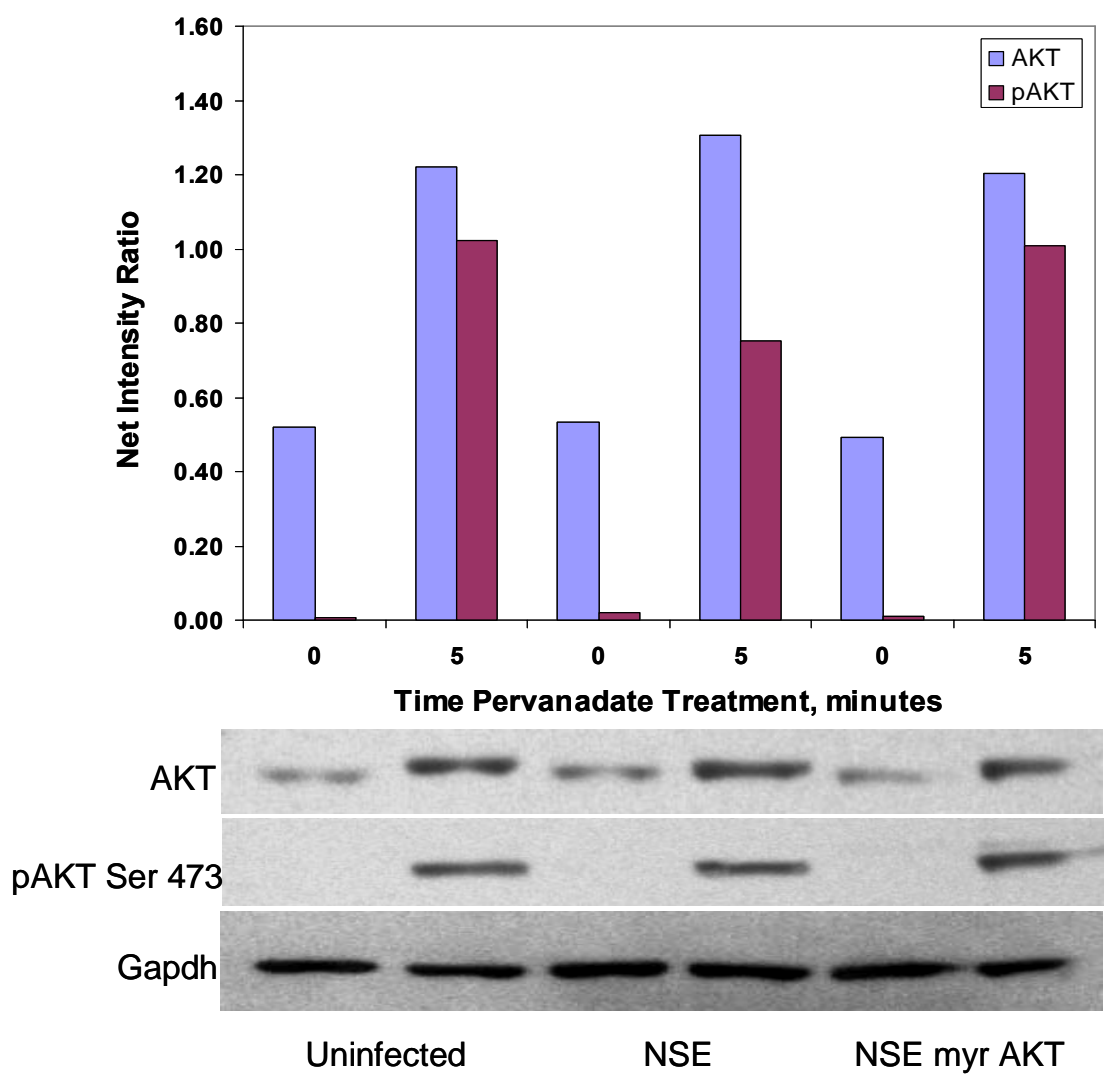

Figure 4.6 Expression of constitutively active myr-AKT in a recombinant MV returns pAKT in bone marrow-derived macrophages infected to uninfected control levels as measured by net signal intensity. Macrophages were infected with Ed-NSE or NSEmyr-AKT $(\mathrm{MOI}=1)$. Macrophages were then treated with pervanadate at $24 \mathrm{hpi}$ to inhibit phosphatase activity. . Data is representative of three independent experiments.

Supplementation of AKT kinase activity in a MV-infected cotton rats does not impact macrophage bacterial killing ability

Infection of cotton rats with wildtype MV (WTFb) prior to co-infection with S. aureus leads to a reduction in bacterial killing and an increase in pulmonary inflammatory infiltrates. To evaluate the effect of AKT supplementation in MV-infected cotton rats we infected cotton rats intranasally with $1 \times 10^{6} \mathrm{TCID}_{50}$ Ed-NSE or NSE-myr-AKT. At three, 
four and five days post MV infection cotton rats were co-infected with $1 \times 10^{9}$ pfu $S$. aureus. At four hours post S. aureus infection the cotton rats were euthanized. Viral titers from the $\mathrm{WTFb}$ and co-infected animals were not significantly different (data not shown). S. aureus titers were not significantly different between the Ed-NSE and NSEmyr-AKT co-infected animals compared to the cotton rats infected with S. aureus alone at any time point. This level of Ed-NSE inoculum results in T-cell proliferation inhibition, it did not inhibit macrophage function. Unexpectedly, $1 \times 10^{6} \mathrm{TCID}_{50}$ of EdNSE did not cause a reduction in bacterial killing as was seen with $1 \times 10^{6} \mathrm{TCID}_{50} \mathrm{WTFb}$.

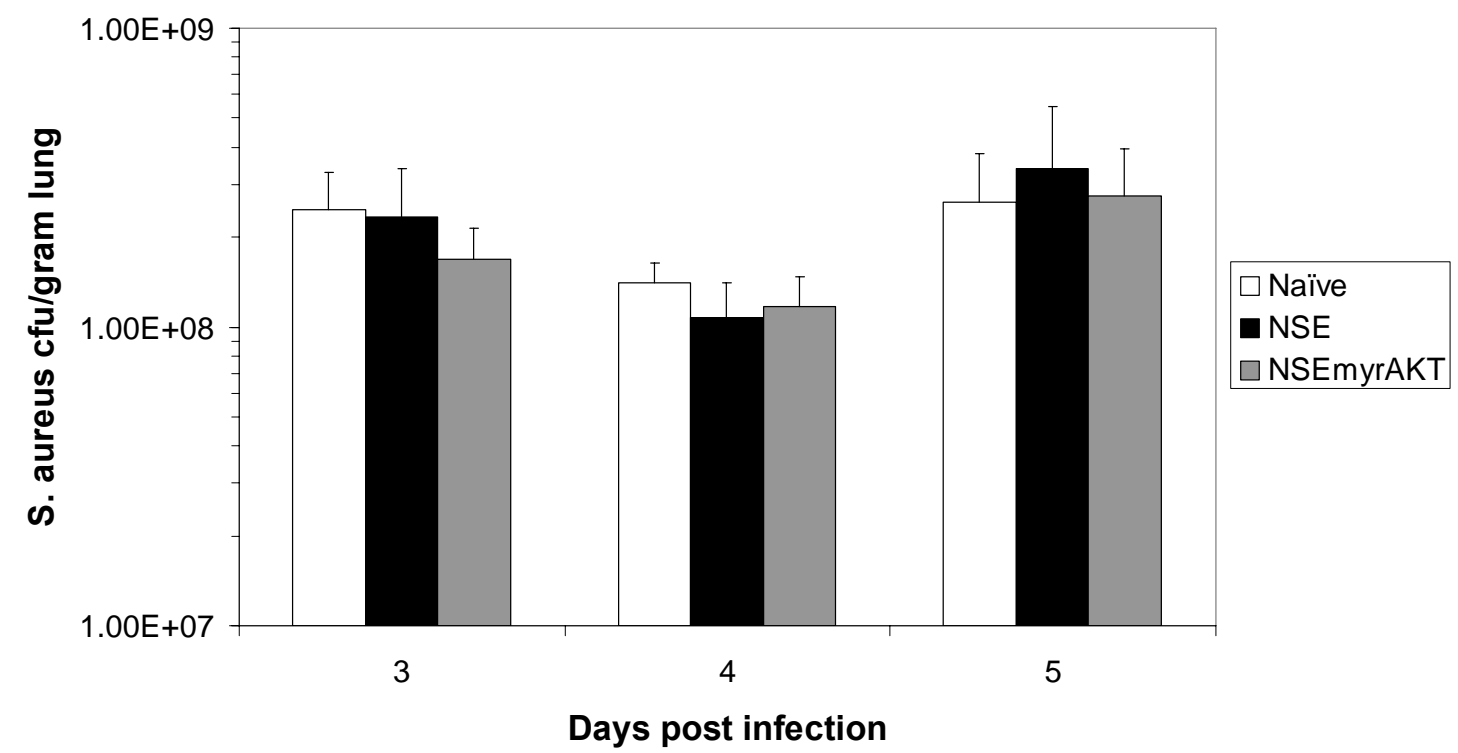

Figure 4.7 Cotton rats co-infected with Ed-NSE or NSE-myr-AKT and S. aureus do not have an increased bacterial burden compared to $S$. aureus infected controls. Cotton rats were intranasally inoculated with Ed-NSE and NSE-myr-AKT and at 4dpi were co-infected with $S$. aureus. At 4 hours post $S$. aureus infection lung tissue was homogenized and serial dilutions were plated to determine $\mathrm{TCID}_{50}$ and cfu/gram lung tissue. Data represents an average of five animals $+/$ - standard deviation. Analysis of variance (ANOVA) was performed using the GraphPad Instat version 3 software. 
To better evaluate inflammatory pulmonary infiltrates bronchoalveolar lavage (BAL) was performed on the right lung lobes and lavage cells were analyzed for the total number of leukocytes $/ \mu 1$ and the percentage of mononuclear cells. Total number of infiltrating leukocytes was comparable between the groups at all time points (data not shown). There is a significant increase in infiltrating macrophages seen in the S. aureus infected animals at 4 days post infection that is not seen in the Ed-NSE and NSE-myrAKT co-infected animals $(\mathrm{p}<0.001)$. Interestingly, this does not correlate with an increase in bacterial titer at this time point.

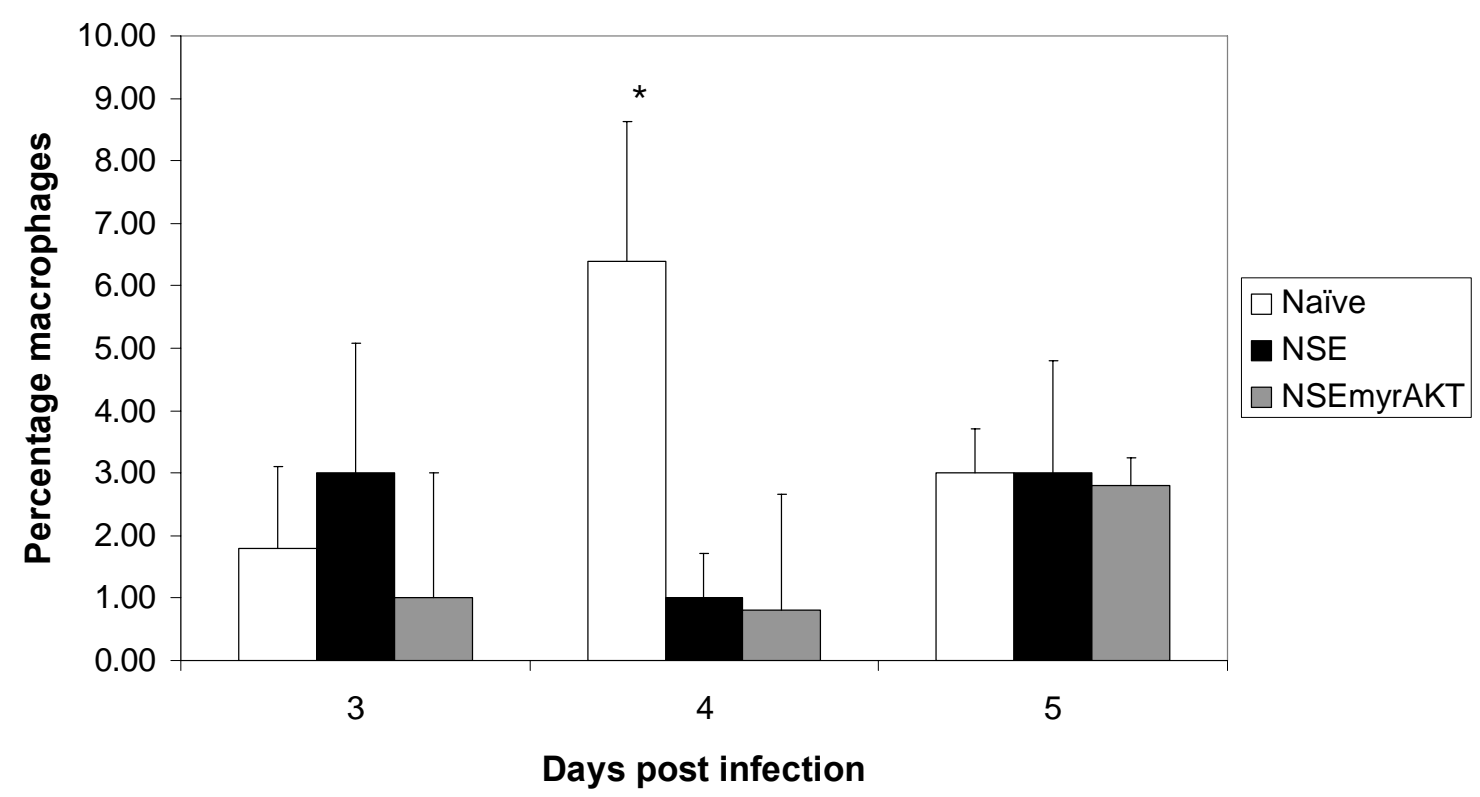

Figure 4.8 Percentage of macrophages in BAL fluid from cotton rats co-infected with Ed-NSE or NSE-myr-AKT and S. aureus. Naïve animals have a significantly increased number of alveolar macrophages at 4dpi compared to co-infected animals. Data represents an average of five animals $+/$ - standard deviation. Analysis of variance (ANOVA) was performed using the GraphPad Instat version 3 software. 


\subsection{Discussion}

Bacterial pneumonia is the most common fatal complication in acute Measles caused by viral-induced immune suppression. The mechanism by which MV leads to an increased incidence of bacterial infections is not known. We have chosen to focus on the effect of MV on macrophage function because macrophages play a central role in the control of bacterial infections due to their innate phagocytic capacity and their ability to stimulate T-cell responses. There are many aspects of macrophage function which are affected by MV infection but the cumulative effect of these changes in vivo is not known. There is a single report suggesting MV-infected monocytes have functional defects resulting in decreased phagocytic and fungicidal activity.

In this report we demonstrate wildtype MV infection causes a significant decrease in phagocytosis of serum-opsonized $E$. coli by IFN $\gamma$-primed bone marrow-derived macrophages compared to uninfected controls. MV-induced reduction in phagocytosis is concurrent with an approximately two-fold reduction in phosphorylation of AKT after infection with both wildtype and vaccine strain MV. There is strong evidence to indicate that these observations are linked. Phagocytosis of E. coli via Fc $\gamma \mathrm{R}$ and CR3 is induced by serum immunoglobulin and complement opsonization and AKT phosphorylation is critical for phagocytosis through both receptors. MV infection with wildtype WTFb also leads to an increased bacterial burden and inflammatory infiltrates in cotton rats coinfected with Staphylococcus aureus.

To prove a causal relationship, we generated a recombinant MV that expresses constitutively active myristoylated AKT, NSE-myr-AKT. Myristoyl-groups are membrane targeting signals that direct AKT to the plasma membrane resulting in constitutive phosphorylation and activation of AKT. It is believed that the upstream 
kinases required for phosphorylation and activation of AKT have limited basal activity that is sufficient to activate membrane targeted AKT [91] [92] [93]. Myristoylated AKT was inserted between the $\mathrm{H}$ and $\mathrm{L}$ genes in the Ed-NSE genome. Ed-NSE is the molecular clone of the Edmonston B vaccine strain. Both WTFb and Ed-NSE suppress AKT phosphorylation to comparable levels in macrophages based on western blot analysis. More importantly, at high inoculums Ed-NSE causes T-cell proliferation inhibition equivalent to the levels seen with the WTFb wildtype virus and overexpression of constitutively active myristoylated AKT leads to reversal of proliferation inhibition in vitro [79].

There is evidence for involvement of AKT in the generation of oxygen radicals, a key effector function of macrophages. The ability to generate toxic oxygen radicals by a multi-enzyme complex, NADPH oxidase, is an important response to invading microorganisms linked to AKT. One possibility for the observed decrease in bacterial killing would be a reduction in oxygen intermediates production, specifically superoxide and hydrogen peroxide. We infected IFN $\gamma$ macrophages with wildtype (WTFb) or vaccine (Ed-NSE) MV and followed superoxide and hydrogen peroxide production for 90 minutes following zymosan stimulation to investigate this possibility. Both superoxide and hydrogen peroxide levels were significantly increased with MV infection compared to uninfected controls (data not shown). There was no difference seen between $\mathrm{WTFb}$ and Ed-NSE.

Unfortunately, the parental Ed-NSE vaccine virus, does not lead to increased susceptibility to bacterial infection like $\mathrm{WTFb}$ in vivo. And there was no significant difference between bacterial burdens or pulmonary infiltrates in Ed-NSE or NSE-myr- 
AKT infected cotton rats. Of note, the Ed-NSE and NSE-myr-AKT animals had significantly less macrophages in their BAL fluid compared to the naïve animals at four days post infection. The PI3 kinase signaling cascade is integral to chemotaxis through regulation and activation of F-actin polymerization and myosin assembly [206]. AKT can bind and phosphorylate actin or the actin-binding protein girdin which accumulates at the leading edge of the membrane and maintains the cyctoskeleton integrity [207, 208]. Ameoba lacking both isoforms of AKT kinase exhibit severe defects in motility [209]. It is possible that downregulation of $\mathrm{AKT}$ in macrophages by $\mathrm{MV}$ inhibits cytoskeletal polymerization and leads to a reduction in accumulation at the site of bacterial infection. BAL results from Ed-NSE infected cotton rats are consistent with this suggestion. In future studies, differential counts on BAL fluid from WTFb infected animals will be analyzed to determine the affect of wildtype infection on chemotaxis of macrophages to the alveolar space.

Direct contact with the MV glycoproteins, fusion (F) and hemagluttinin (H) are responsible for AKT downregulation and proliferation inhibition. Protein sequence comparison based on published mRNA sequences shows a high degree of homology between the WTFb and Ed-NSE strain F (99.8\%) proteins. The WTFb H sequence is not available for comparison. This suggests the difference between the two viruses is more likely a function of receptor usage and viral spread. Viruses expressing the wildtype $\mathrm{H}$ glycoprotein, like WTFb, use signalling lymphocyte activation molecule (SLAM), also known as CD150, which is expressed on activated leukocytes and mediates high affinity binding and entry [13-15]. Vaccine viruses, Ed-NSE use both CD150 and CD46 [16] as receptor molecules Signalling lymphocyte activation molecule (SLAM), also known as 
CD150, is expressed on activated leukocytes and mediates high affinity binding and entry of viruses that express the wildtype hemagglutinin glycoprotein [13-15]. Vaccine strains, like Ed-NSE, preferentially use CD46 [16] as a receptor molecule, but maintains a low affinity CD150. The ability to use CD46 (membrane co-factor protein, a regulator of complement activation is expressed on all human nucleated cells) as a receptor is acquired by vaccine strains after tissue culture adaptation on fibroblast cell lines which solely express CD46 [16]. Vaccine viruses do not cause clinical disease but interestingly do not differ from wildtype strains in their ability to induce proliferation inhibition in tissue culture. In the cotton rat model, it has been demonstrated that viral spread to mediastinal lymph nodes correlates to lung viral titer and proliferation inhibition. This was further correlated to the use of the CD150 receptor molecule using recombinant vaccine viruses expressing wildtype $\mathrm{H}$ that only differed in two amino acids and their ability to bind CD150 [118]. Therefore, viruses which express a wildtype $H$ have the ability to spread farther, infect and affect a greater number of cells which ultimately impacts the phenotype of MV-induced immune suppression. Future studies will focus on the development and use of a molecular clone of the ICB wildtype MV [210] to generate a recombinant wildtype virus that overexpresses AKT. This virus would maintain the wildtype H CD150 receptor usage and should result in decreased bacterial uptake and killing similar to WTFb. 


\subsection{Acknowledgements}

This project was supported by NIH Training Grant RR007073 and the NIH Pediatric Loan Repayment Program. 


\section{Chapter 5}

\section{Role of AKT Kinase in Measles Virus Replication}

\subsection{Abstract}

Many RNA and DNA viruses activate serine-threonine kinase AKT in order to further virus replication. In contrast, measles virus infection leads to downregulation of AKT. This is thought to be beneficial for the virus because it is the mechanism partially responsible for immune suppression. To determine whether this is a sacrifice for the virus, we used a recombinant virus and transfected cells expressing constitutively active AKT and evaluated its effect on virus replication. Overexpression of AKT did not influence virus replication in vitro or in vivo nor did it abrogate proliferation inhibition of spleen cells from MV infected cotton rats.

\subsection{Body of Note}

The serine-threonine kinase AKT plays a central role in growth regulation of cells. After phosphorylation, activated AKT affects multiple cellular targets that increase metabolism, growth, synthetic processes and suppress apoptosis. Viruses as intracellular parasites rely on the growth environment provided by the cell. In agreement with this dependency, a variety of RNA [211] and most DNA [212, 213] viruses stimulate AKT 
activity after infection of cells and are able to overcome control of AKT expression by cellular regulatory mechanisms. An exception is measles virus which not only does not stimulate AKT but reduces expression of phosphorylated (activate AKT) after infection [79]. This reduction has been shown to reduce proliferation of $\mathrm{T}$ cells after infection with the virus or contact with virus infected cells in vitro and in vivo. In consequence, in vivo antigen-specific T-cell responses of both CD4 and CD8 T cells are diminished and this is thought to be (partially) responsible for measles virus induced immune suppression. However, a recent publication suggested that this might be a trade off for the virus [139]. In measles virus infected Vero cells which had been treated with the AKT- specific inhibitor IV, the number of virus particles released into the supernatant was reduced. In contrast, intracellularly produced virus levels were not affected by AKT inhibition. When we repeated these experiments we essentially obtained the same results (data not shown). These experiments were difficult due to the fact that AKT inhibitors severely impair the viability of cells; so that only in a short window of time a distinction between the effect of AKT inhibition or cell death on virus replication can be discerned. For this reason we planned to supply virus infected cells with AKT to measure its effect on virus growth. As AKT cannot be pharmacologically induced selectively, a recombinant measles virus was constructed with an additional gene for myristoylated AKT [96] (GenBank AY781100) between the hemagglutinin and the polymerase gene based on published molecular viral clones [214]. This molecularly cloned virus expressed myristoylated AKT with a glutamine-glutamine tag in infected cells (as detected by Western blotting). After translocation to the inner plasma membrane due to the myristoylation signal, AKT was phosphorylated independent of regulatory cellular signals. This was true in the Vero 
fibroblastoid cell line (African Green Monkey; a standard measles virus substrate; data not shown) and in the Jurkat lymphoid cell line (human CD4 positive $\mathrm{T}$ cell line; see Figure 5.2). In Vero cells, different growth parameters were investigated in comparing the parental Ed-NSE and the recombinant NSE-myr-AKT virus. These parameters included the polymerase elongation rate, the rate of viral transcription and replication, glycoprotein production and intracellular virus production and release from cells. The measurement of the polymerase elongation rate, viral transcription and genome replication was performed as published previously [215]. For primer sequences see reference [215]. Cell-free virus was purified from the supernatant of MV-infected Vero cells by sedimentation on a discontinuous sucrose gradient as described [112]. This virus was used to infect Vero cells at an MOI of 1.0. RNA from infected cells was isolated using the Qiagen RNeasy kit (Qiagen), reverse transcribed and amplified by quantitative PCR (QPCR) using FastStart DNA Master SYBR Green I reagents in Light Cycler 480 System from Roche Applied Science (Meylan, France). All experiments were carried out in duplicate and data was analyzed using the Light Cycler 480 Software and were expressed as copy numbers per $2 \mu \mathrm{g}$ of RNA.

The elongation rate for the parental Ed-NSE virus was comparable to previously published data (1.33 nucleotides/second). In comparison, the polymerase elongation rate of NSE-myr-AKT was slightly reduced (0.66 nucleotides/second). Viral transcription and genome replication were slightly lower in NSE-myr-AKT (Figure 5.1; and data not shown). This slight difference did not translate into measurable differences on the level of glycoproteins or virus replication. The expression of both the hemagglutinin and fusion proteins was identical 24 hours after infection by flow cytometry (data not shown). To 
obtain kinetic growth curves, Vero cells in 6-well plates were infected with Ed-NSE or NSE-myr-AKT (MOI 0.02) and tissue culture supernatants and cell lysates were harvested at $0,12,24,36,48,60$, and 72 hours post infection. Virus titers were quantified by TCID50 assay. For both viruses, the levels of both intracellular virus and virus released from cells were similar over time (Figure 5.1). 
Figure 5.1 Measles virus replication after AKT overexpression in the fibroblast cell line Vero. Accumulation of $\mathrm{N}$ mRNA (A) during primary transcription from Vero cells infected with Ed-NSE and NSE-myr-AKT (MOI 1.0). The kinetics of genome accumulation (B) and progeny release (C) for 72 hours post infection from Ed-NSE and NSE-myr-AKT infected (MOI 0.02) Vero cells did not differ. Data is representative of two independent experiments. 


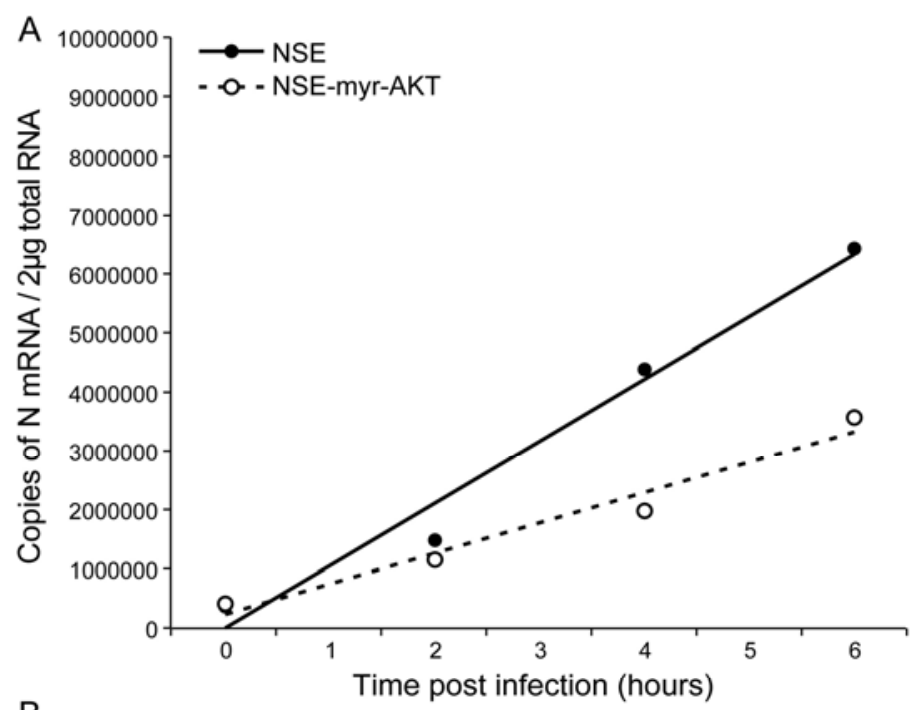

B

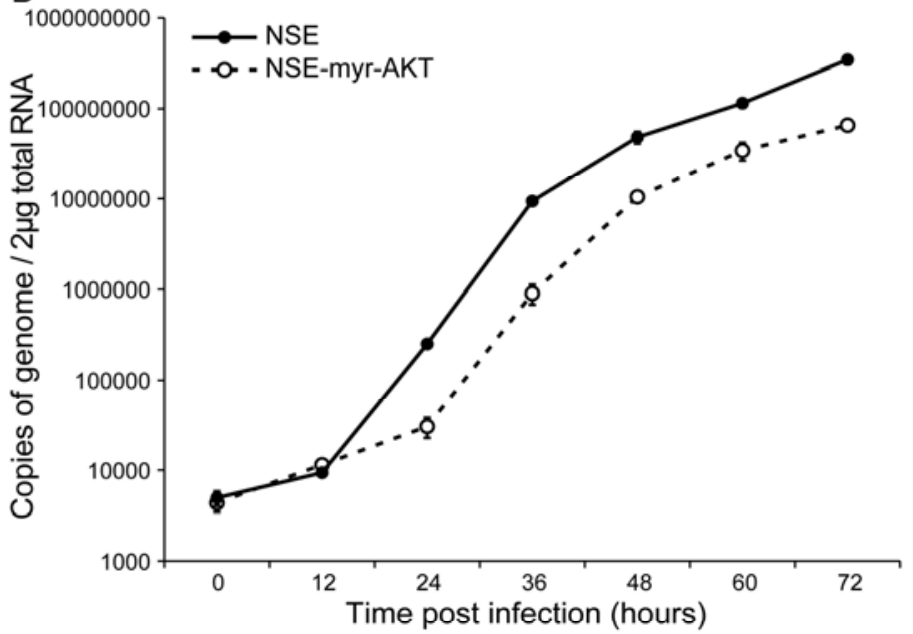

C

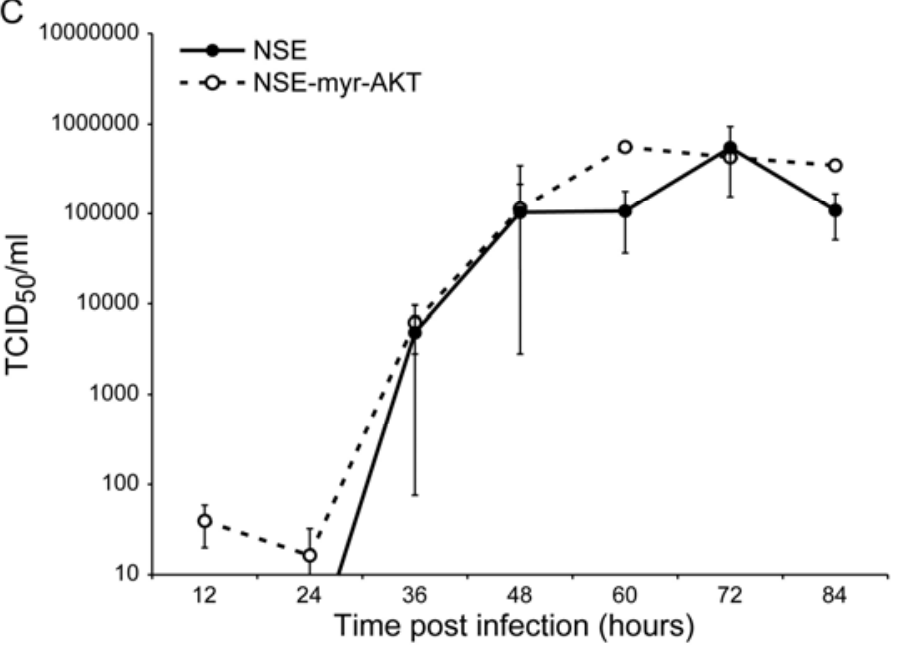


In order to test whether the complete lack of stimulation of virus growth by myrAKT in Vero cells was cell (type) specific, the level of virus replication was also assessed in Jurkat cells. Jurkat cells have the additional advantage that transfected variants exist which overexpress myr-AKT (Jurkat- myr-AKT) [216]. Whereas contact with virus leads to downregulation of AKT and inhibits proliferation of Jurkat cells, this inhibition is overcome in Jurkat cells transfected with myr-AKT [79]. The level of AKT and pAKT levels in uninfected Jurkat and Jurkat-myr- AKT cells or cells infected with Ed-NSE or NSE-myr-AKT was determined by Western blotting. Proteins from cellular lysates 24 hours after infection with an MOI of 0.02 were separated by SDS-PAGE (Invitrogen NuPAGE pre-cast gel system), transferred to nitrocellulose filters, probed with polyclonal antibodies against AKT and pAKT serine 473 (Cell Signaling), and developed by enhanced chemiluminescence (Pierce). Densitometry was used to quantify AKT/pAKT expression in each sample compared to a GADPH control. After infection of Jurkat cells with measles virus, the expression of endogenous phosphorylated AKT is strongly reduced (Figure 5.2a). The myristoylated form is not affected by infection; whether it is expressed in transfected cells or by the recombinant virus. After infection of both Jurkat cells and Jurkat- myr-AKT cells with either Ed-NSE or NSE-myr-AKT no difference in intracellular virus levels could be detected (Figure 5.2b). The level of progeny virus released by the cells was reduced after NSE-myr-AKT infection in comparison to EdNSE infection (Figure 5.2c), irrespective of the cell line used (Jurkat cells or Jurkat- myrAKT).

In order to determine the importance of AKT overexpression in vivo for virus growth, measles virus-specific immunity and immune suppression, cotton rats were 
inoculated intranasally with either virus; lungs, mediastinal lymph node (MDLN) cells and spleen cells were analyzed on day 4 after infection. For this analysis, female inbred cotton rats (Harlan, Indianapolis) were infected intranasally (i.n.). To determine virus titers from lungs, lung tissue was homogenized and tested by the $50 \%$ of inoculated tissue culture dose (TCID50) method [188] . Both Ed-NSE and NSE-myr-AKT viruses grew to comparable titers in cotton rat lungs (Figure 5.3a).

A hallmark of measles virus induced immune suppression is the proliferation inhibition of mitogen-stimulated lymphocytes ex vivo. To test proliferation inhibition, proliferation of spleen cells from infected and naive animals was measured by the $3 \mathrm{H}-$ thymidine incorporation assay [185]. After Concanavalin A stimulation of spleen cells (as described in [185]), proliferation was inhibited compared to naive animals independent of the virus used for infection. To test for MV-specific T cells, an ELISPOT assay was employed as described with modifications [217]. Ninety-six well polysorb-plates (Nunc) were coated with $100 \mu \mathrm{l}$ of $3.3 \mu \mathrm{g} / \mathrm{ml}$ of goat $\alpha$-cotton rat IFN- $\gamma$ (R\&D Systems) capturing antibody per well overnight. After blocking with RPMI/10\% FCS for one hour at $37^{\circ} \mathrm{C}$, lymph node or spleen cells (in triplicate) were added and stimulated with $10 \mu \mathrm{g} / \mathrm{ml}$ of gradient-purified UV-inactivated measles virus antigen for 48 hours at $37^{\circ} \mathrm{C}$. After washing, the plate was incubated with a biotinylated goat $\alpha$-cotton rat IFN- $\gamma$ detection antibody (R\&D Systems) and subsequently with an alkaline phosphatase-conjugated rabbit $\alpha$-goat antibody (Zymed). Finally, spots were developed by adding 3\% agarose solution containing AMP-BCIP substrate as described for B-cell ELISPOT [55]. After incubation for 2 hours at room temperature, spots were counted under a light microscope. 
Figure 5.2 No influence of AKT on viral growth in the lymphoid cell line Jurkat. MV infection leads to a decrease in endogenous pAKT S473 expression in Ed-NSE and NSE-myr-AKT infected (MOI 0.02) Jurkat and Jurkat-myr-AKT cells but does not effect myr-pAKT (A). A doublet is seen in the lanes with lysates from cells infected with NSEmyr-AKT and cells expressing myr-AKT; the upper band is the myristoylated form. Kinetics of intracellular progeny accumulation (B) and progeny release (C) are shown for 84 hours post infection from Ed-NSE and NSE-myr-AKT infected (MOI 0.02) Jurkat and Jurkat-myr-AKT cells. Data is an average of duplicate experiments +/- standard deviation. 

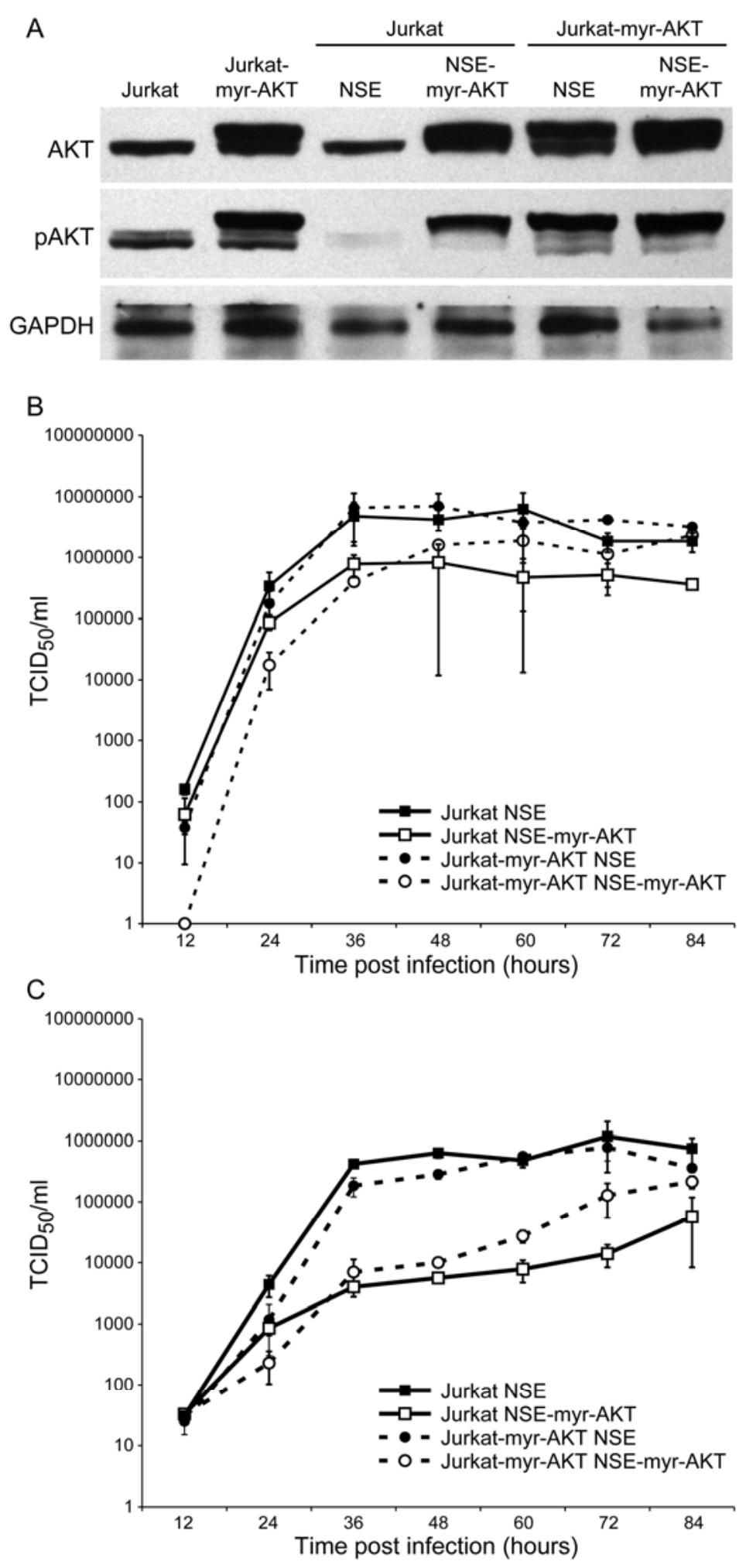
The local immune response is generated in the MDLN, and consistent with this the number of IFN $\gamma$ secreting T cells $/ 10^{6}$ lymph node cells in MDLN was $344 \pm 75$ after Ed-NSE infection and $315 \pm 51$ after NSE-myr-AKT infection. In the spleen, a secondary lymphoid organ, lower numbers IFN $\gamma$ secreting $\mathrm{T}$ cells were found $\left(156 \pm 22 / 10^{6}\right.$ spleen cells after Ed-NSE infection and $171 \pm 16 / 10^{6}$ spleen cells after infection with NSE-myrAKT). These data indicate that both viruses induced a comparable T-cell response after infection.

Usually, the amount of AKT expressed by cells is tightly regulated to maintain the amount necessary for cell survival. However, many RNA and DNA viruses profit from increased levels of pAKT expression and have devised strategies to increase it. Our data indicate that measles virus does not rely on increased levels of phosphorylated AKT for virus replication. However, there is some evidence that might AKT might influence virus release. Measles does not only not benefit from pAKT expression but it reduced pAKT levels in infected cells or cells contacted by virus significantly. This reduction of pAKT in $\mathrm{T}$ cells leads to proliferation inhibition which might be partially responsible for measles virus induced immune suppression. This leads to the conclusion that the reduced amount of pAKT is no trade off for the virus but apparently an evolutionary developed strategy to contain immune responses. 

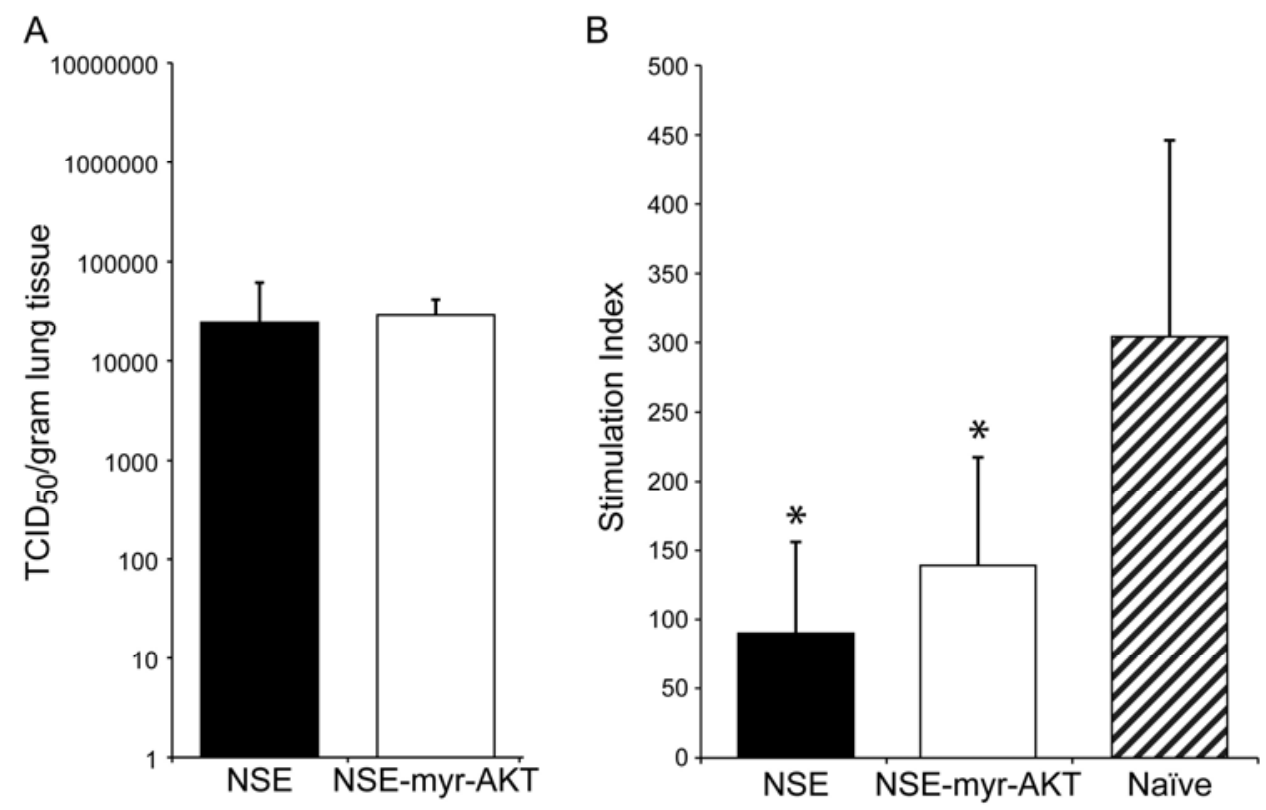

Figure 5.3 In vivo growth of measles virus is not influenced by AKT expression. There is no difference in viral lung titers between Ed-NSE and NSE-myr-AKT infected cotton rats at 4 days post infection (A). Splenocyte proliferation is inhibited in both EdNSE and NSE-myr-AKT infected animals compared to naive cotton rats (5 animals per group). The differences between infected and naive animals were statistically significant $\left({ }^{*} p<0.05\right)$. Data represents an average of five animals $+/-$ standard deviation. Twotailed student's T-test (A) and ANOVA (B) were performed using the GraphPad Instat version 3 software.

\subsection{Acknowledgements}

The plasmid expressing the bovine myristoylated AKT was kindly provided by Dr. Susheela Tridandapani, The Ohio State University, Columbus, Ohio.

Jurkat cells expressing myristoylated AKT were a kind gift from Lawrence P. Kane, University of Pittsburgh, Pittsburgh, Pennsylvania. 


\section{Chapter 6}

\section{Perspectives and Future Directions}

Macrophages are important effector and regulatory cells linking innate and adaptive immunity that play a central role in the control of bacterial infections. It is likely that macrophage dysfunction during acute MV infection is at least partially responsible for the increased incidence of bacterial pneumonia, the most common fatal complication seen in Measles patients.

MV interferes with the immune responses of macrophages by altering phagocytosis and bacterial killing, antigen presentation and cytokine secretion. MVinfected monocytes have functional defects resulting in decreased phagocytic and fungicidal capacities ex vivo. Alterations in cytokine production, including IL1 $\beta$, TNF, IL-12p40 and IL12p70 have also been demonstrated in macrophage cell lines and monocyte-derived macrophages. Individually there are many aspects of macrophage function which are affected by MV infection but the cumulative effect of these changes in vivo and their contribution to MV-induced immune suppression is not known. 
We have established the culture of cotton rat macrophages using recombinant mouse M-CSF for use in in vitro modeling of MV infection. Cotton rat bone marrowderived macrophages are phenotypically and functionally more similar to human macrophages than rodent due to their characteristic low production of nitric oxide. Mycobacterium tuberculosis infected primary human monocytes and macrophages do not appear to depend on inducible nitric oxide synthase (iNOS) but use NO-independent antimicrobial mechanisms (for review [218]). Cotton rats are highly susceptible to a variety of human pathogens, including M. tuberculosis [123, 219], and therefore offer a rodent model of infectious diseases with similar characteristics to humans in terms of NO production.

Additionally, it has been suggested that the MV-induced reduction in IL12 secretion results in a shift toward a $\mathrm{TH} 2$ response contributing to the T-cell proliferation inhibition seen in acute Measles but this has not been modelled in vivo. Studies in humans have reported conflicting results in detecting either a $\mathrm{TH} 2$ or a $\mathrm{TH} 1$ cytokine response following $\mathrm{MV}$ infection. We used bone marrow-derived macrophages and inbred cotton rats to investigate the correlation between a $\mathrm{TH} 2$ response and immune suppression and compare the ability of wildtype and vaccine measles virus to inhibit IL12 secretion. After infection, IL12 secretion was suppressed with both wildtype and vaccine virus in vivo. We demonstrated generation of a TH1 response toward MV antigen and generation of a TH0 response after stimulation with PMA/ionomycin. Measles virus infection leads to a decrease in IL12 secretion and an increase in IL4 secretion but this does not seem to correlate with development of immune suppression. A recombinant vaccine virus which secretes cotton rat IL4, an important TH2 cytokine, did not decrease T-cell proliferation. 
Thus, measles virus infection leads to a decrease in IL12 secretion and an increase in IL4 secretion but this does not seem to correlate with generation of a TH2 response or T-cell proliferation inhibition

One mechanism responsible for inhibition of mitogen-stimulated proliferation of $\mathrm{T}$ cells after $\mathrm{MV}$ infection or by direct contact with the MV F and $\mathrm{H}$ glycoprotein complex and is due to a reduction in AKT kinase activity. Inhibition of AKT kinase by MV infection is a mechanism with potentially far reaching consequences because AKT is a key regulatory molecule for a number of cellular pathways including macrophage effector mechanisms. We show that wildtype MV infection leads to a downregulation of AKT activity in macrophages concurrent to decreased phagocytosis and bacterial killing and increased susceptibility to S. aureus pneumonia.

In vitro, overexpression of constitutively active AKT is able to overcome MVinduced inhibition of T-cell proliferation. Based on these data we predicted that a recombinant MV expressing myr-AKT would restore phagocytosis in macrophages that we could use to probe the causal relationship between reduced AKT and reduced macrophage function following MV infection.

Though both WTFb and Ed-NSE (parental vaccine clone) suppress AKT phosphorylation to comparable levels in macrophages in vitro and suppress T-cell proliferation in vivo (Ed-NSE requires a high inoculum), the parental Ed-NSE vaccine virus did not lead to increased susceptibility to bacterial infection like WTFb in vivo and therefore supplementation of constitutively active AKT in this system had little to no effect. This difference is likely due to receptor usage between wildtype and vaccine virus which has been linked to viral spread and immune suppression. Future studies will focus 
on the development and use of a molecular clone of the ICB wildtype MV [210] to generate a recombinant wildtype virus that overexpresses AKT, a virus which would maintain the wildtype $\mathrm{H}$ CD150 receptor usage and better model our findings with WTFb. Determining how MV infection suppresses antibacterial immune responses should allow a better understanding of MV pathogenesis in infected humans and aid in the development of better strategies for treatment.

The PI3K-AKT pathway is an important mechanism through which viral infection influences various cell functions. Activating the PI3K-AKT signaling pathway is a strategy used by viruses to slow down apoptosis and create a favorable environment for virus replication and virion. MV is unusual in that it downregulates AKT kinase activity which, as mentioned, results in lymphocyte proliferation inhibition and supplementation of constitutively active AKT reverses this affect. A report suggests that AKT plays a critical role in replication of negative-stranded RNA viruses, including MV by demonstration of a an significant reduction in progeny release from MV infected Vero after treatment with AKT specific inhibitor. This suggests MV requires AKT to enhance synthesis of viral progeny. Alternatively an increase in PI3K-AKT activity might impede viral propagation through activation of cellular defenses. We show that MV does not rely on increased levels of phosphorylated AKT for virus replication as is seen with many other viruses. Measles does not benefit from pAKT expression. In fact, viral transcription, replication and progeny release were reduced in the presence of AKT constitutive activation. This leads us to conclusion that reduction of AKT kinase activity does not have a detrimental effect on the virus. And we propose MV's effect on AKT may be an evolutionarily developed strategy to suppress immune responses. 


\section{Appendix}

The following tables are compilations of priming and stimulation condition permutations attempted during optimization of cotton rat bone marrow-derived macrophage culture to elicit cytokine (Table A.1) and nitric oxide production (Table A.2).

\begin{tabular}{|c|c|c|}
\hline & Priming (48 hours) & Stimulation (24 hours) \\
\hline Unsuccessful & $\begin{array}{l}\text { Tissue culture supernatant from ConA } \\
\text { stimulated cotton rat splenocytes - } \\
10 \%\end{array}$ & $\begin{array}{l}\text { Lipopolysaccharide } \\
\text { E. coli 0111:B4 (Sigma \# } \\
\text { L2630) - 100ng/mL }\end{array}$ \\
\hline Successful & $\begin{array}{l}\text { Recombinant cotton rat IFN } \gamma- \\
\text { 20ng/mL } \\
\text { Tissue culture supernatant from ConA } \\
\text { stimulated cotton rat splenocytes - } \\
20 \%\end{array}$ & $\begin{array}{l}\text { Lipopolysaccharide } \\
\text { E. coli 0127:B8 (Sigma \# } \\
\text { L3129) } \\
\text { S. typhimurium (Sigma \# } \\
\text { L6511) } \\
\text { P. aeruginosa (Sigma \# } \\
\text { L9143) } 10-100 \mathrm{ng} / \mathrm{mL}\end{array}$ \\
\hline
\end{tabular}

Table A.1 Culture condition permutations used during optimization of cotton rat bone marrow-derived macrophage stimulation for cytokine expression measurement. 


\begin{tabular}{|l|l|l|}
\hline & Priming & Stimulation \\
\hline $\begin{array}{l}\text { Bone marrow derived } \\
\text { macrophages }\end{array}$ & IFN $\gamma(2,4,6,8$ or $10 \mathrm{U} / \mathrm{mL}$ and & $\begin{array}{l}100 \mathrm{ng} / \mathrm{mL} \text { LPS and Listeria } \\
\text { monocytogenes (MOI }=10)\end{array}$ \\
\hline $\begin{array}{l}\text { Bone marrow derived } \\
\text { macrophages }\end{array}$ & $\begin{array}{l}\text { IFN } \gamma(2,4,6,8 \text { or } 10 \mathrm{U} / \mathrm{mL} \text { and } \\
20 \% \text { ConA TCS }\end{array}$ & PMA $100 \mathrm{ng} / \mathrm{mL}$ \\
\hline $\begin{array}{l}\text { Bone marrow derived } \\
\text { macrophages }\end{array}$ & $\begin{array}{l}\text { IFN } \gamma(2,4,6,8 \text { or } 10 \mathrm{U} / \mathrm{mL} \text { and } \\
20 \% \text { ConA TCS }\end{array}$ & TNF $10 \mathrm{pg} / \mathrm{ml}$ \\
\hline
\end{tabular}

Table A.2 Stimulating agents used for induction of nitric oxide synthesis by bone marrow-derived and elicited peritoneal macrophages.

The following table and figure show the threshold of sensitivity for the cytokine real time RT-PCR assays (Table A.3) and one representative standard curve with analysis for IL12p35.

\begin{tabular}{|l|l|}
\hline Target gene & Sensitivity (Copies per 250 $\mu \mathrm{g})$ \\
\hline IL12p35 & $10^{2}$ \\
\hline IL18 & $10^{2}$ \\
\hline TNF $\alpha$ & 10 \\
\hline TGF $\beta$ & 10 \\
\hline$\beta$-actin & $10^{2}$ \\
\hline
\end{tabular}

Table A.3 Detection threshold of real time RT-PCR cytokine assays. Copy number is derived from linear regression analysis of a standard curve of serially diluted template. 


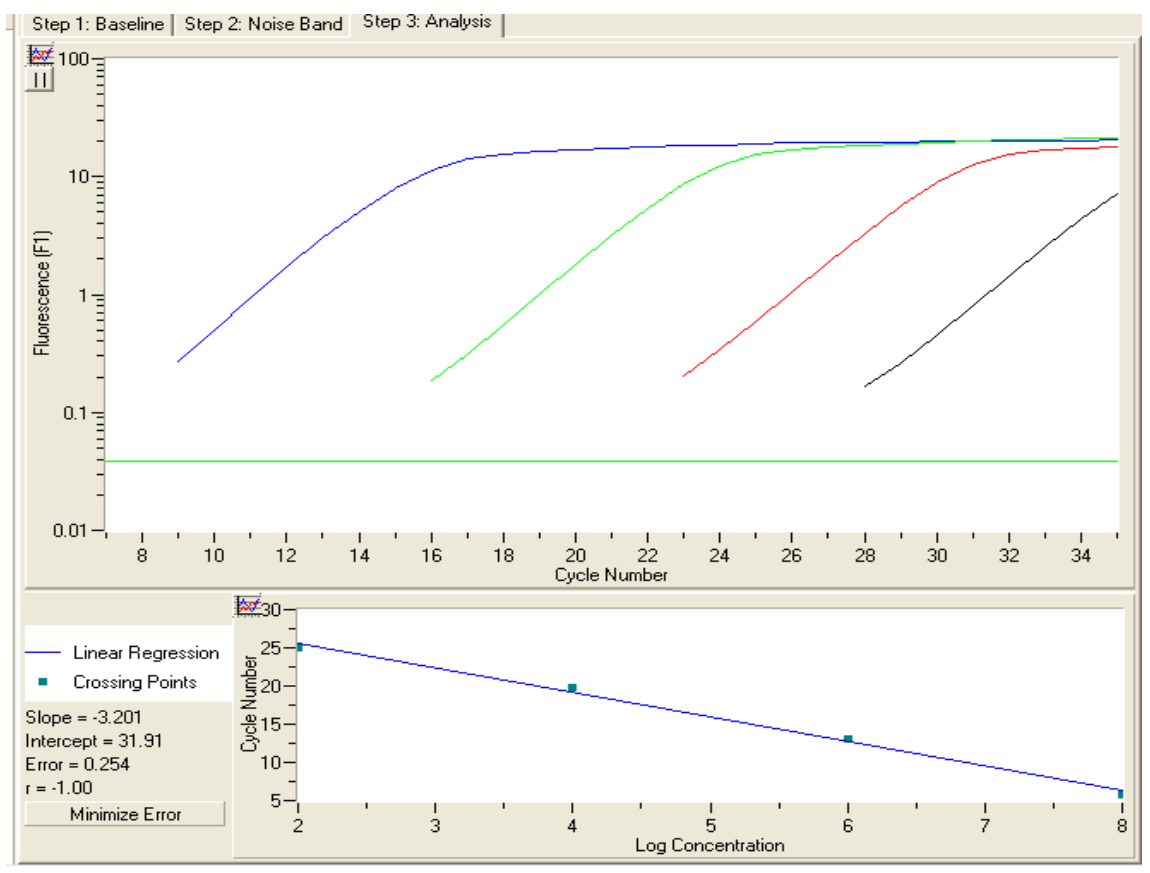

Figure A.1 Four point standard curve of real time RT-PCR to detect IL12p35 expression. 


\section{Bibliography}

1. Dubois-Dalcq, M., J.M. Coblentz, and A.B. Pleet, Subacute sclerosing panencephalitis. Unusual nuclear inclusions and lengthy clinical course. Arch Neurol, 1974. 31(6): p. 355-63.

2. Paula-Barbosa, M.M. and C. Cruz, Nerve cell fusion in a case of subacute sclerosing panencephalitis. Ann Neurol, 1981. 9(4): p. 400-3.

3. Rima, B.K. and W.P. Duprex, Molecular mechanisms of measles virus persistence. Virus Res, 2005. 111(2): p. 132-47.

4. Johnson, R.T., et al., Measles encephalomyelitis--clinical and immunologic studies. N Engl J Med, 1984. 310(3): p. 137-41.

5. Norrby, E. and K. Kristensson, Measles virus in the brain. Brain Res Bull, 1997. 44(3): p. 213-20.

6. Curran, J. and D. Kolakofsky, Replication of paramyxoviruses. Adv Virus Res, 1999. 54: p. 403-22.

7. Rima, B.K. and W.P. Duprex, The measles virus replication cycle. Curr Top Microbiol Immunol, 2009. 329: p. 77-102.

8. $\quad$ Radecke, F., et al., Rescue of measles viruses from cloned DNA. Embo J, 1995. 14(23): p. 5773-84.

9. Ohgimoto, S., et al., The haemagglutinin protein is an important determinant of measles virus tropism for dendritic cells in vitro. J Gen Virol, 2001. 82(Pt 8): p. 1835-44.

10. Tober, C., et al., Expression of measles virus $V$ protein is associated with transcriptional control and pathogenicity. J. Virol., 1998. 72: p. 8124-8132.

11. Erlenhofer, C., et al., Analysis of receptor (CD46, CD150) usage by measles virus. J Gen Virol, 2002. 83(Pt 6): p. 1431-6. 
12. Singh, M. and M.A. Billeter, A recombinant measles virus expressing biologically active human interleukin-12. J Gen Virol, 1999. 80 ( Pt 1): p. 101-6.

13. Tatsuo, H., et al., SLAM (CDw150) is a cellular receptor for measles virus. Nature 2000. 406(6798): p. 893-897.

14. Hsu, E.C., et al., CDw150(SLAM) is a receptor for a lymphotropic strain of measles virus and may account for the immunosuppressive properties of this virus. Virology, 2001. 279(1): p. 9-21.

15. Erlenhoefer, C., et al., CD150 (SLAM) is a receptor for measles virus but is not involved in viral contact-mediated proliferation inhibition. J Virol, 2001. 75(10): p. 4499-505.

16. Doerig, R.E., et al., The human CD46 molecule is a receptor for measles virus (Edmonston strain). Cell, 1993. 75: p. 295-305.

17. Shibahara, K., et al., Increased binding activity of measles virus to monkey red blood cells after long-term passage in Vero cell cultures. J Gen Virol, 1994. 75 ( Pt 12): p. 3511-6.

18. Witte, L.d., et al., Measles Virus Targets DC-SIGN To Enhance Dendritic Cell Infection. JOURNAL OF VIROLOGY, 2006. 80(7): p. 3477-3486.

19. Kimura, A., K. Tosaka, and T. Nakao, Measles rash. I. Light and electron microscopic study of skin eruptions. Arch Virol, 1975. 47(4): p. 295-307.

20. Lightwood, R. and R. Nolan, Epithelial giant cells in measles as an acid in diagnosis. J Pediatr, 1970. 77(1): p. 59-64.

21. Nii, S., et al., Experimental Pathology of Measles in Monkeys. Biken J, 1964. 6: p. 271-97.

22. Olding-Stenkvist, E. and B. Bjorvatn, Rapid detection of measles virus in skin rashes by immunofluroescence. J Infect Dis, 1976. 134(5): p. 463-9.

23. Sakaguchi, M., et al., Growth of measles virus in epithelial and lymphoid tissues of cynomolgus monkeys. Microbiol Immunol, 1986. 30(10): p. 1067-73.

24. Tahara, M., et al., Measles virus infects both polarized epithelial and immune cells by using distinctive receptor-binding sites on its hemagglutinin. J Virol, 2008. 82(9): p. 4630-7.

25. Takeda, M., et al., A human lung carcinoma cell line supports efficient measles virus growth and syncytium formation via a SLAM- and CD46-independent mechanism. J Virol, 2007. 81(21): p. 12091-6.

26. Leonard, V.H., et al., Measles virus blind to its epithelial cell receptor remains 
virulent in rhesus monkeys but cannot cross the airway epithelium and is not shed. J Clin Invest, 2008. 118(7): p. 2448-58.

27. Perry, R.T. and N.A. Halsey, The clinical significance of measles: a review. J Infect Dis, 2004. 189 Suppl 1: p. S4-16.

28. Coovadia, H.M., et al., Immunoparesis and outcome in measles. Lancet, 1977. 1(8012): p. 619-21.

29. Kobune, F., et al., Nonhuman primate models of measles. Lab Anim Sci, 1996. 46(3): p. 315-20.

30. Okada, H., et al., Extensive lymphopenia due to apoptosis of uninfected lymphocytes in acute measles patients. Arch Virol, 2000. 145(5): p. 905-20.

31. Arneborn, P., and G. Biberfeld. , T lymphocyte subpopulations in relation to immunosuppression in measles and varicella. Infect. Immun., 1983. 39: p. 29-37.

32. Esolen LM, W.B., Moench TR, Griffin DE, Infection of monocytes during measles. J Infect Dis 1993. 168(1): p. 47-52.

33. Schneider-Schaulies, S., et al., Expression of measles virus RNA in peripheral blood mononuclear cells of patients with measles, SSPE, and autoimmune diseases. Virology, 1991. 182(2): p. 703-11.

34. Forthal, D.N., et al., Degree and length of viremia in adults with measles. J Infect Dis, 1992. 166(2): p. 421-4.

35. de Swart, R.L., et al., Predominant infection of CD150+ lymphocytes and dendritic cells during measles virus infection of macaques. PLoS Pathog, 2007. 3(11): p. e178.

36. Hussey, G., Clements, CJ, , Clinical Problems in Measles Case Management. Ann Trop Paediatr, 1996. 16: p. 307-17.

37. Duke, T. and C.S. Mgone, Measles: not just another viral exanthem. Lancet, 2003. 361(9359): p. 763-73.

38. Loukides, S., et al., Bacterial pneumonia as a superinfection in young adults with measles. Eur Respir J, 1999. 13(2): p. 356-60.

39. Berman, S., Epidemiology of acute respiratory infections in children of developing countries. Rev Infect Dis, 1991. 13(Suppl 6): p. S454-62.

40. Berkowitz, F.a.C., MF, Endotrahceal aspiration for the bacterial diagnosis of nosocomial- and measles-associated pneumonia Ann Trop Paediatr, 1988. 8(4): p. 217-21. 
41. Flick, J.A., Does measles really predispose to tuberculosis? Am Rev Respir Dis, 1976. 114(2): p. 257-65.

42. Black, J.B., et al., Seroconversion to human herpesvirus 6 and human herpesvirus 7 among brazilian children with clinical diagnosis of measles or rubella. Clin. Infect. Dis., 1996. 23: p. 1156-1158.

43. Fujinami, R.S., et al., Modulation of immune system function by measles virus infection: role of soluble factor and direct infection. J. Virol., 1998. 72: p. 94219427.

44. Sun, X., et al., Suppression of antigen-specific $T$ cell proliferation by measles virus infection: role of a soluble factor in suppression. Virology, 1998. 246(1): p. 24-33.

45. Esolen, L.M., et al., Apoptosis as a cause of death in measles virus-infected cells. J Virol, 1995. 69(6): p. 3955-8.

46. Fugier-Vivier, I., et al., Measles virus suppresses cell-mediated immunity by interfering with the survival and functions of dendritic and T cells. J Exp Med, 1997. 186(6): p. 813-23.

47. Auwaerter, P.G., et al., Measles virus infection of thymic epithelium in the SCIDhu mouse leads to thymocyte apoptosis. J Virol, 1996. 70(6): p. 3734-40.

48. Auwaerter, P.G., et al., Measles virus infection in rhesus macaques: altered immune responses and comparison of the virulence of six different virus strains. J Infect Dis, 1999. 180(4): p. 950-8.

49. Griffin, D.E. and B.J. Ward, Differential CD4 T cell activation in measles. J Infect Dis, 1993. 168(2): p. 275-81.

50. Joffe, M.I., N.R. Sukha, and A.R. Rabson, Lymphocyte subsets in measles. Depressed helper/inducer subpopulation reversed by in vitro treatment with levamisole and ascorbic acid. J Clin Invest, 1983. 72(3): p. 971-80.

51. Moss, W.J., et al., Suppression of human immunodeficiency virus replication during acute measles. J Infect Dis, 2002. 185(8): p. 1035-42.

52. Streif, S., et al., Effector CD8+T cells are suppressed by measles virus infection during delayed type hypersensitivity reaction. Viral Immunol, 2004. 17(4): p. 604-8.

53. Thatte, U.M., et al., Polymorphonuclear and monocyte functions in measles. J Trop Pediatr, 1991. 37(2): p. 67-70.

54. Atabani SF, B.A., Jaye A, Kidd IM, Magnusen AF, Whittle H, Natural measles 
causes prolonged suppression of interleukin-12 production. J Infect Dis, 2001. 184(1): p. 1-9.

55. Niewiesk, S., M. Gotzelmann, and V. ter Meulen, Selective in vivo suppression of T lymphocyte responses in experimental measles virus infection. Proc Natl Acad Sci U S A, 2000. 97(8): p. 4251-5.

56. Sanchez-Lanier, M., et al., Measles virus-induced suppression of lymphocyte proliferation. Cell Immunol, 1988. 116(2): p. 367-81.

57. Schlender, J., et al., Interaction of measles virus glycoproteins with the surface of uninfected peripheral blood lymphocytes induces immunosuppression in vitro. Proc Natl Acad Sci U S A, 1996. 93(23): p. 13194-9.

58. Schnorr, J.J., et al., Cell cycle arrest rather than apoptosis is associated with measles virus contact-mediated immunosuppression in vitro. J Gen Virol, 1997. 78 ( Pt 12): p. 3217-26.

59. Yanagi, Y., B.A. Cubitt, and M.B. Oldstone, Measles virus inhibits mitogeninduced $T$ cell proliferation but does not directly perturb the $T$ cell activation process inside the cell. Virology, 1992. 187(1): p. 280-9.

60. Schlender, J., J. J. Schnorr, T. Cattomen, R. Cattaneo, M. A. Billeter, V. Ter Meulen, and S. Schneider-Schaulies Surface interaction of measles virus glycoproteins is necessary and sufficient for the induction of proliferative inhibition of human peripheral blood mononuclear cells. . Proc. Natl. Acad. Sci. , 1996. 93: p. 13194-13199.

61. Griffin, D.E., Immune responses during measles virus infection. Measles virus, ed. M.B.a.V.t. Meulen. Vol. 191. 1995, Berlin: Springer. 117-134.

62. Karp, C.L., et al., Mechanism of suppression of cell-mediated immunity by measles virus. Science, 1996. 273(5272): p. 228-31.

63. Polack FP, H.S., Moss WJ, Griffin DE., Altered synthesis of interleukin-12 and type 1 and type 2 cytokinesin rhesus macaques during measles and atypical measles. . J Infect Dis, 2002. 185(1): p. 13-19.

64. Hoffman SJ, P.F., Hauer DA, Singh M, Billeter MA, Adams RJ, Vaccination of rhesus macaques with a recombinant measles virus expressing interleukin-12 alters humoral and cellular immune responses. J Infect Dis, 2003. 188(10): p. 1553-1561.

65. Hahm, B., N. Arbour, and M.B. Oldstone, Measles virus interacts with human SLAM receptor on dendritic cells to cause immunosuppression. Virology, 2004. 323(2): p. 292-302. 
66. Mrkic, B., et al., Lymphatic dissemination and comparative pathology of recombinant measles viruses in genetically modified mice. J Virol, 2000. 74(3): p. 1364-72.

67. Mrkic, B., et al., Measles virus spread and pathogenesis in genetically modified mice. J Virol, 1998. 72(9): p. 7420-7.

68. Bour, H., et al., Major histocompatibility complex class I-restricted CD8+ T cells and class II-restricted CD4+ T cells, respectively, mediate and regulate contact sensitivity to dinitrofluorobenzene. Eur J Immunol, 1995. 25(11): p. 3006-10.

69. Grosjean, I., et al., Measles virus infects human dendritic cells and blocks their allostimulatory properties for CD4+ T cells. J Exp Med, 1997. 186(6): p. 801-12.

70. Schnorr, J.J., et al., Induction of maturation of human blood dendritic cell precursors by measles virus is associated with immunosuppression. Proc Natl Acad Sci U S A, 1997. 94(10): p. 5326-31.

71. Steineur, M.P., et al., Langerhans cells are susceptible to measles virus infection and actively suppress T cell proliferation. Eur J Dermatol, 1998. 8(6): p. 413-20.

72. Klagge, I.M., V. ter Meulen, and S. Schneider-Schaulies, Measles virus-induced promotion of dendritic cell maturation by soluble mediators does not overcome the immunosuppressive activity of viral glycoproteins on the cell surface. Eur J Immunol, 2000. 30(10): p. 2741-50.

73. Servet-Delprat, C., et al., Measles virus induces abnormal differentiation of CD40 ligand-activated human dendritic cells. J Immunol, 2000. 164(4): p. 1753-60.

74. Dubois, B., et al., Measles virus exploits dendritic cells to suppress CD4+ T-cell proliferation via expression of surface viral glycoproteins independently of T-cell trans-infection. Cell Immunol, 2001. 214(2): p. 173-83.

75. Griffin, D.E., et al., Immune activation during measles: interferon-gamma and neopterin in plasma and cerebrospinal fluid in complicated and uncomplicated disease. J Infect Dis, 1990. 161(3): p. 449-53.

76. Schnorr, J.J., et al., Immune modulation after measles vaccination of 6-9 months old Bangladeshi infants. Vaccine, 2001. 19(11-12): p. 1503-10.

77. Ward, B.J., et al., Cytokine production in vitro and the lymphoproliferative defect of natural measles virus infection. Clin Immunol Immunopathol, 1991. 61(2 Pt 1): p. 236-48.

78. Gans, H.A., et al., IL-12, IFN-gamma, and $T$ cell proliferation to measles in immunized infants. J Immunol, 1999. 162(9): p. 5569-75. 
79. Avota, E., et al., Disruption of Akt kinase activation is important for immunosuppression induced by measles virus. Nat Med, 2001. 7(6): p. 725-31.

80. Okada, H., et al., Comparative analysis of host responses related to immunosuppression between measles patients and vaccine recipients with live attenuated measles vaccines. Arch Virol, 2001. 146(5): p. 859-74.

81. Yu, X.L., et al., Measles virus infection in adults induces production of IL-10 and is associated with increased CD4+ CD25+ regulatory T cells. J Immunol, 2008. 181(10): p. 7356-66.

82. Ward, B.J. and D.E. Griffin, Changes in cytokine production after measles virus vaccination: predominant production of IL-4 suggests induction of a Th2 response. Clin Immunol Immunopathol, 1993. 67(2): p. 171-7.

83. Dhiman, N., et al., Interleukin-4 induced by measles virus and measles-derived peptides as measured by IL-4 receptor-blocking ELISA. J Immunol Methods, 2004. 287(1-2): p. 217-25.

84. Howe, R.C., et al., Identification of Th0 cells responding to measles virus. Hum Immunol, 2005. 66(2): p. 104-15.

85. Avota, E., et al., Measles virus interacts with and alters signal transduction in Tcell lipid rafts. J Virol, 2004. 78(17): p. 9552-9.

86. Griffin, D.E., et al., In vitro studies of the role of monocytes in the immunosuppression associated with natural measles virus infections. Clin Immunol Immunopathol, 1987. 45(3): p. 375-83.

87. Niewiesk, S., et al., Measles virus-induced immune suppression in the cotton rat (Sigmodon hispidus) model depends on viral glycoproteins. J Virol, 1997. 71(10): p. 7214-9.

88. Kandel, E.S. and N. Hay, The regulation and activities of the multifunctional serine/threonine kinase Akt/PKB. Exp Cell Res, 1999. 253(1): p. 210-29.

89. Franke, T.F., Intracellular signaling by Akt: bound to be specific. Sci Signal, 2008. 1(24): p. pe29.

90. Avota, E., H. Harms, and S. Schneider-Schaulies, Measles virus induces expression of SIP110, a constitutively membrane clustered lipid phosphatase, which inhibits T cell proliferation. Cellular Microbiology, 2006.

91. Alessi, D.R., et al., Characterization of a 3-phosphoinositide-dependent protein kinase which phosphorylates and activates protein kinase Balpha. Curr Biol, 1997. 7(4): p. 261-9. 
92. Currie, R.A., et al., Biochem. J, 1999( 337): p. 575-583.

93. Datta, S.R., A. Brunet, and M.E. Greenberg, Genes Dev. , 1999. 13: p. 29052927.

94. Laine, D., et al., Measles virus nucleoprotein induces cell-proliferation arrest and apoptosis through NTAIL-NR and NCORE-FcgammaRIIB1 interactions, respectively. J Gen Virol, 2005. 86(Pt 6): p. 1771-84.

95. Laine, D., et al., Measles virus (MV) nucleoprotein binds to a novel cell surface receptor distinct from FcgammaRII via its C-terminal domain: role in $M V$ induced immunosuppression. J Virol, 2003. 77(21): p. 11332-46.

96. Ganesan, L.P., et al., The serine/threonine kinase Akt Promotes Fc gamma receptor-mediated phagocytosis in murine macrophages through the activation of p70S6 kinase. J Biol Chem, 2004. 279(52): p. 54416-25.

97. Lutz MA, C., PH, Activation of CR3-mediated phagocytosis by MSP requires the RON receptor, tyrosine kinase activity, phosphatidylinositol 3-kinase, and protein kinase C zeta. . J Leukoc Biol., 2003. 73(6): p. 802-14.

98. Skeel, A., Leonard, E. J., Action and target cell specificity of human macrophagestimulating protein (MSP) J. Immunol. , 1994. 152: p. 4618-4623.

99. Chen, Q., et al., Akt phosphorylates p47phox and mediates respiratory burst activity in human neutrophils. J Immunol, 2003. 170(10): p. 5302-8.

100. van Binnendijk, R.S., et al., Protective immunity in macaques vaccinated with live attenuated, recombinant, and subunit measles vaccines in the presence of passively acquired antibodies. J Infect Dis, 1997. 175(3): p. 524-32.

101. DeSwart, R.L., Measles studies in the macaque model. Curr Top Microbiol Immunol, 2009. 330: p. 55-72.

102. Polack, F.P., et al., Production of atypical measles in rhesus macaques: evidence for disease mediated by immune complex formation and eosinophils in the presence of fusion-inhibiting antibody. Nat Med, 1999. 5(6): p. 629-34.

103. Pillet, S., N. Svitek, and V. von Messling, Ferrets as a model for morbillivirus pathogenesis, complications, and vaccines. Curr Top Microbiol Immunol, 2009. 330: p. 73-87.

104. Thormar, H., et al., Measles virus encephalitis in ferrets as a model for subacute sclerosing panencephalitis. Lab Anim Sci, 1985. 35(3): p. 229-32.

105. Rudd, P.A., R. Cattaneo, and V. von Messling, Canine distemper virus uses both the anterograde and the hematogenous pathway for neuroinvasion. J Virol, 2006. 
80(19): p. 9361-70.

106. McFarland, H.F., The effect of measles virus infection on $T$ and $B$ lymphocytes in the mouse. J. Immunol., 1974. 113: p. 1978-1983.

107. Burnstein, T., J.H. Jensen, and B.H. Waksman, The development of a neurotropic strain of measles virus in hamsters and mice. J. Infect. Dis., 1963. 113: p. 265272.

108. Niewiesk, S., et al., Susceptibility to measles virus-induced encephalitis in mice correlates with impaired antigen presentation to cytotoxic T lymphocytes. J Virol, 1993. 67(1): p. 75-81.

109. Ono, N., et al., V domain of human SLAM (CDw150) is essential for its function as a measles virus receptor. J Virol, 2001. 75(4): p. 1594-600.

110. Dorig, R.E., et al., The human CD46 molecule is a receptor for measles virus (Edmonston strain). Cell, 1993. 75(2): p. 295-305.

111. Manchester, M., et al., Multiple isoforms of CD46 (membrane cofactor protein) serve as receptors for measles virus. Proc Natl Acad Sci U S A, 1994. 91(6): p. 2161-5.

112. Naniche, D., et al., Human membrane cofactor protein (CD46) acts as a cellular receptor for measles virus. J Virol, 1993. 67(10): p. 6025-32.

113. Sellin, C.I. and B. Horvat, Current animal models: transgenic animal models for the study of measles pathogenesis. Curr Top Microbiol Immunol, 2009. 330: p. $111-27$.

114. Evlashev, A., et al., Differential permissivity to measles virus infection of human and CD46-transgenic murine lymphocytes. J Gen Virol, 2001. 82(Pt 9): p. 2125-9.

115. Druelle, J., et al., Wild type measles virus attenuation independent of type I IFN. Virol J, 2008. 5: p. 22.

116. Shingai, M., et al., Wild-type measles virus infection in human CD46/CD150transgenic mice: CD11c-positive dendritic cells establish systemic viral infection. J Immunol, 2005. 175(5): p. 3252-61.

117. Wyde, P.R., et al., Measles virus replication in lungs of hispid cotton rats after intranasal inoculation. Proc Soc Exp Biol Med, 1992. 201(1): p. 80-7.

118. Pfeuffer, J., et al., Extent of measles virus spread and immune suppression differentiates between wild-type and vaccine strains in the cotton rat model (Sigmodon hispidus). J Virol, 2003. 77(1): p. 150-8.

119. Wyde, P.R., et al., Replication of clinical measles virus strains in hispid cotton 
rats. Proc Soc Exp Biol Med, 1999. 221(1): p. 53-62.

120. Pletneva, L.M., et al., Induction of type I interferons and interferon-inducible $M x$ genes during respiratory syncytial virus infection and reinfection in cotton rats. $\mathrm{J}$ Gen Virol, 2008. 89(Pt 1): p. 261-70.

121. Schlereth, B., et al., Successful mucosal immunization of cotton rats in the presence of measles virus-specific antibodies depends on degree of attenuation of vaccine vector and virus dose. J Gen Virol, 2003. 84(Pt 8): p. 2145-51.

122. Niewiesk, S., Measles virus. Viral Immunol, 2002. 15(3): p. 397-8.

123. Elwood, R.L., et al., The American cotton rat: a novel model for pulmonary tuberculosis. Tuberculosis (Edinb), 2007. 87(2): p. 145-54.

124. Richter, B.W., et al., Antigen-dependent proliferation and cytokine induction in respiratory syncytial virus-infected cotton rats reflect the presence of effectormemory T cells. Virology, 2005. 337(1): p. 102-10.

125. Carsillo, M., et al., Nitric oxide production and nitric oxide synthase type 2 expression by cotton rat (Sigmodon hispidus) macrophages reflect the same pattern as human macrophages. Dev Comp Immunol, 2009. 33(5): p. 718-24.

126. Eichelberger, M.C., et al., Distinct cellular immune responses following primary and secondary influenza virus challenge in cotton rats. Cell Immunol, 2006. 243(2): p. 67-74.

127. Pueschel, K., et al., Measles virus-specific CD4 T-cell activity does not correlate with protection against lung infection or viral clearance. J Virol, 2007. 81(16): p. 8571-8.

128. Schachtner, S.K., et al., In vivo adenovirus-mediated gene transfer via the pulmonary artery of rats. Circ Res, 1995. 76(5): p. 701-9.

129. Blanco, J.C., et al., Cytokine and chemokine gene expression after primary and secondary respiratory syncytial virus infection in cotton rats. J Infect Dis, 2002. 185(12): p. 1780-5.

130. Prince, G.A., The cotton rat in biomedical research. Anim. Welf. Inf. Cent. Newsl., 1994. 5.

131. Prince, G.A., et al., The pathogenesis of respiratory syncytial virus infection in cotton rats. Am J Pathol, 1978. 93(3): p. 771-91.

132. Langley, R.J., G.A. Prince, and H.S. Ginsberg, HIV type-1 infection of the cotton rat (Sigmodon fulviventer and S. hispidus). Proc Natl Acad Sci U S A, 1998. 95(24): p. 14355-60. 
133. Mahler, M., et al., Experimental Helicobacter pylori infection induces antralpredominant, chronic active gastritis in hispid cotton rats (Sigmodon hispidus). Helicobacter, 2005. 10(4): p. 332-44.

134. Kokai-Kun, J.F., et al., Lysostaphin cream eradicates Staphylococcus aureus nasal colonization in a cotton rat model. Antimicrob Agents Chemother, 2003. 47(5): p. 1589-97.

135. Elwooda, R.L., Samuel Wilsona, Jorge C.G. Blancob, Kevin Yimb,, B.N. Luba Pletnevab, Rowena Samalac, Swati Joshid, Val, and b. G. Hemminga, Michele Trucksisd,, The American cotton rat: A novel model for pulmonary tuberculosis. Tuberculosis, 2006.

136. Braun, L.E., et al., Co-infection of the cotton rat (Sigmodon hispidus) with Staphylococcus aureus and influenza A virus results in synergistic disease. Microb Pathog, 2007. 43(5-6): p. 208-16.

137. Bellacosa, A., et al., Akt activation by growth factors is a multiple-step process: the role of the PH domain. Oncogene, 1998. 17(3): p. 313-25.

138. Burgering, B.M. and P.J. Coffer, Protein kinase B (c-Akt) in phosphatidylinositol3-OH kinase signal transduction. Nature, 1995. 376(6541): p. 599-602.

139. Sun, M., et al., Akt plays a critical role in replication of nonsegmented negativestranded RNA viruses. J Virol, 2008. 82(1): p. 105-14.

140. Underhill, D.M. and A. Ozinsky, Phagocytosis of microbes: complexity in action. Annu Rev Immunol, 2002. 20: p. 825-52.

141. MacMicking, J., Q.W. Xie, and C. Nathan, Nitric oxide and macrophage function. Annu Rev Immunol, 1997. 15: p. 323-50.

142. Weinberg, J.B., Nitric oxide production and nitric oxide synthase type 2 expression by human mononuclear phagocytes: a review. Mol Med, 1998. 4(9): p. $557-91$.

143. Gantt, K.R., et al., Oxidative responses of human and murine macrophages during phagocytosis of Leishmania chagasi. J Immunol, 2001. 167(2): p. 893901.

144. Hickman-Davis, J.M., et al., Killing of Klebsiella pneumoniae by human alveolar macrophages. Am J Physiol Lung Cell Mol Physiol, 2002. 282(5): p. L944-56.

145. Niewiesk, S. and G.A. Prince, Diversifying animal models: the use of hispid cotton rats (Sigmodon hispidus) in infectious diseases. Laboratory Animals, 2002. 36: p. 357-372. 
146. Dreizin, R.S., et al., [Experimental RS virus infection of cotton rats. A viral and immunofluorescent study]. Vopr Virusol, 1971. 16(6): p. 670-6.

147. Murphy, B.R., et al., Enhanced pulmonary histopathology is observed in cotton rats immunized with formalin-inactivated respiratory syncytial virus (RSV) or purified F glycoprotein and challenged with RSV 3-6 months after immunization. Vaccine, 1990. 8(5): p. 497-502.

148. Wyde, P.R., et al., Development of a cotton rat-human metapneumovirus (hMPV) model for identifying and evaluating potential $h M P V$ antivirals and vaccines. Antiviral Res, 2005. 66(1): p. 57-66.

149. Williams, J.V., et al., The cotton rat (Sigmodon hispidus) is a permissive small animal model of human metapneumovirus infection, pathogenesis, and protective immunity. J Virol, 2005. 79(17): p. 10944-51.

150. Hamelin, M.E., et al., Pathogenesis of human metapneumovirus lung infection in $B A L B / c$ mice and cotton rats. J Virol, 2005. 79(14): p. 8894-903.

151. Murphy, T.F., E.J. Dubovi, and W.A. Clyde, Jr., The cotton rat as an experimental model of human parainfluenza virus type 3 disease. Exp Lung Res, 1981. 2(2): p. 97-109.

152. Brydak, L., Studies on adaptation of influenza virus replicated at low temperature.IV. Sensitivity of neuraminidase and hemagglutinin to some proteolytic enzymes, detergents and chemical agents. Acta Microbiol Pol, 1990. 39(3-4): p. 137-47.

153. Ottolini, M., et al., Combination anti-inflammatory and antiviral therapy of influenza in a cotton rat model. Pediatr Pulmonol, 2003. 36(4): p. 290-4.

154. Rytik, P.G., et al., [The use of the polymerase chain reaction in modelling HIV infection in animals]. Zh Mikrobiol Epidemiol Immunobiol, 1995(3): p. 86-9.

155. Lewandowski, G., et al., Herpes simplex type 1 infects and establishes latency in the brain and trigeminal ganglia during primary infection of the lip in cotton rats and mice. Arch Virol, 2002. 147(1): p. 167-79.

156. Yim, K.C., et al., The cotton rat provides a novel model to study genital herpes infection and to evaluate preventive strategies. J. Virol., 2005. 79: p. 1463214639.

157. Pacini, D.L., E.J. Dubovi, and W.A. Clyde, Jr., A new animal model for human respiratory tract disease due to adenovirus. J Infect Dis, 1984. 150(1): p. 92-7.

158. Weidenmaier, C., et al., Role of teichoic acids in Staphylococcus aureus nasal colonization, a major risk factor in nosocomial infections. Nat Med, 2004. 10(3): 
p. 243-5.

159. Burgdorfer, W. and K.L. Gage, Susceptibility of the hispid cotton rat (Sigmodon hispidus) to the Lyme disease spirochete (Borrelia burgdorferi). Am J Trop Med Hyg, 1987. 37(3): p. 624-8.

160. Oliver, J.H., Jr., et al., Natural occurrence and characterization of the Lyme disease spirochete, Borrelia burgdorferi, in cotton rats (Sigmodon hispidus) from Georgia and Florida. J Parasitol, 1995. 81(1): p. 30-6.

161. Lowery, G.H., The mammals of Lousiana and its adjacent waters. 1981 Baton Rouge: Louisiana State University Press.

162. Blanco, J.C., et al., The cotton rat: an underutilized animal model for human infectious diseases can now be exploited using specific reagents to cytokines, chemokines, and interferons. J. Interferon Cytokine Res., 2004. 24: p. 21-28.

163. Shields, M.J. and R.K. Ribaudo, Mapping of the monoclonal antibody W6/32: sensitivity to the amino terminus of beta2-microglobulin. Tissue Antigens, 1998. 51(5): p. 567-70.

164. Hämmerling, G.J., U. Hämmerling, and H. Lemke, Isolation of twelve monoclonal antibodies against Ia and $\mathrm{H}-2$ antigen. Serological characterization and reactivity with B- and T-lymphocytes. Immunogenetics, 1979. 8(1): p. 433-445.

165. Wang, P. and J.L. Zweier, Measurement of nitric oxide and peroxynitrite generation in the postischemic heart. Evidence for peroxynitrite-mediated reperfusion injury. J Biol Chem, 1996. 271(46): p. 29223-30.

166. Pandian, R.P., et al., Lipopolysaccharide-induced alterations in oxygen consumption and radical generation in endothelial cells. Mol Cell Biochem, 2005. 278(1-2): p. 119-27.

167. Bubert, A., et al., Differential expression of Listeria monocytogenes virulence genes in mammalian host cells. Mol Gen Genet, 1999. 261(2): p. 323-36.

168. Campbell, P.A., B.P. Canono, and D.A. Drevets, Measurement of bacterial ingestion and killing by macrophages. Curr Protoc Immunol, 2001. Chapter 14: p. Unit 146.

169. Schook, L.B., et al., Characterization and expression of H-21 region gene products on bone marrow-derived macrophages. Eur J Immunol, 1982. 12(12): p. 991-7.

170. Gessl, A., et al., Expression of MHC class II antigens on rat bone marrow cells and macrophages, and their modulation during culture with murine GM-CSF or M-CSF. Immunobiology, 1995. 192(3-4): p. 185-97. 
171. Crocker, P.R., et al., Species heterogeneity in macrophage expression of the CD4 antigen. J Exp Med, 1987. 166(2): p. 613-8.

172. Nathan, C., Inducible nitric oxide synthase: what difference does it make? J Clin Invest, 1997. 100(10): p. 2417-23.

173. Gupta, R., et al., Macrophages in the development of protective immunity against experimental Brugia malayi infection. Parasitology, 2004. 129(Pt 3): p. 311-23.

174. McCartney-Francis, N.L. and S.M. Wahl, Dysregulation of IFN-gamma signaling pathways in the absence of TGF-beta 1. J Immunol, 2002. 169(10): p. 5941-7.

175. Mestas, J. and C.C. Hughes, Of mice and not men: differences between mouse and human immunology. J Immunol, 2004. 172(5): p. 2731-8.

176. Schneemann, M., et al., Nitric oxide synthase is not a constituent of the antimicrobial armature of human mononuclear phagocytes. J Infect Dis, 1993. 167(6): p. 1358-63.

177. Schon, T., et al., Local production of nitric oxide in patients with tuberculosis. Int J Tuberc Lung Dis, 2004. 8(9): p. 1134-7.

178. Nicholson, S., et al., Inducible nitric oxide synthase in pulmonary alveolar macrophages from patients with tuberculosis. J Exp Med, 1996. 183(5): p. 2293302.

179. Sable, S.B., et al., Lung and blood mononuclear cell responses of tuberculosis patients to mycobacterial proteins. Eur Respir J, 2007. 29(2): p. 337-46.

180. Bose, M., et al., Nitric oxide dependent killing of mycobacterium tuberculosis by human mononuclear phagocytes from patients with active tuberculosis. Int $\mathrm{J}$ Immunopathol Pharmacol, 1999. 12(2): p. 69-79.

181. Sun, X., et al., Suppression of antigen-specific $T$ cell proliferation by measles virus infection: role of a soluble factor in suppression. Virology, 1998. 246: p. 24-33.

182. Wang, M., et al., Modulation of immune system function by measles virus infection. II. Infection of $B$ cells leads to the production of a soluble factor that arrests uninfected B cells in G0/G1. Viral Immunol, 2003. 16(1): p. 45-55.

183. Fontana, J.M., B. Bankamp, and P.A. Rota, Inhibition of interferon induction and signaling by paramyxoviruses. Immunol Rev, 2008. 225: p. 46-67.

184. Fujinami, R.S., X. Sun, and J. Burns. Inhibition of antigen specific $T$ cell proliferation by measles virus infection. in 10th International conference on negative strand viruses. 1997. Dublin. 
185. Niewiesk, S., et al., Measles virus-induced immune suppression in the cotton rat (Sigmodon hispidus) model depends on viral glycoproteins. J. Virol., 1997. 71: p. 7214-7219.

186. Schneider-Schaulies, J. and S. Schneider-Schaulies, Receptor interactions, tropism, and mechanisms involved in morbillivirus-induced immunomodulation. Adv Virus Res, 2008. 71: p. 173-205.

187. Ovsyannikova, I.G., et al., Immunologic significance of HLA class I genes in measles virus-specific IFN-gamma and IL-4 cytokine immune responses. Immunogenetics, 2005. 57(11): p. 828-36.

188. Reed, L.J.a.H.M., A simple method of estimating fifty percent endpoints. Am. J. Hygiene, 1938. 27: p. 493-497.

189. Kovacs, G.R., et al., Enhanced genetic rescue of negative-strand RNA viruses: use of an MVA-T7 RNA polymerase vector and DNA replication inhibitors. J Virol Methods, 2003. 111(1): p. 29-36.

190. Ohno, S., et al., Dissection of measles virus $V$ protein in relation to its ability to block alpha/beta interferon signal transduction. J Gen Virol, 2004. 85(Pt 10): p. 2991-9.

191. Carsillo, M., et al., Nitric oxide production and nitric oxide synthase type 2 expression by cotton rat (Sigmodon hispidus) macrophages reflect the same pattern as human macrophages. Dev. Comp. Immunol., 2009. 33: p. 718-724.

192. Carsillo, T., et al., Hyperthermic pre-conditioning promotes measles virus clearance from brain in a mouse model of persistent infection. Brain Res, 2004. 1004(1-2): p. 73-82.

193. Noelle, R., et al., Increased expression of Ia antigens on resting B cells: an additional role for B-cell growth factor. Proc Natl Acad Sci U S A, 1984. 81(19): p. 6149-53.

194. O'Garra, A., et al., Interleukin 4 (B-cell growth factor II/eosinophil differentiation factor) is a mitogen and differentiation factor for preactivated murine $B$ lymphocytes. Proc Natl Acad Sci U S A, 1986. 83(14): p. 5228-32.

195. Yokota, S., et al., Measles virus $P$ protein suppresses Toll-like receptor signal through up-regulation of ubiquitin-modifying enzyme A20. Faseb J, 2008. 22(1): p. $74-83$.

196. Gringhuis, S.I., et al., C-type lectin DC-SIGN modulates Toll-like receptor signaling via Raf-1 kinase-dependent acetylation of transcription factor NFkappaB. Immunity, 2007. 26(5): p. 605-16. 
197. Caparros, E., et al., DC-SIGN ligation on dendritic cells results in ERK and PI3K activation and modulates cytokine production. Blood, 2006. 107(10): p. 3950-8.

198. Klagge, I.M., et al., Impact of measles virus dendritic-cell infection on Th-cell polarization in vitro. J Gen Virol, 2004. 85(Pt 11): p. 3239-47.

199. Pasetti, M.F., et al., Sindbis virus-based measles DNA vaccines protect cotton rats against respiratory measles: relevance of antibodies, mucosal and systemic antibody-secreting cells, memory B cells, and Th1-type cytokines as correlates of immunity. J Virol, 2009. 83(6): p. 2789-94.

200. Jackson, R.J., et al., Expression of mouse interleukin-4 by a recombinant ectromelia virus suppresses cytolytic lymphocyte responses and overcomes genetic resistance to mousepox. J Virol, 2001. 75(3): p. 1205-10.

201. Leopardi, R., et al., Effect of measles virus infection on MHC class II expression and antigen presentation in human monocytes. Cell Immunol, 1993. 147(2): p. 388-96.

202. Leopardi, R., Vainionpaa, R., Hurme, M., Siljander, P., and Salmi, A., Measles Virus Infection Enhances IL1 beta but Reduces Tumor Necrosis Factor alpha Expression in Human Monocytes. Journal of Immunology, 1992. 149(7): p. 23972401.

203. Jakab, G.J., Suppression of pulmonary antibacterial activity following Sendai virus infection in mice: dependence on virus dose. Arch Virol, 1975. 48(4): p. 385-90.

204. Mills, J., Effects of Sendai virus infection on function of cultured mouse alveolar macrophages. Am Rev Respir Dis, 1979. 120(6): p. 1239-44.

205. Parks, C.L., et al., Enhanced measles virus cDNA rescue and gene expression after heat shock. J Virol, 1999. 73(5): p. 3560-6.

206. Kolsch, V., P.G. Charest, and R.A. Firtel, The regulation of cell motility and chemotaxis by phospholipid signaling. J Cell Sci, 2008. 121(Pt 5): p. 551-9.

207. Cenni, V., et al., Targeting of the Akt/PKB kinase to the actin skeleton. Cell Mol Life Sci, 2003. 60(12): p. 2710-20.

208. Vandermoere, F., et al., Proteomics exploration reveals that actin is a signaling target of the kinase Akt. Mol Cell Proteomics, 2007. 6(1): p. 114-24.

209. Meili, R., C. Ellsworth, and R.A. Firtel, A novel Akt/PKB-related kinase is essential for morphogenesis in Dictyostelium. Curr Biol, 2000. 10(12): p. 708-17.

210. Takeda, M., et al., Generation of measles virus with a segmented RNA genome. J 
Virol, 2006. 80(9): p. 4242-8.

211. Cooray, S., The pivotal role of phosphatidylinositol 3-kinase-Akt signal transduction in virus survival. J Gen Virol, 2004. 85(Pt 5): p. 1065-76.

212. Ji, W.T. and H.J. Liu, PI3K-Akt signaling and viral infection. Recent Pat Biotechnol, 2008. 2(3): p. 218-26.

213. Buchkovich, N.J., et al., The TORrid affairs of viruses: effects of mammalian DNA viruses on the PI3K-Akt-mTOR signalling pathway. Nat Rev Microbiol, 2008. 6(4): p. 266-75.

214. Carsillo, M., K. Klapproth, and S. Niewiesk, Cytokine imbalance after measles virus infection but no correlation with immune suppression. (submitted), 2009.

215. Plumet, S., Duprex, W. Paul and Gerlier, Denis, Dynamics of Viral RNA Synthesis during Measles Virus Infection. Journal of Virology, 2005. 79(11): p. 6900-6908.

216. Kane, L.P., et al., Induction of NF-kappaB by the Akt/PKB kinase. Curr Biol, 1999. 9(11): p. 601-4.

217. Zhan, X., et al., Respiratory syncytial virus (RSV) fusion protein expressed by recombinant Sendai virus elicits B-cell and T-cell responses in cotton rats and confers protection against RSV subtypes A and B. Vaccine, 2007. 25(52): p. 878293.

218. Liu, P.T. and R.L. Modlin, Human macrophage host defense against Mycobacterium tuberculosis. Curr Opin Immunol, 2008. 20(4): p. 371-6.

219. Elwood, R.L., et al., Characterization of late tuberculosis infection in Sigmodon hispidus. Tuberculosis (Edinb), 2009. 89(2): p. 183-8.

220. Isa, M.B., et al., Comparison of immunoglobulin $G$ subclass profiles induced by measles virus in vaccinated and naturally infected individuals. Clin Diagn Lab Immunol, 2002. 9(3): p. 693-7.

221. Isa, M.B., et al., Measles virus-specific immunoglobulin $G$ isotype immune response in early and late infections. J Clin Microbiol, 2001. 39(1): p. 170-4.

222. Snapper, C.M. and W.E. Paul, Interferon-gamma and B cell stimulatory factor-1 reciprocally regulate Ig isotype production. Science, 1987. 236(4804): p. 944-7.

223. Coffman, R.L. and T.R. Mosmann, Isotype regulation by helper $T$ cells and lymphokines. Monogr Allergy, 1988. 24: p. 96-103.

224. Esser, C. and A. Radbruch, Immunoglobulin class switching: molecular and cellular analysis. Annu Rev Immunol, 1990. 8: p. 717-35. 
225. Finkelman, F.D., et al., Lymphokine control of in vivo immunoglobulin isotype selection. Annu Rev Immunol, 1990. 8: p. 303-33.

226. Rothenberg, M.E., Eosinophilia. N Engl J Med, 1998. 338(22): p. 1592-600. 